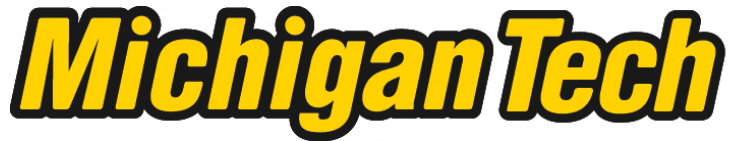 \\ Michigan Technological University Create the Future Digital Commons @ Michigan Tech
}

Dissertations, Master's Theses and Master's Reports - Open

Dissertations, Master's Theses and Master's

Reports

2006

Shear band evolution in $\mathrm{Zr} / \mathrm{Hf}$-based bulk metallic glasses under static and dynamic indentations

Hongwen Zhang

Michigan Technological University

Follow this and additional works at: https://digitalcommons.mtu.edu/etds

Part of the Engineering Science and Materials Commons

Copyright 2006 Hongwen Zhang

\section{Recommended Citation}

Zhang, Hongwen, "Shear band evolution in $\mathrm{Zr} / \mathrm{Hf}$-based bulk metallic glasses under static and dynamic indentations", Dissertation, Michigan Technological University, 2006.

https://doi.org/10.37099/mtu.dc.etds/23

Follow this and additional works at: https://digitalcommons.mtu.edu/etds

Part of the Engineering Science and Materials Commons 


\title{
Shear Band Evolution in Zr/Hf-based Bulk Metallic Glasses under Static and Dynamic Indentations
}

\author{
By \\ Hongwen Zhang
}

\author{
A DISSERTATION \\ Submitted in partial fulfillment of the requirements \\ for the degree of \\ DOCTOR OF PHILOSOPHY \\ (Materials Science and Engineering) \\ MICHIGAN TECHNOLOGICAL UNIVERSITY \\ 2006
}


This dissertation, "Shear Band Evolution of Zr/Hf-based Bulk Metallic Glasses under Static and Dynamic Indentations” is hereby approved in partial fulfillment of the requirements for the degree of DOCTOR OF PHILOSOPHY in the field of Materials Science and Engineering.

Department of Materials Science and Engineering

Dissertation Advisor:

Dr. Ghatu Subhash

Department Chair:

Dr. Mark R. Plichta

Date 


\begin{abstract}
Bulk metallic glasses (BMGs) exhibit superior mechanical properties as compared with other conventional materials and have been proposed for numerous engineering and technological applications. Zr/Hf-based BMGs or tungsten reinforced BMG composites are considered as a potential replacement for depleted uranium armor-piercing projectiles because of their ability to form localized shear bands during impact, which has been known to be the dominant plastic deformation mechanism in BMGs. However, in conventional tensile, compressive and bending tests, limited ductility has been observed because of fracture initiation immediately following the shear band formation. To fully investigate shear band characteristics, indentation tests that can confine the deformation in a limited region have been pursued. In this thesis, a detailed investigation of thermal stability and mechanical deformation behavior of $\mathrm{Zr} / \mathrm{Hf}$-based BMGs is conducted. First, systematic studies had been implemented to understand the influence of relative compositions of $\mathrm{Zr}$ and Hf on thermal stability and mechanical property evolution. Second, shear band evolution under indentations were investigated experimentally and theoretically. Three kinds of indentation studies were conducted on BMGs in the current study.
\end{abstract}

(a) Nano-indentation to determine the mechanical properties as a function of $\mathrm{Hf} / \mathrm{Zr}$ content.

(b) Static Vickers indentation on bonded split specimens to investigate the shear band evolution characteristics beneath the indention.

(c) Dynamic Vickers indentation on bonded split specimens to investigate the 
influence of strain rate.

It was found in the present work that gradually replacing $\mathrm{Zr}$ by $\mathrm{Hf}$ remarkably increases the density and improves the mechanical properties. However, a slight decrease in glass forming ability with increasing Hf content has also been identified through thermodynamic analysis although all the materials in the current study were still found to be amorphous.

Many indentation studies have revealed only a few shear bands surrounding the indent on the top surface of the specimen. This small number of shear bands cannot account for the large plastic deformation beneath the indentations. Therefore, a bonded interface technique has been used to observe the slip-steps due to shear band evolution. Vickers indentations were performed along the interface of the bonded split specimen at increasing loads. At small indentation loads, the plastic deformation was primarily accommodated by semi-circular primary shear bands surrounding the indentation. At higher loads, secondary and tertiary shear bands were formed inside this plastic zone. A modified expanding cavity model was then used to predict the plastic zone size characterized by the shear bands and to identify the stress components responsible for the evolution of the various types of shear bands.

The applicability of various hardness-yield-strength $\left(H-\sigma_{y}\right)$ relationships currently available in the literature for bulk metallic glasses (BMGs) is also investigated. Experimental data generated on ZrHf-based BMGs in the current study and those available elsewhere on other BMG compositions were used to validate the models. A modified expanding-cavity model, employed in earlier work, was extended 
to propose a new $H-\sigma_{y}$ relationship. Unlike previous models, the proposed model takes into account not only the indenter geometry and the material properties, but also the pressure sensitivity index of the BMGs. The influence of various model parameters is systematically analyzed. It is shown that there is a good correlation between the model predictions and the experimental data for a wide range of BMG compositions.

Under dynamic Vickers indentation, a decrease in indentation hardness at high loading rate was observed compared to static indentation hardness. It was observed that at equivalent loads, dynamic indentations produced more severe deformation features on the loading surface than static indentations. Different from static indentation, two sets of widely spaced semi-circular shear bands with two different curvatures were observed. The observed shear band pattern and the strain rate softening in indentation hardness were rationalized based on the variations in the normal stress on the slip plane, the strain rate of shear and the temperature rise associated with the indentation deformation.

Finally, a coupled thermo-mechanical model is proposed that utilizes a momentum diffusion mechanism for the growth and evolution of the final spacing of shear bands. The influence of strain rate, confinement pressure and critical shear displacement on the shear band spacing, temperature rise within the shear band, and the associated variation in flow stress have been captured and analyzed. Consistent with the known pressure sensitive behavior of BMGs, the current model clearly captures the influence 
of the normal stress in the formation of shear bands. The normal stress not only reduces the time to reach critical shear displacement but also causes a significant temperature rise during the shear band formation. Based on this observation, the variation of shear band spacing in a typical dynamic indentation test has been rationalized. The temperature rise within a shear band can be in excess of $2000 \mathrm{~K}$ at high strain rate and high confinement pressure conditions. The associated drop in viscosity and flow stress may explain the observed decrease in fracture strength and indentation hardness.

The above investigations provide valuable insight into the deformation behavior of BMGs under static and dynamic loading conditions. The shear band patterns observed in the above indentation studies can be helpful to understand and model the deformation features under complex loading scenarios such as the interaction of a penetrator with armor.

Future work encompasses (1) extending and modifying the coupled thermo-mechanical model to account for the temperature rise in quasistatic deformation; and (2) expanding this model to account for the microstructural variation-crystallization and free volume migration associated with the deformation. 


\section{Acknowledgements}

First, I would like to thank my advisor, Dr Ghatu Subhash for his support and guidance of this Ph.D. thesis project.

I would like to thank the Army Research Laboratory, Aberdeen Proving Ground, MD for their financial support for this project. Also, the finishing fellowship from Graduate School in the later stage of this project is appreciated. Special thanks to Dr Jong K Lee for his personal financial support during this research.

I would like thank Dr Laszlo J Kecskes for providing us the materials in current project and all committee members, Dr Ghatu Subhash, Dr Jong K Lee, Dr Bruce Pletka and Dr Gregory M Odegard for their time of reviewing my thesis and helpful suggestions.

Finally, I would like to express my sincere thanks to my wife, Han-bing and my daughter, Xin-xin for their love, patience and understanding. Additionally, thanks to my parents, Gui-ying and Yao-an for their continuous and unconditional support for my life and work. 


\section{Table of content}

CHAPTER 1. INTRODUCTION

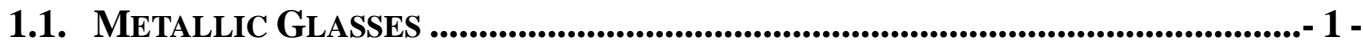

1.2. BUlK METALlic GlasSES ..................................................................................... 5 -

1.3. MEchanical PRoperties of BMGs ........................................................ 7 -

1.4. OBJECTIVE AND BACKGROUND ....................................................................... 12 -

CHAPTER 2. STRUCTURAL CHARACTERIZATION, CRYSTALLIZATION BEHAVIOR AND MECHANICAL PROPERTIES OF ZRHF-BASED BMGS- 19 $=$

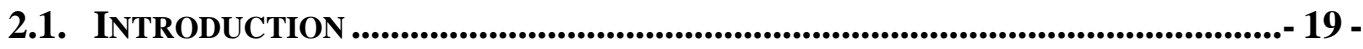

2.2. SAMPLE PREPARATION.......................................................................... 20 -

2.3. DENSITY MEASUREMENT ....................................................................... 20 -

2.4. STRUCTURAL CHARACTERIZATION ............................................................. 21 -

2.5. CRYSTALLIZATION BEHAVIOR .............................................................. 24 -

2.6. NANO-INDENTATION TESTS ON BMGS ........................................................ 29 -

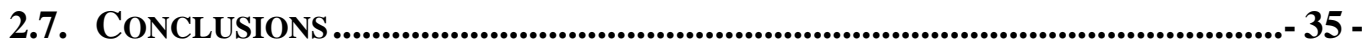

CHAPTER 3. INVESTIGATION OF SHEAR BAND EVOLUTION IN BMGS BENEATH QUASISTATIC VICKERS INDENTATIONS................................ - 37 -

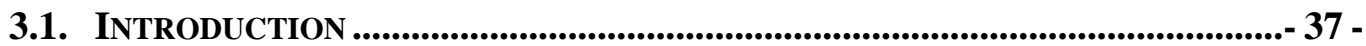

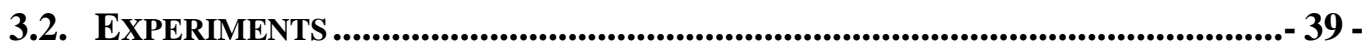

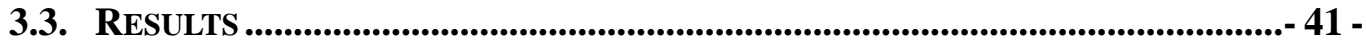

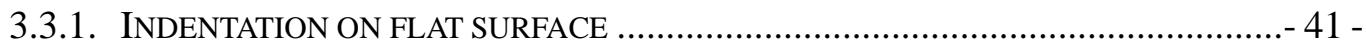

3.3.2. INDENTATION ALONG THE INTERFACE ......................................................... 42 -

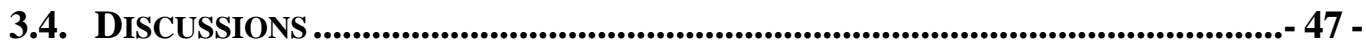

3.4.1. GEOMETRY OF DEFORMATION REGION BENEATH THE VICKERS INDENTATION - 52 -

3.4.2. EVALUATION OF STRESS FIELD BENEATH THE INDENTATION ............................ 55 -

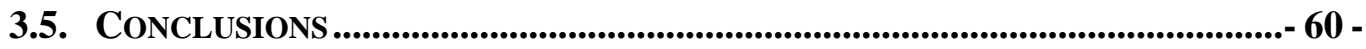

CHAPTER 4. EVALUATION OF HARDNESS-YIELD-STRENGTH RELATIONSHIPS FOR BULK METALLIC GLASSES................................ - 63 -

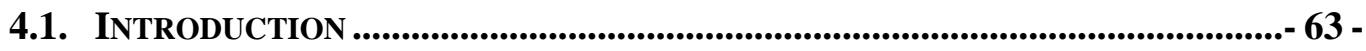

4.2. THEORETICAL FRAMEWORK ......................................................................... 68 -

4.3. EXPERIMENTAL PROCEDURE .......................................................................... 72 -

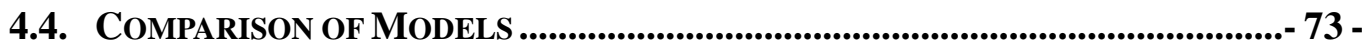

4.5. CONCLUSIONS ................................................................................................................ 81 - 
CHAPTER 5. EXPERIMENTAL INVESTIGATION OF DYNAMIC RESPONSE AND SHEAR BAND EVOLUTION IN ZRHF-BASED BMGS - 84 -

5.1. INTRODUCTION ..................................................................................................... 84 -

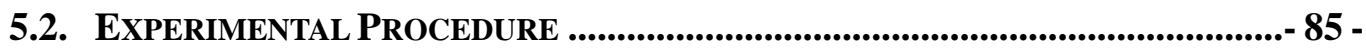

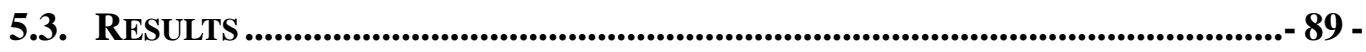

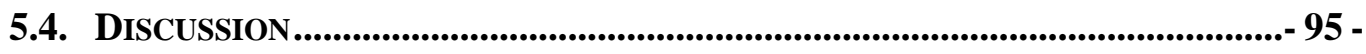

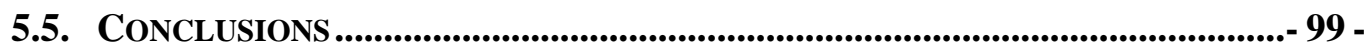

CHAPTER 6. THEORETICAL INVESTIGATION OF DYNAMIC RESPONSE AND SHEAR BANDS EVOLUTION IN ZRHF-BASED BMGS ................. - 102 -

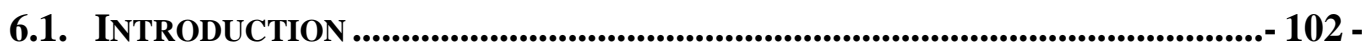

6.2. ANALYTICAL MODEL FOR DYNAMIC SHEAR BAND EVOLUTION .................... 103 -

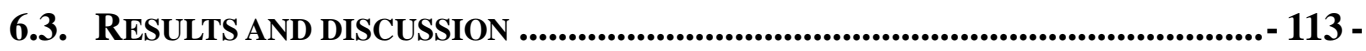

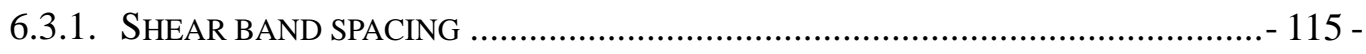

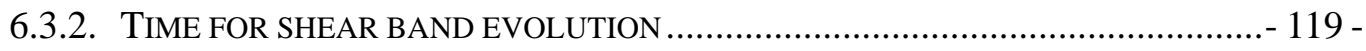

6.3.3. TEMPERATURE RISE INSIDE SHEAR BANDS ................................................ 120 -

6.3.4. FLOW STRESS VARIATION ASSOCIATED WITH TEMPERATURE RISE .................. 123 -

6.5. CONCLUSIONS ................................................................................................... 127 -

CHAPTER 7. CONCLUSIONS AND FUTURE WORK............................ - 131 - 


\section{Chapter 1. Introduction}

\subsection{Metallic Glasses}

Perfect crystals are solid materials in which the atoms are arranged in a pattern that repeats periodically in three dimensions to an infinite extent [1]. In practice, if a material possesses such long-range order (LRO) over a distance much larger than the repeated unit size, it is called crystalline. Based on a similar topological viewpoint, non-crystalline or amorphous materials are materials that do not exhibit LRO, although they may inherit certain short-range order or even medium-range order from their parent materials. Such non-crystalline materials include amorphous semiconductors, amorphous polymers, amorphous oxides and amorphous alloys. A great number of amorphous alloys, such as Mg-Ln-TM, Ln-Al-TM, Zr-Al-TM, Ti-Zr-TM, Zr-Ti-TM-Be, Zr-(Ti, Nb, Pd)-Al-Tm, Pd-Cu-Ni-P, Fe-(Al,Ga)-(P,C,B,Si), (Fe,Co,Ni)-(Zr,Hf,Nb)-B and Pd-Ni-Fe-P (Ln=Lanthanide metal, TM=transition metal), have been synthesized by various preparation methods of rapid quenching from liquid or vapor and solid-state reactions.

‘Metallic glasses’ are conventionally a term reserved for an amorphous alloy prepared by solidification from its molten state, which has an atomic structure similar to their liquid precursor [2]. When a liquid is cooled down, one of two competitive events may occur: (1) crystallization below the melting temperature; or (2) the liquid may become undercooled below the melting temperature $T_{m}$. As a result the viscosity of the undercooled liquid continuously and quickly increases with further decreasing 
temperature to the glass transition temperature $T_{g}$, forming a glass.

Silicate glasses have been made as early as 300BC by using a blowing iron technique. Duwez and his co-workers prepared the first metallic glass with the eutectic composition of $\mathrm{Au}_{75} \mathrm{Si}_{25}$, at the end of the 1950s through rapidly solidifying a molten liquid [3]. The primary difference between the silicate glasses and metallic glasses exist in the following aspects: (1) Silicate glasses with strong covalent bonding between atoms are characterized by a very high viscosity, which places severe limits on the rate of atomic or molecular rearrangements necessary for keeping the thermodynamic equilibrium upon cooling. Thus, the cooling rate for silicate glasses is often less than $10^{-2} \mathrm{~K} / \mathrm{s}$. (2) Metallic glasses, in contrast, have non-directional bonding, so that atomic rearrangements in the liquid state occur very easily and rapidly. Hence, high cooling rates $\left(10^{3} \sim 10^{5} \mathrm{~K} / \mathrm{s}\right)$ are required to prepare conventional metallic glasses. Since the pioneering work by Duwez and his co-workers, many efforts have been made to search for new metallic glasses and to develop innovative rapid-solidification technologies [4-8]. Because the essence of rapid solidification is dissipating the heat as quickly as possible in at least one direction, these early metallic glasses were thus limited to shapes of ribbons or powders, which are also called conventional metallic glasses in contrast to the bulk metallic glasses [9-11] which appeared around the late 1980s.

On the way to produce bulk metallic glasses, a few practical criteria for composition selection have been developed and widely used to seek systems with high glass forming ability (GFA) [2, 12-15]. The temperature-time-transformation (TTT) 
diagram provides a reliable way to estimate the GFA of metallic glasses. Figure 1.1 exhibits two C-shape curves representing the start and the completion of crystallization within a particular temperature region, respectively. The critical cooling rate $R_{\text {crit }}$ is defined as the slope of the dashed line (shown in Figure 1.1), which just touches the nose of the starting crystallization curve. The following equation predict the critical cooling rate for glass formation.

$$
R_{\text {crit }}=\frac{T_{m}-T_{N}}{t_{N}}
$$

where $T_{N}$ and $t_{N}$ are the temperature and the time at the nose of the starting curve. In practice, the slower the critical cooling rate, the easier it is to form metallic glasses. However, $T_{N}$ and $t_{N}$ are not easily obtained experimentally (it requires a complete TTT curve), which make it difficult to determine $R_{\text {crit }}$ accurately.

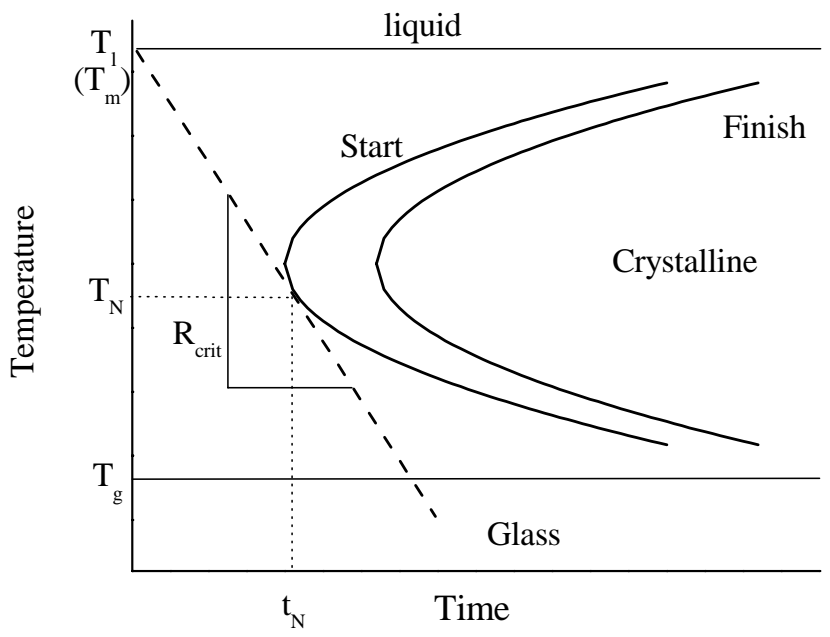

Figure 1.1 Schematic TTT diagram. The critical cooling rate for glass formation can be obtained through the TTT diagram.

To identify the GFA more conveniently, Turnbull et al. [12-15] suggested the reduced glass transition temperature $T_{r g}$ could be used to evaluate the GFA of different alloys: 


$$
T_{r g}=\frac{T_{g}}{T_{m}} \quad \text { or } \quad T_{r g}=\frac{T_{g}}{T_{l}}
$$

When $T_{r g}$ is larger than $2 / 3$ (as for silicate or organic glasses), $R_{\text {crit }}$ can be as low as $1 \mathrm{~K} / \mathrm{s}$. With decreasing $T_{r g}, R_{c r i t}$ increase quickly ( $R_{\text {crit }}$ is around $10^{5} \mathrm{~K} / \mathrm{s}$ when $T_{r g}=0.45$ ) $[16,17]$. Although there is still no precise quantitative relation established between $R_{c r i t}$ and $T_{r g}$, Eq. (1.2) has still been found helpful and suitable to describe the GFA of the bulk metallic glasses $[18,19]$. According to Eq. (1.2), the GFA is closely related to $T_{m}$ and $T_{g}$. It is known that $T_{g}$ is less sensitive to the composition of alloys than $T_{m}$; thus decreasing $T_{m}$ of the system was found to be effective to increase the GFA $[17,20]$. From the viewpoint of thermodynamics, $T_{m}$ is significantly lower near the eutectic point. Thus, it is expected that the glass formation may be easier in systems near eutectic compositions. Also from the viewpoint of structure, the structural rearrangement from a liquid to two solids near a eutectic point is very large and this also helps to retard crystallization.

In addition, a dense random packing configuration of the liquid phase can further favor glass formation by kinetically postponing the crystallization. Pronounced different atomic sizes in a multi-component system and the negative mixing energy among primary elements will be helpful to achieve the dense structure [19, 21]. Based on the above ideas, Inoue suggested three empirical rules to stabilize the supercooled liquid and achieve high glass-forming ability in multi-component alloys: (1) multiple components, (2) negative heats of mixing and (3) large atomic size ratios above $12 \%$ between different kinds of elements. Table 1.1 exhibits how these three rules play roles in improving the GFA of alloys. 


\section{Table 1.1 Mechanism for stabilization of supercooled liquid and the glass-forming ability for multicomponent alloys which satisfy the three empirical rules [19]}

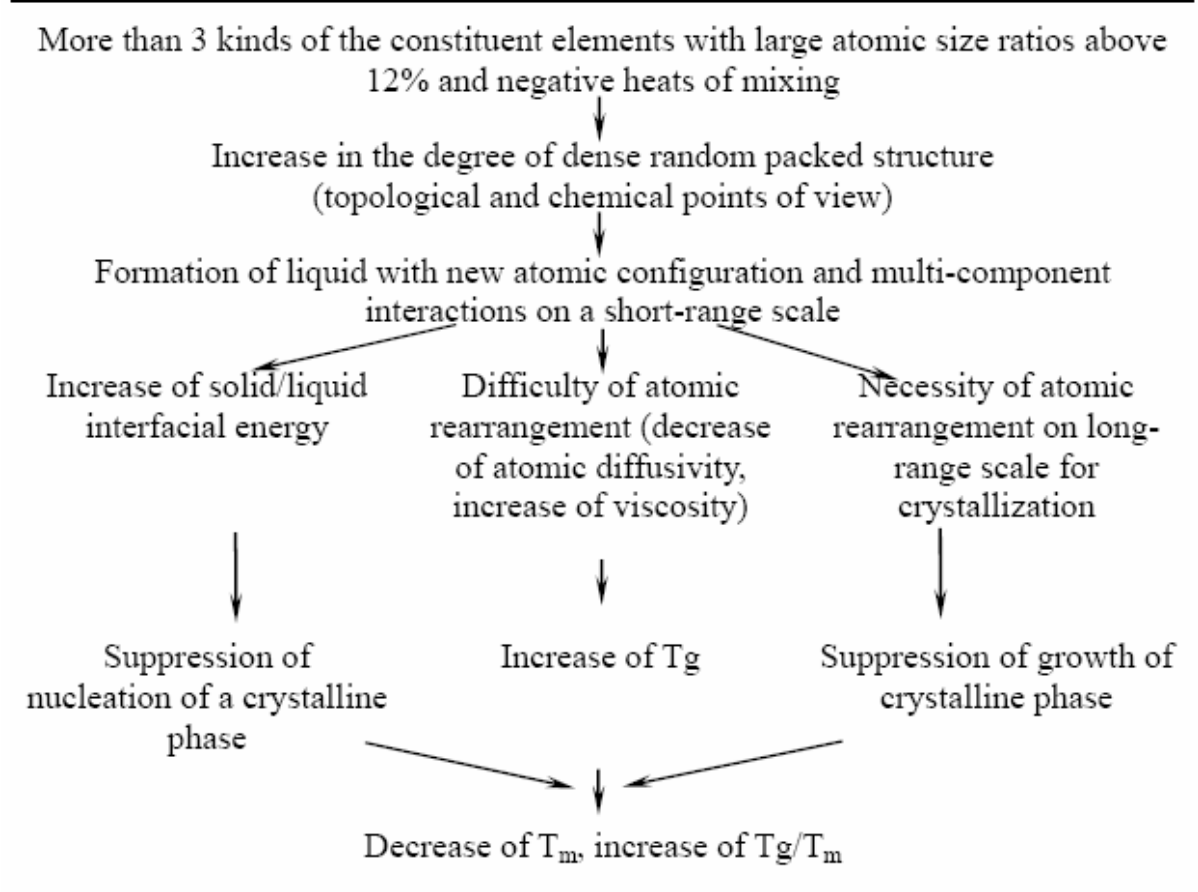

From the viewpoint of crystallization kinetics, if the start of crystallization is kinetically postponed, alloys could also be quenched into a glassy state at a lower cooling rate and thus enlarge the dimensions of the alloys. On the basis of classical nucleation theory, heterogeneous nucleation is much easier than homogeneous nucleation due to the smaller Gibbs free energy required to form critical nuclei. Thus, removing heterogeneous nucleation sites could further assist to suppress the crystallization process and make large metallic glasses. Indeed, based on all the considerations of alloy selection and improved casting technology, various metallic glasses and bulk metallic glasses have been successfully prepared [22 25].

\subsection{Bulk Metallic Glasses}

Bulk metallic glasses commonly denote metallic glasses with the size of at least one 
dimension larger than $1 \mathrm{~mm}$. Since the first appearance of bulk metallic glasses (BMGs) in the late 1980s, bulk metallic glasses have been successfully prepared in Al-, Zr-, Ti-, Cu-, Mg-, Co-, Fe-, PdCu-, PtCu- and Ln- (Ln=lanthanide metals) based systems [26-51]. Among these different systems, Zr-based BMGs have attracted the most wide and intense interest. Zr-Ti-Cu-Ni-Be, Zr-Ti-Al-Cu, Zr-Ni-Al-Cu and Zr-(Ti/Nb)-Al-Ni-Cu BMG systems [35,47-51] are often employed in research because of the following three major attractive factors: (1) they have good GFA and can be prepared at cooling rates below $10^{2} \mathrm{~K} / \mathrm{s}$; (2) they have a broad undercooled liquid region (30-100K) and good thermal stability; and (3) these alloys also have good mechanical properties.

There exist significant property differences between crystalline metallic alloys and metallic glasses because of the quite different structures. The properties of crystalline materials are closely controlled by the long-range periodicity of the lattice structure and plenty of theoretical models have been developed to explore the relationship between the properties and the structure. However, the properties of metallic glasses, due to the lack of an accurate structural model and the experimental difficulties in investigating a disordered system, are not yet clarified theoretically. Nevertheless, a wide range of excellent properties of metallic glasses have been measured and potential applications have also been expected as shown in Table 1.2 [73]. 
Table 1.2 Fundamental characteristic and potential applications of BMGs [73]

\begin{tabular}{ll}
\hline Fundamental Characteristic & Application Field \\
\hline High strength & Machinery structural materials \\
High hardness & Cutting materials \\
High fracture toughness & Die materials \\
High impact fracture energy & Bonding materials \\
High fatigue energy & Tool materials \\
High elastic energy & Sporting goods materials \\
High corrosion resistance & Corrosion resistant materials \\
High wear resistance & Ornamental materials \\
High viscous flow ability & Composite materials \\
High reflection ratio & Optical precision materials \\
Good soft magnetism & Soft magnetic materials \\
High frequency permeability & Writing application materials \\
Efficient electrode & Electrode materials \\
High hydrogen storage & Hydrogen storage materials \\
\hline
\end{tabular}

\subsection{Mechanical Properties of BMGs}

Of all of the properties of bulk metallic glasses, mechanical properties have attracted the most intense interest. Figure 1.2 reveals the property combinations or material indices $\sigma_{y} / E$ and $\sigma_{y}^{2} / E$, in which the first is the yield strain and the second is termed as resilience-a measure of the ability of the material to store elastic energy. By these measures, the metallic glasses excel, having a large yield strain and storing more elastic energy per unit volume than any of the other 1500 materials on the plot [68].

Comparison between, for example, Vitreloy-1 $\left(\mathrm{Zr}_{41.25} \mathrm{Ti}_{13.75} \mathrm{Ni}_{10} \mathrm{Cu}_{12.5} \mathrm{Be}_{22.5}\right)$ and some conventional alloys has been exhibited in Table 1.3. The high yield strength, the high elastic strain limit and the high specific strength made bulk metallic glasses attractive in both military and engineering applications. 


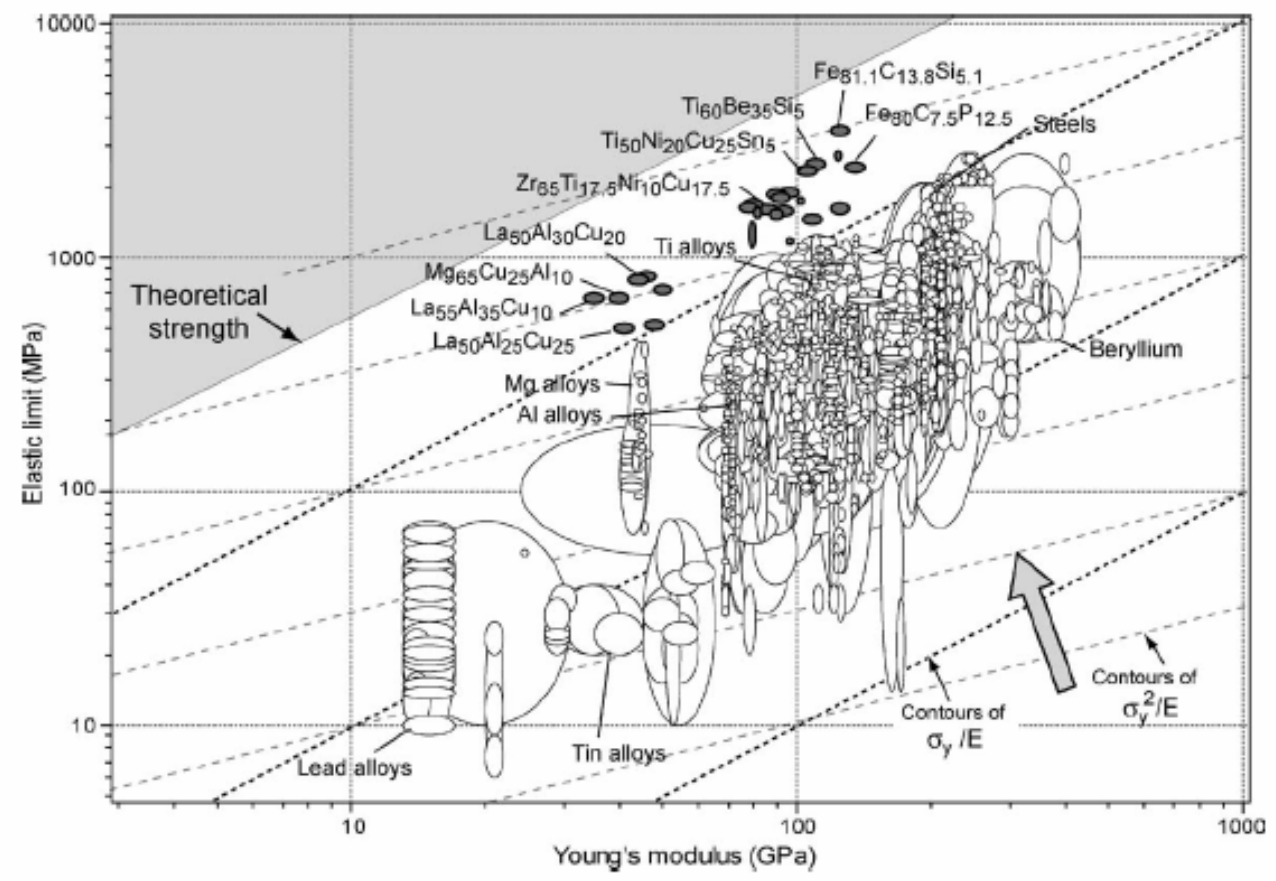

Figure 1.2 Elastic limit $\sigma_{\mathrm{y}}$ against modulus $E$ for 1507 metals, metal matrix composites and metallic glasses. The contours show the yield strain $\sigma_{y} / E$ and the resilience $\sigma^{2} / E[68]$.

Table 1.3 Comparison of mechanical properties between Vitreloy-1 and some conventional alloys

$\begin{array}{ccccc}\text { Property } & \text { Vitreloy-1 } & \begin{array}{c}\text { Aluminum } \\ \text { alloys }\end{array} & \begin{array}{c}\text { Titanium } \\ \text { alloys }\end{array} & \begin{array}{c}\text { Steel } \\ \text { alloys }\end{array} \\ \text { Density (g/cm3) } & 6.0 & 2.6-2.9 & 4.3-5.1 & 7.8 \\ \text { Yield strength (GPa) } & 1.9 & 0.1-0.63 & 0.18-1.32 & 0.5-1.60 \\ \begin{array}{c}\text { Elastic strain limit (\%) } \\ \begin{array}{c}\text { Fracture toughness } \\ \left(\mathrm{MPa} \mathrm{m}^{1 / 2}\right)\end{array}\end{array} & 2 & \sim 0.5 & \sim 0.5 & \sim 0.5 \\ \begin{array}{c}\text { Specific strength } \\ (\mathrm{GPa} / \mathrm{g} / \mathrm{cm} 3)\end{array} & 0.32 & 23-45 & 55-115 & 50-154 \\ \end{array}$


Table 1.4 Mechanical Properties of BMGs

\begin{tabular}{|c|c|c|c|c|c|}
\hline Alloy & $\sigma_{\mathrm{y}}(\mathrm{GPa})$ & $\mathrm{E}(\mathrm{GPa})$ & $\mathrm{Hv}(\mathrm{GPa})$ & $\mathrm{E} / \sigma_{\mathrm{y}}$ & $\mathrm{Hv} / \sigma_{\mathrm{y}}$ \\
\hline$\left(\mathrm{Al}_{0.84} \mathrm{Y}_{0.09} \mathrm{Ni}_{0.05} \mathrm{Co}_{0.02}\right)_{95} \mathrm{Sc}_{5}$ & 1.51 & 78 & 4.4 & 52 & 2.9 \\
\hline$\left(\mathrm{Al}_{0.85} \mathrm{Y}_{0.08} \mathrm{Ni}_{0.05} \mathrm{Co}_{0.02}\right)_{95} \mathrm{Sc}_{5}$ & 1.45 & 75 & 4.0 & 52 & 2.8 \\
\hline $\mathrm{Co}_{78} \mathrm{Si}_{10} \mathrm{~B}_{12}$ & 3.00 & 88 & 8.9 & 30 & 3.0 \\
\hline $\mathrm{Cu}_{60} \mathrm{Hf}_{25} \mathrm{Ti}_{15}$ & $1.92^{\mathrm{T}} / 2.01$ & 124 & 6.7 & 62 & 3.2 \\
\hline $\mathrm{Cu}_{60} \mathrm{Hf}_{30} \mathrm{Ti}_{10}$ & 2.00 & 119 & 6.3 & 60 & 3.2 \\
\hline $\mathrm{Cu}_{47.5} \mathrm{Zr}_{47.5} \mathrm{Al}_{5}$ & 1.55 & 87 & - & 56 & - \\
\hline $\mathrm{Fe}_{80} \mathrm{~B}_{20}$ & 3.40 & 167 & 10.6 & 49 & 3.1 \\
\hline $\mathrm{Fe}_{80} \mathrm{P}_{13} \mathrm{C}_{7}$ & 3.04 & 118 & 7.5 & 39 & 2.5 \\
\hline $\mathrm{Fe}_{78} \mathrm{~B}_{10} \mathrm{Si}_{12}$ & 3.33 & 118 & 8.9 & 35 & 2.7 \\
\hline$\left(\mathrm{Fe}_{0.75} \mathrm{~B}_{0.2} \mathrm{Si}_{0.05}\right)_{96} \mathrm{Nb}_{4}$ & 3.16 & 180 & 10.5 & 56 & 3.3 \\
\hline$\left.\left(\mathrm{Fe}_{0.9} \mathrm{Co}_{0.1}\right)_{0.75} \mathrm{~B}_{0.2} \mathrm{Si}_{0.05}\right)_{96} \mathrm{Nb}_{4}$ & 3.82 & 190 & 11.3 & 50 & 3.0 \\
\hline$\left.\left(\mathrm{Fe}_{0.8} \mathrm{Co}_{0.2}\right)_{0.75} \mathrm{~B}_{0.2} \mathrm{Si}_{0.05}\right)_{96} \mathrm{Nb}_{4}$ & 4.05 & 205 & 12.0 & 51 & 3.0 \\
\hline$\left.\left(\mathrm{Fe}_{0.7} \mathrm{Co}_{0.3}\right)_{0.75} \mathrm{~B}_{0.2} \mathrm{Si}_{0.05}\right)_{96} \mathrm{Nb}_{4}$ & 4.10 & 210 & 12.2 & 51 & 3.0 \\
\hline$\left.\left(\mathrm{Fe}_{0.6} \mathrm{Co}_{0.4}\right)_{0.75} \mathrm{~B}_{0.2} \mathrm{Si}_{0.05}\right)_{96} \mathrm{Nb}_{4}$ & 4.10 & 210 & 12.3 & 51 & 3.0 \\
\hline$\left.\left(\mathrm{Fe}_{0.5} \mathrm{Co}_{0.5}\right)_{0.75} \mathrm{~B}_{0.2} \mathrm{Si}_{0.05}\right)_{96} \mathrm{Nb}_{4}$ & 4.07 & 210 & 12.0 & 51 & 2.9 \\
\hline $\mathrm{Ni}_{78} \mathrm{Si}_{10} \mathrm{~B}_{12}$ & 2.45 & 78 & 8.4 & 32 & 3.4 \\
\hline $\mathrm{Ni}_{45} \mathrm{Ti}_{20} \mathrm{Zr}_{25} \mathrm{Al}_{10}$ & 2.37 & 114 & 7.8 & 50 & 3.4 \\
\hline $\mathrm{Ni}_{40} \mathrm{Cu}_{6} \mathrm{Ti}_{16} \mathrm{Zr}_{28} \mathrm{Al}_{10}$ & 2.18 & 111 & 7.6 & 51 & 3.5 \\
\hline $\mathrm{Ni}_{40} \mathrm{Cu}_{5} \mathrm{Ti}_{17} \mathrm{Zr}_{28} \mathrm{Al}_{10}$ & 2.30 & 134 & 8.4 & 58 & 3.7 \\
\hline $\mathrm{Ni}_{40} \mathrm{Cu}_{5} \mathrm{Ti}_{16.5} \mathrm{Zr}_{28.5} \mathrm{Al}_{10}$ & 2.30 & 122 & 7.8 & 53 & 3.4 \\
\hline $\mathrm{Ni}_{39.8} \mathrm{Cu}_{5.97} \mathrm{Ti}_{15.92} \mathrm{Zr}_{27.86} \mathrm{Al}_{9.95} \mathrm{Si}_{0.5}$ & 2.32 & 117 & 8.1 & 50 & 3.5 \\
\hline $\mathrm{Zr}_{41.25} \mathrm{Ti}_{13.75} \mathrm{Ni}_{10} \mathrm{Cu}_{12.5} \mathrm{Be}_{22.5}$ & 1.90 & 96 & 5.2 & 51 & 2.7 \\
\hline $\mathrm{Zr}_{52.5} \mathrm{Ti}_{5} \mathrm{Cu}_{17.9} \mathrm{Ni}_{14.6} \mathrm{Al}_{10}$ & 1.65 & 89 & 6.2 & 54 & 3.8 \\
\hline $\mathrm{Zr}_{57} \mathrm{Ti}_{5} \mathrm{Cu}_{20} \mathrm{Ni}_{8} \mathrm{Al}_{10}$ & 1.56 & 62 & 5.0 & 42 & 3.2 \\
\hline $\mathrm{Zr}_{57} \mathrm{Nb}_{5} \mathrm{Cu}_{15.4} \mathrm{Ni}_{12.6} \mathrm{Al}_{10}$ & $1.20^{\mathrm{T}} / 1.8$ & 85 & 4.9 & 48 & 2.7 \\
\hline $\mathrm{Zr}_{54.4} \mathrm{Cu}_{25.6} \mathrm{Fe}_{8} \mathrm{Al}_{12}$ & 1.69 & - & 5.5 & - & 3.3 \\
\hline $\mathrm{Zr}_{58} \mathrm{Cu}_{22} \mathrm{Fe}_{8} \mathrm{Al}_{12}$ & 1.63 & - & 5.3 & - & 3.3 \\
\hline $\mathrm{Zr}_{61.6} \mathrm{Cu}_{18.4} \mathrm{Fe}_{8} \mathrm{Al}_{12}$ & 1.56 & - & 5.1 & - & 3.3 \\
\hline $\mathrm{Pd}_{80} \mathrm{Si}_{20}$ & 1.34 & 67 & 3.2 & 50 & 2.4 \\
\hline $\mathrm{Pd}_{40} \mathrm{Ni}_{40} \mathrm{P}_{20}$ & $1.46^{\mathrm{T}} / 1.78$ & 108 & 5.3 & 68 & 3.0 \\
\hline $\mathrm{Pd}_{77.5} \mathrm{Cu}_{6} \mathrm{Si}_{16.5}$ & $1.44^{\mathrm{T}} / 1.54$ & 88 & 4.9 & 61 & 3.4 \\
\hline $\mathrm{Pt}_{57.5} \mathrm{Cu}_{14.7} \mathrm{Ni}_{5.3} \mathrm{P}_{22.5}$ & 1.40 & 94.8 & - & 68 & - \\
\hline
\end{tabular}

Table 1.4 reveals the yield strength $\sigma_{y}$, Young's modulus $E$ and hardness $H v$ of some bulk metallic glasses [26-51]. Bulk metallic glasses have very high yield strengths $(>1.5 \mathrm{GPa})$ and the constraint factors $\frac{H v}{\sigma_{y}}$ range from 2.7 to 3.8 . The ratio 
of $\frac{E}{\sigma_{y}}$ is around 50. The theoretical strength of perfect crystalline solids is commonly around $1 / 5$ of their elastic modulus [54]. Because of the defects and the impurities in polycrystalline materials, the real strength is far smaller than the theoretical one. For example, the ratio $\frac{E}{\sigma_{y}}$ of polycrystalline Fe is around 1050, which indicates that the real strength is only around $1 / 200$ of the theoretical strength. For metallic glasses, their real strength has reached up to $\sim 1 / 10$ of the theoretical strength, on the same order as crystalline fibers.

Although the elastic limit of metallic glasses is much higher than most of the conventional alloys, limited macro-plasticity in uniaxial compression and tension (heterogeneous deformation) in metallic glasses had been widely reported at ambient temperature and high stress. It is widely recognized that the plastic flow of metallic glasses is primarily accommodated through the formation of localized shear bands. The rapid evolution of the localized shear bands finally results in catastrophic facture, which limit the macroscopic plastic strain of BMGs to less than $2 \%$ although the local plastic strain inside the shear bands is pretty high. Moreover, their stress-strain curves do not show evidence of work-hardening behavior during continuous deformation.

Since the shear localization governs most room-temperature mechanical properties of metallic glasses, it is important to understand the formation and the evolution of these shear bands. Two major models were established to account for their formation: (1) a free volume model and (2) an adiabatic heating model. 
Polk and Turnbull [55] have suggested that deformation of metallic glasses below their glass transition temperature could form a more compositional disordered structure. This decreases the apparent viscosity and thus localized plastic deformation occurs. Pampillo [56] reported a preferential etching effect on shear bands of a metallic glass which gave some support to Polk and Turnbull's theory. The preferential etching susceptibility of shear bands means that the chemical potential within the bands has been changed with respect to the rest of materials, and this is corresponding to structural change-the reduction of short range order in shear bands. Spaepen and Turnbull [57] suggested that dilation associated with plastic shear strain also contribute to the weakening across sheared planes of metallic glasses. The shear viscosity should be lowered in regions which are dilated by stress concentration. Such a marked lowering of viscosity with dilation would be in accordance with the free volume model for transport, as developed by Cohen and Turnbull [58]. A local dilatancy induces a greater local free volume that serves to catalyze localized flow and leads to formation of a shear band. Further, the difference in volume between the materials within a formed shear band and the underformed material adjacent to it leads to a stress concentration at the interface between these regions. This stress concentration is large enough to propagate the band at a stress level less than that required to form a second band. The above idea composed the main idea of free-volume model accounting for the deformation of metallic glasses.

Leamy, Chen and Wang [59] suggested that the fracture is initiated by adiabatic shear. They suppose that the plastic zone becomes heated to temperatures exceeding the 
glass temperature by the adiabatic release of the deformation energy. The decrease in viscosity due to a local temperature increase inside the shear bands will facilitate the formation of a shear band. Bruck, Rosakis and Johnson [60], Flores [69], Yang [70], Lewandowski and Greer [71] reported temperature increases due to the adiabatic heating occur only after the onset of inhomogeneous deformation. They also found temperatures near the melting point of $\mathrm{Zr}-\mathrm{Ti}-\mathrm{Cu}-\mathrm{Ni}$-Be alloys may be approached within shear bands after the specimen has failed.

Wright [61] and Suresh [62] et al. studied the serrated plastic flow in Zr-Ti-Cu-Ni-Be and $\mathrm{Zr}-\mathrm{Nb}-\mathrm{Cu}-\mathrm{Ni}-\mathrm{Al}$ BMGs under uniaxial compression and nano-indentation, respectively, and the estimated temperature increase is only a few Kelvin. This indicates that the dramatically decreased viscosity in shear bands may not result from local adiabatic heating. Moreover, TEM observation of the deformed Ni-P and Fe-Ni-B ribbon suggested $[63,64]$ that the deformed material was dilated while shear bands occurring, implying the validity of free volume model. However, Lewandowski et al. [65] found that the fracture stress did not show an evident relationship with the hydrostatic pressure as suggested by free volume model. Therefore, there still exists controversy and no conclusive argument has been reached. These disagreements may result from (1) the loading state and the strain induced during the deformation, and (2) the strain rate inside the shear bands.

\subsection{Objective and Background}

Zr-based bulk metallic glasses have attracted considerable interest because of their 
good GFA, good thermal stability and excellent mechanical properties. However, like most other BMGs, they deform by shear localization and the rapid propagation of shear bands which leads to catastrophic failure and is characterized by limited plastic strain before fracture. Under most circumstances, shear localization is undesired because of the poor ductility. In kinetic energy armor-piercing projectiles, however, the formation of shear bands allows the penetrator to slough off the deformed materials (self-sharpening). This prevents a "mushroom” head of the penetrator upon impacting, allowing it to penetrate more effectively [66]. Presently, depleted Uranium (DU) is used as the penetrator material because of its high density $\left(>17 \mathrm{~g} / \mathrm{cm}^{3}\right)$ and its self-sharpening behavior during piercing. However, DU emits low-level radiation. The health and environmental concerns associated with the use of DU make a replacement desirable. Metallic glasses are a potential replacement since they also exhibit self-sharpening. However, the low density of existing Zr-based alloys $\left(5-7 \mathrm{~g} / \mathrm{cm}^{3}\right)$ limited their use in this field. Tungsten-fiber reinforced $\mathrm{Zr}-\mathrm{Ti}-\mathrm{Cu}-\mathrm{Ni}-\mathrm{Be}$ matrix composites with significantly increased density $\left(\sim 17.3 \mathrm{~g} / \mathrm{cm}^{3}\right.$ at $85 \%$ volume fraction tungsten) have been produced [67]. Ballistic tests of these materials show promising penetration performance. Further improvement may be possible by increasing the density of the glassy matrix in these composites.

Hf has quite similar chemical and physical properties to $\mathrm{Zr}$ as shown in Table 1.3. Within the same group (IVB) in the periodic table, Hf and $\mathrm{Zr}$ exhibit the same crystal structure (HCP) with close lattice constants. They also have similar atomic and ionic radius. But the density of $\mathrm{Hf}$ is almost twice of $\mathrm{Zr}$ due to the greater atomic weight of 
Hf. Thus, it is expected that the substitution of $\mathrm{Hf}$ for $\mathrm{Zr}$ will increase the density while retaining the GFA.

Table 1.3 Physical properties of Zirconium and Hafnium

\begin{tabular}{lcc}
\hline Properties & $\mathrm{Zr}$ & $\mathrm{Hf}$ \\
\hline Atomic number & 40 & 72 \\
Atomic weight $(\mathrm{g} / \mathrm{mol})$ & 91.22 & 178.9 \\
Density $\left(\mathrm{g} / \mathrm{cm}^{3}\right)$ & 6.49 & 13.1 \\
Atomic radius $(\mathrm{nm})$ & 0.158 & 0.159 \\
Ionic radius $(\mathrm{nm})$ & $0.087\left(\mathrm{Zr}^{4+}\right)$ & $0.084\left(\mathrm{Hf}^{4+}\right)$ \\
Crystal structure & $\mathrm{HCP}(\alpha) / \mathrm{BCC}(\beta)$ & $\mathrm{HCP}(\alpha) / \mathrm{BCC}(\beta)$ \\
$\alpha-\beta$ Transition temperature $(\mathrm{K})$ & 1138 & 2033 \\
Melting temperature $(\mathrm{K})$ & 2125 & 2495 \\
Boiling temperature $(\mathrm{K})$ & 4650 & 4875 \\
Heat capacity $(\mathrm{J} / \mathrm{kg}-\mathrm{K})$ & 285 & 117 \\
Thermal Expandion $\quad \mathrm{coefficient}$ & $5.89 \times 10^{-6}$ & $5.90 \times 10^{-6}$ \\
$\left(\mathrm{~K}^{-1}\right)$ & & \\
Electrical resistively $(\mu \Omega \mathrm{m})$ & 0.397 & 0.351 \\
Thermal conductivity $(\mathrm{W} / \mathrm{m}-\mathrm{K})$ & 22.0 & 23.0 \\
Young's Modulus $(\mathrm{GPa})$ & 99 & 135 \\
\hline
\end{tabular}

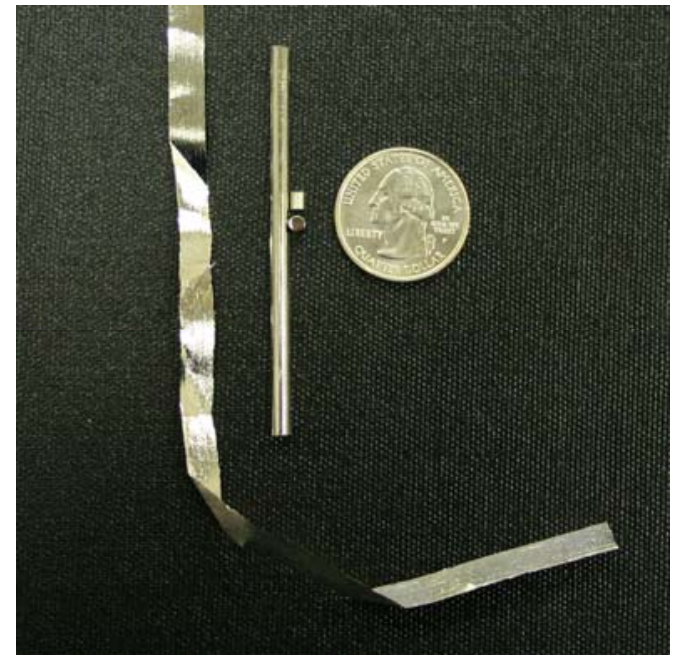

Figure 1.3. Morphology of as-prepared glassy ribbons and rods.

ZrHf-based BMGs, $\left(\mathrm{Hf}_{\mathrm{x}} \mathrm{Zr}_{1-\mathrm{x}}\right)_{52.5} \mathrm{Ti}_{5} \mathrm{Ni}_{14.6} \mathrm{Cu}_{17.9} \mathrm{Al}_{10} \quad(\mathrm{x}=0,0.2,0.4,0.6,0.8,1)$ $\left(\mathrm{Hf}_{\mathrm{x}} \mathrm{Zr}_{1-\mathrm{x}}\right)_{57} \mathrm{Ti}_{5} \mathrm{Ni}_{8} \mathrm{Cu}_{20} \mathrm{Al}_{10}(\mathrm{x}=0,0.2,0.4)$ and $\mathrm{Zr}_{57} \mathrm{Nb}_{5} \mathrm{Ni}_{12.6} \mathrm{Cu}_{15.4} \mathrm{Al}_{10}$ were employed in the present studies. Ribbons and cylindrical rods were obtained for future 
investigation and Figure 1.3 displays the morphology of the ribbons and the rods. To prepare the specimens, pure elements with the nominal composition were first arc-melt repeatedly into small buttons [72]. Melt-spinning technique was used to prepare the glassy ribbons. Cylindrical ingots of 3mm diameter were prepared by the suction casting technique as described in [72].

In this dissertation, the investigations are focused on clarifying the effects of the $\mathrm{Hf}$ addition in Chapter 2 on (i) the crystallization behavior and the glass forming ability through various thermodynamic and kinetic analysis, and (ii) the hardness and the modulus of the as cast alloys through nano-indentation tests. Chapter 3 reveals the investigation on the variation of shear band patterns under static indentation tests with increasing load from $10 \mathrm{~g}$ to $1000 \mathrm{~g}$ and the rationalization of the initiation of different sets of shear bands on the basis of a stress component analysis. In Chapter 4, the relationship between the hardness and the yield strength in various BMGs is studied on the basis of a modified expanding cavity model incorporating a pressure sensitivity index. In Chapter 5, the evolution of shear bands beneath dynamic indentations is experimentally identified and a strain rate softening of indentation hardness is also reported. Chapter 6 is concerned with a theoretical model accounting for the shear band evolution under dynamic loading. Shear displacement, strain rate, normal stress and the associated temperature rise during deformation are considered in this model and an explanation from this model for the shear band patterns is provided. 


\section{Reference}

1. Elliot S.R., Physics of Amorphous Materials, $2^{\text {nd }}$, Longman Group UK Ltd., London 1990

2. Johnson WL, MRS Bull, 1999; 10: 42

3. Klement W., Willens R.J., Duwez P., Nature 1960; 187:869

4. Pond R.B, Maddin R., Trans Met Soc AIME, 1969;245:2475

5. Boswell P.G., Chadwick G.A., J Phys E,1976;9:523

6. $\quad$ Chen H.S., Miller C.E., Mater Res Bull, 1976;11;49

7. Pond R.B., US Patent No.2,825,108, 1958, March

8. Liebermann H.H., Graham C.D., IEEE Trans Mag., 1976;12:921

9. Cahn R.W., In Rapidly Solidified Alloys: Processes, Structures, Properties, Application, pp1, edited by Liebermann, Dekker, New York, 1993

10. Jones, Rapid Solidification of Metals and Alloys, Inst. Of Metallurgists, London, 1982

11. Gilman J.J., Science, 1980;208:856

12. Turnbull D., Fisher J.C., J Chem Phys, 1949;17:71

13. Turnbull D., Comtemp Phys, 1969;10:473

14. Cohen M.H., Turnbull D., J Chem Phys, 1959;31:1164

15. Turnbull D., Cohen M.H., J Chem Phys, 1961;34:120

16. Davies H.A., In Rapidly Quenched Metals III, Vol 1, pp1, edited by Liebermann, Metals Society, London, 1978

17. Luborsky FE ed. Amorphous Metallic Alloys, Butterworth, London, 1983

18. Inoue A. Bulk amorphous alloys: Preparation and Fundamental Characteristics. Switzerland: Trans Tech Publication; 1998.

19. Inoue A, Acta Mater, 2000; 48:279.

20. Chen H.S., Rep Prog Phys., 1980;43:353

21. Inoue A, Takeuchi A, Mater Sci Forum, 2002;403;1

22. Chen H S, Turnbull D, J Chem phys,1969;48:2560

23. Chen H S, Acta Mater, 1974;22:1505

24. Drehman A.J., Greer A L, Turnbull D, Appl Phys Lett, 1982;41:716

25. Kui H W, Turnbull D, Appl Phys Lett, 1984;45:615 
26. Inoue A, Sobu S, Louzguine D, Kimura H, Sasamori K, J Mater Res, 2004;19:1539

27. Inoue A, Ohtera K, Kita K, Masumoto T, Jpn J Appl Phys, 1988;27:_2248

28. Inoue A, Zhang T, Masumono T, Mater Trans JIM, 1989;30:965

29. Inoue A, Kato A, Zhang T, Kim S G, Masumono T, Mater Trans JIM, 1991;32:609

30. Inoue A, Nakamura $\mathrm{T}$, Nishiyama $\mathrm{N}$, Masumono $\mathrm{T}$, Mater Trans JIM, 1992;33:937

31. Busch R., Liu W, Johnson W L, J Appl Phys, 1998;83:4134

32. Kang H G, Park E S, Kim K T, Kim D H, Cho H K, Mater Trsns JIM, 2000;41:846

33. Amiya K, Inoue A, Mater Trans JIM, 2000;41:1460

34. Inoue A, Zhang T, Masumoto T, Mater Trans JIM, 1990;31:425

35. Inoue A, Zhang T, Masumoto T, Mater Trans JIM, 1990;31:177

36. Peker A, Johnson W L, Appl Phys Lett; 1993;63:2342

37. Donovan PE, J Mater Sci; 1989;24:523

38. Donovan PE, Stobbs WM, Acta Metall, 1981;29:1419

39. He Y, Poon S J, Shiflet G J, Science; 1988;241:1640

40. Inoue A, Zhang T, Kita K, Masumoto, Mater Trans JIM, 1989;30:870

41. Inoue A, Zhang T, Nishiyama N, Ohba K, masumoto T, Mater Lett, 1994;19:131

42. Lin X H, Johnson W L, J Appl Phys; 1995;78:6514

43. Zhang T, Inoue A, Mater Trans JIM, 1999;40:301

44. Schroers J, Johnson WJ, Phys Rev Lett., 2004;93:255506

45. Inoue A, Shen BL, Chang CT, Acta Mater, 2004;52:4093

46. Inoue A, Negishi T, Kimura H M, Zhang T, Yavari A R, Mater Trans JIM, 1998;39:318

47. Zhang T, Inoue A, Mater Trans JIM, 1998;39:857

48. Xing L Q, Ochin P, Harmelin M, Faudot F, Bigot, J Non-Cryst Solids, 1996;205-207:597

49. Hays C C, Schroers J, Geyer U, Bossuyt S, Stein N, Johnson W L, Mater Sci Forum, 2000;343-346:103

50. Conner RD, Dandliker RB, Johnson WL, Acta Mater, 1998;46:6089 
51. Conner R D, Kim C H, Johnson W L, J Mater Res, 1999;14:3292

52. Greer AL, Mater Sci\&Eng, 2001;A304-306:68

53. Inoue A, Prog. in Mater Sci;1998; 43:365

54. Hertzberg RW, Deformation and Fracture Mechanisms of Engineering Materials, $2^{\text {nd }}$ Ed., John Wiley and Sons, New York, 1983

55. Polk DE and Turnbull D., Acta Met, 1972;20:493

56. Pampillo CA, Scripta Met, 1972;6:915

57. Spaepen F, Turnbull D, Scripta Met, 1974;8:563

58. Cohen MH, Turnbull D, J Chem Phys, 1970;52:3038

59. Leamy HJ, Chen HS, Wang TT, Met Trans, 1972;3:699

60. Bruck HA, Rosakis AJ, Johnson WL, J Mater Res, 1996;11:503

61. Wright WJ, Schwartz, Nix WD, Mater Sci \&Eng, 2001;A319-321:229

62. Kim J-J, Choi Y, Suresh S, Argon AS, Science, 2002;295:654

63. Donovan PE, Stobbs WM, J Non-cryst Solids, 1983;55:61

64. Donovan PE, Stobbs WM, Philos Mag A, 1983;47:537

65. Lowhaphandu P, Montgomery SL, Lewandowski JJ, Scr Mater; 1999;41:19

66. Dandliker RB, Conner RD, Johnson WL, App Phys Lett, 1998;13:2896

67. Gu X., Xing L.Q., Hufnagel T.C., J. Non-cryst. Solids, 2002;311:77

68. Ashby, M.F., Greer, A.L., Scripta Mater., 2006:54:321

69. Flores, K.M., Dauskardt, R.H., J of Mater. Res., 1999;14:638

70. Yang, B., Morrison, M.L., Liaw, P.K., Buchanan R.A., Wang, G., Liu, C.T., Denda, M., Applied Physics Letters, 2005; 86:141904

71. Lewandowski, J.J., Shazly, M., Shamini Nouri, A., Scripta Mater., 2006; 54:337

72. Gu X, PhD Thesis, Johns Hopkins University, Baltimore, Maryland, 2003.

73. Wang WH, Dong C, Shek CH, Mater. Sic\&Eng. 2004;R44:45 


\section{Chapter 2. Structural Characterization, Crystallization Behavior and Mechanical Properties of ZrHf-based BMGs}

\subsection{Introduction}

Multi-component Zr-based bulk metallic glasses (BMGs) can be manufactured at cooling rates below $10^{2} \mathrm{~K} / \mathrm{s}$, which facilitates the preparation of specimens in large sizes (up to centimeters for at least one dimension). $\mathrm{Zr}_{41.2} \mathrm{Ti}_{13.8} \mathrm{Ni}_{10} \mathrm{Cu}_{12.5} \mathrm{Be}_{22.5}$ (Vitreloy 1), manufactured first by Peker and Johnson [1], exhibits a high GFA, which allows it to be prepared at a cooling rate as low as $1 \mathrm{~K} / \mathrm{s}$. $\mathrm{Zr}_{65} \mathrm{Al}_{7.5} \mathrm{Ni}_{10} \mathrm{Cu}_{17.5}$, another BMG with good GFA developed by Zhang and Inoue [2], has the broadest undercooled liquid region $(\sim 127 \mathrm{~K})$ in metallic glasses to date. Two quinary Zr-based BMGs $\mathrm{Zr}_{52.5} \mathrm{Ti}_{5} \mathrm{Ni}_{14.6} \mathrm{Cu}_{17.9} \mathrm{Al}_{10}$ and $\mathrm{Zr}_{57} \mathrm{Ti}_{5} \mathrm{Ni}_{8} \mathrm{Cu}_{20} \mathrm{Al}_{10}$ without the toxic Be element have been first prepared by Lin [3] and Xing [4,5], which also display a great GFA and excellent thermal stability. As mentioned in the previous chapter, to achieve the high density for application in certain specific fields, Hf was used to substitute for the $\mathrm{Zr}$ element because of the similar chemical and physical properties of $\mathrm{Hf}$ and $\mathrm{Zr}$ as shown in Table 1.3. Previous results [6-8] have revealed that the replacement of Zr by Hf will not significantly decrease the glass forming ability for certain compositions. Moreover, improved mechanical properties with increasing Hf content have also been predicted and observed in $\left(\mathrm{Hf}_{\mathrm{x}} \mathrm{Zr}_{1-\mathrm{x}}\right)_{52.5} \mathrm{Ti}_{5} \mathrm{Ni}_{14.6} \mathrm{Cu}_{17.9} \mathrm{Al}_{10},(\mathrm{x}=0,1 / 3,1 / 2,2 / 3$ and 1$)$, $\left(\mathrm{Hf}_{\mathrm{x}} \mathrm{Zr}_{1-\mathrm{x}}\right)_{57} \mathrm{Ti}_{5} \mathrm{Ni}_{8} \mathrm{Cu}_{20} \mathrm{Al}_{10}(\mathrm{x}=0,0.09$, ,018, 0.35, 0.5, 0.74) [8]. BMG compositions of $\quad\left(\mathrm{Hf}_{\mathrm{x}} \mathrm{Zr}_{1-\mathrm{x}}\right)_{52.5} \mathrm{Ti}_{5} \mathrm{Ni}_{14.6} \mathrm{Cu}_{17.9} \mathrm{Al}_{10}, \quad(\mathrm{x}=0, \quad 0.2, \quad 0.4, \quad 0.6, \quad 0.8$ and 1$)$, 
$\left(\mathrm{Hf}_{\mathrm{x}} \mathrm{Zr}_{1-\mathrm{x}}\right)_{57} \mathrm{Ti}_{5} \mathrm{Ni}_{8} \mathrm{Cu}_{20} \mathrm{Al}_{10}(\mathrm{x}=0,0.2, \quad 0.4)$ and $\mathrm{Zr}_{57} \mathrm{Nb}_{5} \mathrm{Ni}_{12.6} \mathrm{Cu}_{15.4} \mathrm{Al}_{10}$ have been prepared at John Hopkins University with the help by Professor Todd Hufnagel and provided by Laszlo J Kecskes. In the current chapter, their amorphous structure was characterized by x-ray diffraction (XRD) and transmission electron microscopy (TEM) and the crystallization behavior was investigated by differential scanning calorimetry (DSC). Mechanical properties, namely, modulus and hardness are measured through nano-indentation tests.

\subsection{Sample preparation}

As mentioned in Chapter 1, cylindrical ingots of 3mm diameter with the nominal compositions $\left(\mathrm{Hf}_{\mathrm{x}} \mathrm{Zr}_{1-\mathrm{x}}\right)_{52.5} \mathrm{Ti}_{5} \mathrm{Ni}_{14.6} \mathrm{Cu}_{17.9} \mathrm{Al}_{10}, \quad(\mathrm{x}=0,0.2, \quad 0.4, \quad 0.6, \quad 0.8$ and 1$)$, $\left(\mathrm{Hf}_{\mathrm{x}} \mathrm{Zr}_{1-\mathrm{x}}\right)_{57} \mathrm{Ti}_{5} \mathrm{Ni}_{8} \mathrm{Cu}_{20} \mathrm{Al}_{10}(\mathrm{x}=0,0.2,0.4)$ and $\mathrm{Zr}_{57} \mathrm{Nb}_{5} \mathrm{Ni}_{12.6} \mathrm{Cu}_{15.4} \mathrm{Al}_{10}$ were prepared from high purity elements by repeated arc melting and a suction casting technique as described in [8]. To implement the structural identification and indentation tests, small rods 3.4 3.6mm in length were first cut from the cylindrical ingots by electrical discharge machining (EDM).

\subsection{Density measurement}

The density of these small rods was measured using Archimedes method and the measured values change from a minimum of $6.55 \mathrm{~g} / \mathrm{cm}^{3}$ for $\mathrm{Zr}_{57} \mathrm{Ti}_{5} \mathrm{Ni}_{8} \mathrm{Cu}_{20} \mathrm{Al}_{10}$ to a maximum of $11.00 \mathrm{~g} / \mathrm{cm}^{3}$ for $\mathrm{Hf}_{52.5} \mathrm{Ti}_{5} \mathrm{Ni}_{14.6} \mathrm{Cu}_{17.9} \mathrm{Al}_{10}$ with increasing $\mathrm{Hf}$ content as shown in Table 2.1. Assuming that Hf atoms play the same role as $\mathrm{Zr}$ atoms in these alloys due to their similar physical and chemical properties, the density of these alloys 
with Hf substitution for $\mathrm{Zr}$ can thus be predicted based on role of mixtures and the results are shown in Figure 2.1. A good agreement between the measured and the predicted density has been achieved in Figure 2.1. At high Hf content ( $x=0.6,0.8$ and 1 in $\left.\left(\mathrm{Hf}_{\mathrm{x}} \mathrm{Zr}_{1-\mathrm{x}}\right)_{52.5} \mathrm{Ti}_{5} \mathrm{Ni}_{14.6} \mathrm{Cu}_{17.9} \mathrm{Al}_{10}\right)$, the measured density reveals to be slightly higher than the predicted values. This may result from denser atomic packing structure at high Hf content or even slight crystallization with Hf substitution.

Table 2.1 Compositional dependence of $T_{g}, T_{x 1}, T_{m}, T_{l}, T_{g} / T_{m}, T_{g} / T_{l}, \Delta T$,

$$
\rho, \Delta E_{T g} \text { and } \Delta E_{T \times 1}
$$

\begin{tabular}{l|cccccccccc}
\hline Composition & $T_{g}$ & $T_{x 1}$ & $T_{m}$ & $T_{l}$ & $T_{g} / T_{m}$ & $T_{g} / T_{l}$ & $\Delta T_{x}$ & $\Delta E_{T g}$ & $\Delta E_{T x 1}$ & $\begin{array}{l}\rho \\
\left(\mathrm{g} / \mathrm{cm}^{3}\right)\end{array}$ \\
& $(K)$ & $(K)$ & $(K)$ & $(K)$ & & & $(K)$ & $(\mathrm{kJ} / \mathrm{mol})$ & $(\mathrm{kJ} / \mathrm{mol})$ & \\
\hline $\mathrm{Zr}_{52.5} \mathrm{Ti}_{5} \mathrm{Ni}_{14.6} \mathrm{Cu}_{17.9} \mathrm{Al}_{10}$ & 684 & 729 & 1075 & 1133 & 0.64 & 0.604 & 45 & 237.5 & 240.7 & $6.64 \pm 0.02$ \\
$\left(\mathrm{Hf}_{0.2} \mathrm{Zr}_{0.8}\right)_{52.5} \mathrm{Ti}_{5} \mathrm{Ni}_{14.6} \mathrm{Cu}_{17.9} \mathrm{Al}_{10}$ & 698 & 743 & 1096 & 1151 & 0.64 & 0.606 & 45 & 319.7 & 235.9 & $7.44 \pm 0.01$ \\
$\left(\mathrm{Hf}_{0.4} \mathrm{Zr}_{0.6}\right)_{52.5} \mathrm{Ti}_{5} \mathrm{Ni}_{14.6} \mathrm{Cu}_{17.9} \mathrm{Al}_{10}$ & 714 & 764 & 1132 & 1190 & 0.63 & 0.600 & 51 & 336.9 & 219.8 & $8.22 \pm 0.02$ \\
$\left(\mathrm{Hf}_{0.6} \mathrm{Zr}_{0.4}\right)_{52.5} \mathrm{Ti}_{5} \mathrm{Ni}_{14.6} \mathrm{Cu}_{17.9} \mathrm{Al}_{10}$ & 733 & 786 & 1175 & 1234 & 0.62 & 0.594 & 53 & 341.5 & 248.2 & $9.21 \pm 0.01$ \\
$\left(\mathrm{Hf}_{0.8} \mathrm{Zr}_{0.2}\right)_{52.5} \mathrm{Ti}_{5} \mathrm{Ni}_{14.6} \mathrm{Cu}_{17.9} \mathrm{Al}_{10}$ & 740 & 792 & 1207 & 1247 & 0.61 & 0.593 & 52 & 495.3 & 271.0 & $10.10 \pm 0.01$ \\
$\mathrm{Hf}_{52.5} \mathrm{Ti}_{5} \mathrm{Ni}_{14.6} \mathrm{Cu}_{17.9} \mathrm{Al}_{10}$ & 768 & 826 & 1247 & 1283 & 0.62 & 0.599 & 57 & 567.3 & 245.8 & $11.00 \pm 0.02$ \\
$\mathrm{Zr}_{57} \mathrm{Ti}_{5} \mathrm{Ni}_{8} \mathrm{Cu}_{20} \mathrm{Al}_{10}$ & 654 & 688 & 1080 & 1140 & 0.61 & 0.57 & 34 & 206.8 & 294.8 & $6.55 \pm 0.02$ \\
$\left(\mathrm{Hf}_{0.2} \mathrm{Zr}_{0.8}\right)_{57} \mathrm{Ti}_{5} \mathrm{Ni}_{8} \mathrm{Cu}_{20} \mathrm{Al}_{10}$ & - & - & - & - & - & - & - & - & - & $7.52 \pm 0.01$ \\
$\left(\mathrm{Hf}_{0.4} \mathrm{Zr}_{0.6}\right)_{57} \mathrm{Ti}_{5} \mathrm{Ni}_{8} \mathrm{Cu}_{20} \mathrm{Al}_{10}$ & 683 & 715 & 1163 & 1215 & 0.59 & 0.56 & 32 & 256.1 & 248.6 & $8.35 \pm 0.02$ \\
$\mathrm{Zr}_{57} \mathrm{Nb}_{5} \mathrm{Ni}_{12.6} \mathrm{Cu}_{15.4} \mathrm{Al}_{10}$ & 673 & 745 & 1057 & 1111 & 0.64 & 0.61 & 72 & 312.2 & 317.1 & $6.75 \pm 0.02$ \\
\hline
\end{tabular}

\subsection{Structural Characterization}

To implement XRD measurements, the $3.4 \sim 3.6 \mathrm{~mm}$ long rods were vertically cut into two halves by a diamond saw. The vertical surfaces of these split samples were mechanically polished to US grit size 1200 for XRD measurement (Scintag XDS 2000). $\mathrm{Cu} \mathrm{K}_{\alpha}$ radiation and a zero-background plate to reduce the interference on the diffraction spectrum from the amorphous specimen were used in the XRD analysis. These specimens do not show sharp crystalline diffraction peaks and the 
representative XRD spectrum for all the compositions are shown in Figure 2.2. Instead, a broad peak appears around $2 \theta=38^{\circ}$ in each of the XRD curves, indicating that an amorphous structure is achieved in all these alloys.

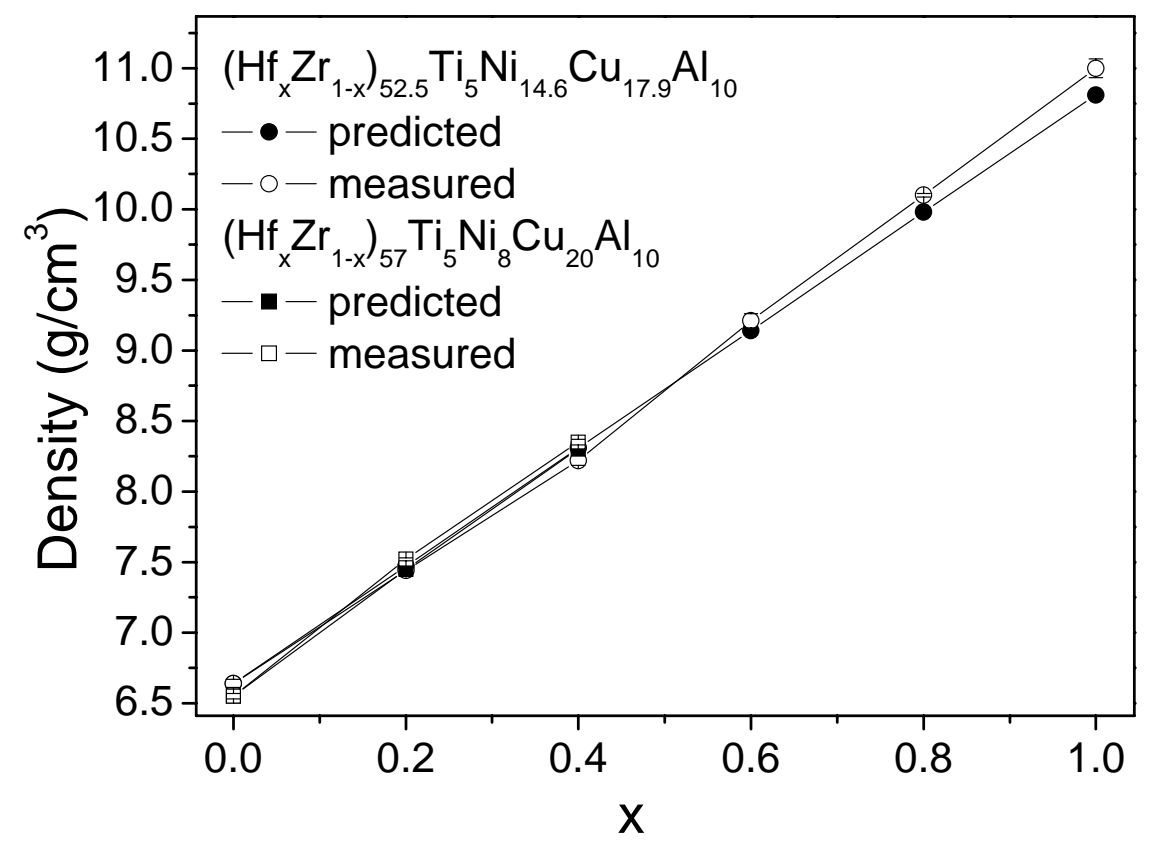

Figure 2.1 Measured and theoretical density of ZrHf-based BMGs as a function of Hf content

Foils with a thickness of from 200 to 500 microns were cut from the cylinder samples by a diamond saw. After mechanical thinning to around microns and cleaning, a twin-jet electro-polishing technique was used to prepare them into the TEM specimens by using a solution of $30 \%$ perchloric acid $+70 \%$ ethanol at $243 \mathrm{~K}$. Electro-polishing stopped when multiple small holes appeared in the foils. The thinned foils were finally cleaned ultrasonically with methanol. TEM images and diffraction patterns were taken in the thinned regions surrounding the holes under an 
operating voltage of $200 \mathrm{kV}$. Figure 2.3 shows a representative bright field TEM image for $\mathrm{Hf}_{52.5} \mathrm{Ti}_{5} \mathrm{Ni}_{14.6} \mathrm{Cu}_{17.9} \mathrm{Al}_{10}$, where only thickness contrast has been revealed and no evidence of a crystalline phase has been identified. At the same time, the selected area electron diffraction (SAED) patterns (JEOL JEM-100CXF) in the regions corresponding to where the BF images were obtained further verified the amorphous structure of these alloys. Typically a broad halo indicating the non-crystalline structure is obtained and shown in the inset of Figure 2.3.

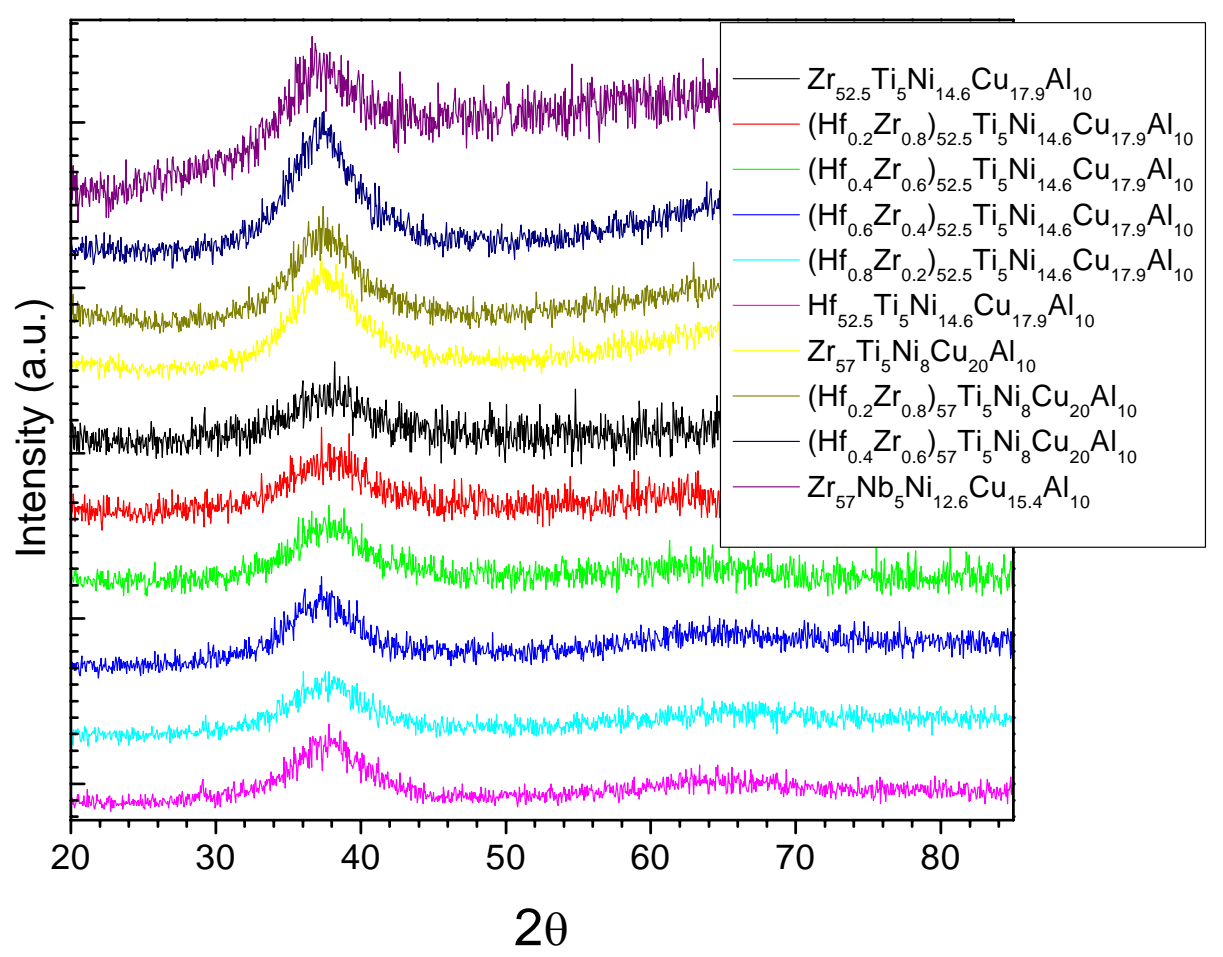

Figure 2.2 XRD pattern of as cast ZrHf-based BMGs 


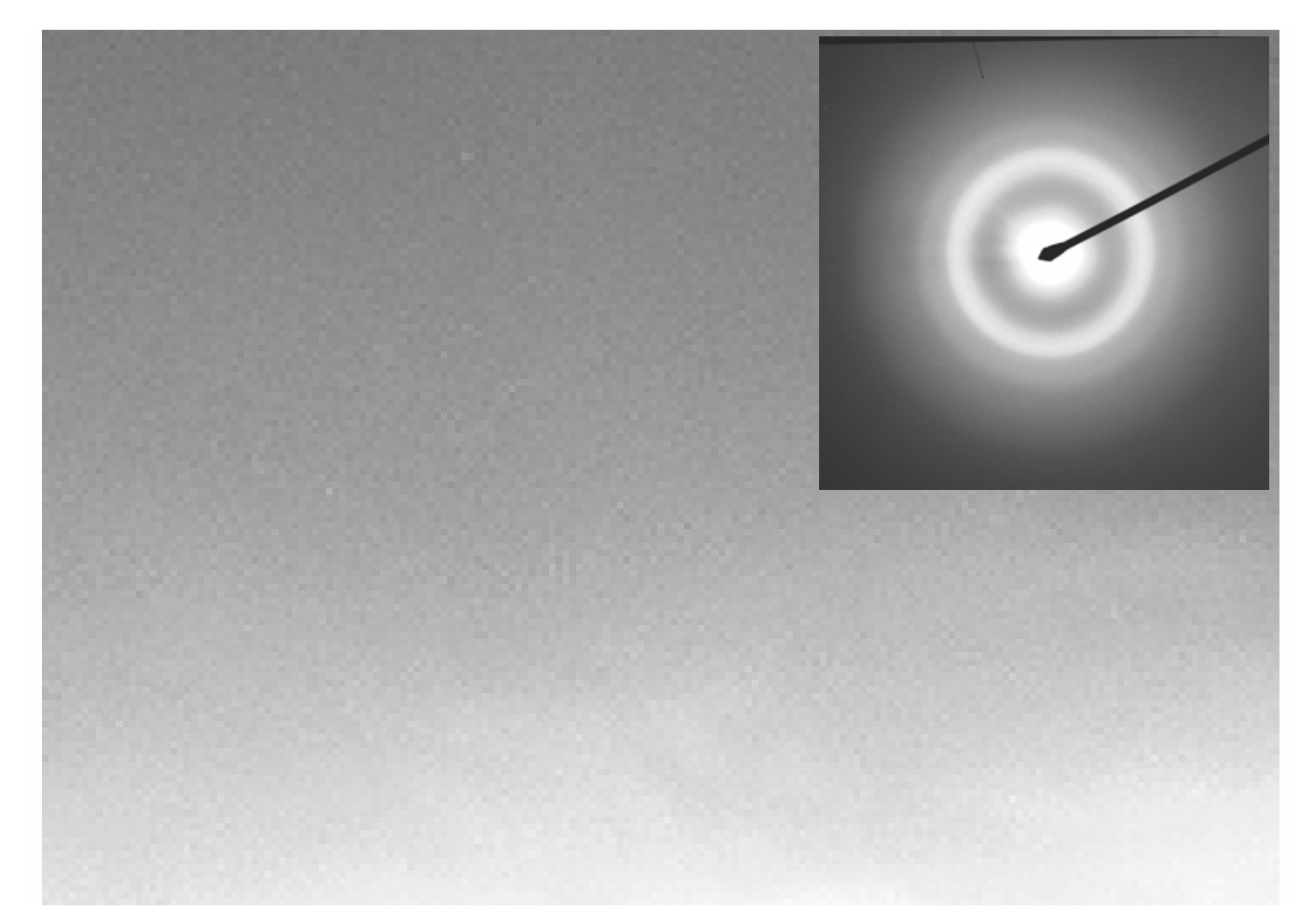

Figure 2.3 Representative bright field transmission electron microscopy (TEM) image and selected area electron diffraction (SAED) pattern of $\mathrm{Hf}_{52.5} \mathrm{Ti}_{5} \mathrm{Ni}_{14.6} \mathrm{Cu}_{17.9} \mathrm{Al}_{10} \mathrm{BMG}$

\subsection{Crystallization behavior}

Characteristic temperatures associated with the crystallization reaction of these ZrHf-based amorphous alloys, for example the glass transition temperature $\left(T_{g}\right)$, onset crystallization temperature $\left(T_{x 1}\right)$, melting temperature $\left(T_{m}\right)$ and liquidus temperature $\left(T_{l}\right)$, had been identified by DSC measurement (Netzsch DSC 404). In DSC curves, each of the exothermic or endothermic peaks or the endothermic peaks relates to certain transition or transformation temperatures. DSC measurements are implemented at a constant Ar flow of $50 \mathrm{ml} /$ minute. The procedure for DSC is specified as following: (1) pre-heating the specimen to $323 \mathrm{~K}$ at $10 \mathrm{~K} / \mathrm{min}$; (2) holding at $323 \mathrm{~K}$ for 5 minutes and then heating the specimen at a desired heating rate to above the liquidus temperature (first run) (3) cooling down at $40 \mathrm{~K} / \mathrm{min}$ to $323 \mathrm{~K}$; (3) 
repeating steps (2) and (3) to obtain the second run DSC curve as an in situ recording of the baseline. Subtraction of this baseline (second run) from the first run allows for a correction of the apparatus specific baseline shift and as a result, the measurement curve was obtained. DSC curves for Vitreloy 106, $\left(\mathrm{Zr}_{57} \mathrm{Nb}_{5} \mathrm{Ni}_{12.6} \mathrm{Cu}_{15.4} \mathrm{Al}_{10}\right)$ at heating rate of 5, 10, 20 and 40K/s are representatively shown in Figure 2.4. A broad endothermic plateau, before the first crystallization reaction (the first exothermic peak), corresponding to the glass transition and the following exothermic peaks corresponding to various crystallization and transformation reactions have been observed. The characteristic temperatures $\left(T_{g}, T_{x 1}, T_{m}\right.$ and $\left.T_{l}\right)$ relating to the corresponding reactions are also marked in the figure.

The characteristic temperatures $T_{g}, T_{x 1}, T_{m}$ and $T_{l}$ are observed to increase with an increasing Hf content as shown in Table 2.1 and Figure 2.5.

The reduced glass transition temperature $\left(T_{r g}=T_{g} / T_{m}\right.$ or $\left.T_{r g}=T_{g} / T_{l}\right)$ is often used to estimate the glass forming ability (GFA) for metallic glasses. Shown in Figure 2.6, a slight decrease of $T_{r g}$ with increasing $\mathrm{Hf}$ content has been observed, which may indicate the slight reduction of GFA.

The Kissinger method is commonly used to study the kinetics of various transitions or transformations [9], which is expressed as follows:

$\ln \left(\frac{B}{T^{2}}\right)=-\frac{\Delta E_{a}}{R \cdot T}+C$

where $B$ is the heating rate from the DSC analysis, $T$ the characteristic temperature for various transitions, $R$ the gas constant and $C$ is a constant. 


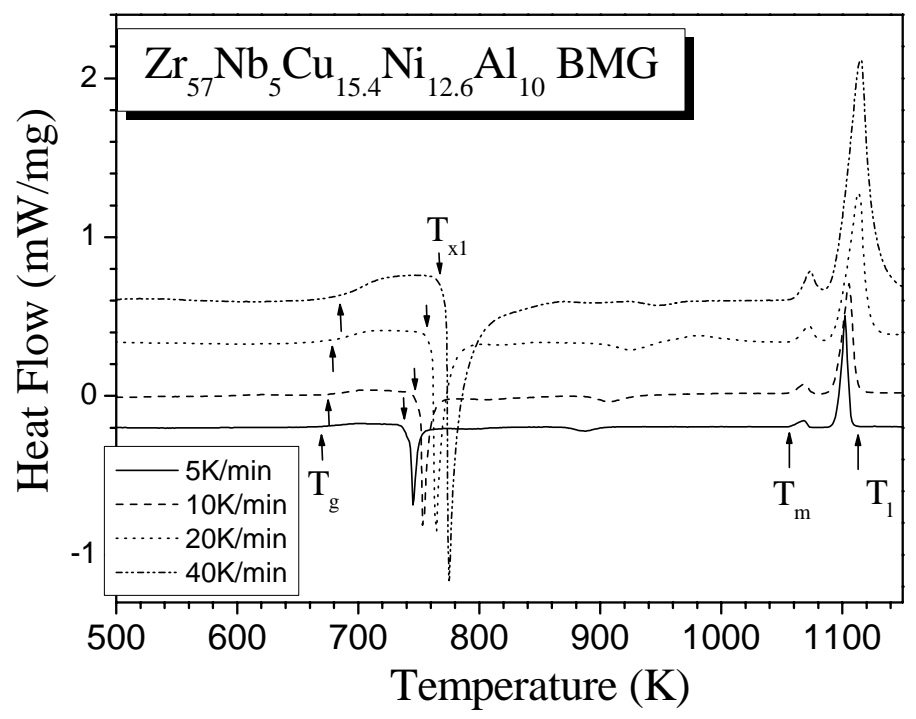

Figure 2.4 Typical differential scanning calorimetry curves of a BMG during heating revealing various transition temperatures: glass $\operatorname{transition} T_{g}$, onset of crystallization $T_{x 1}$, melting $T_{m}$ and liquidus $T_{l}$.

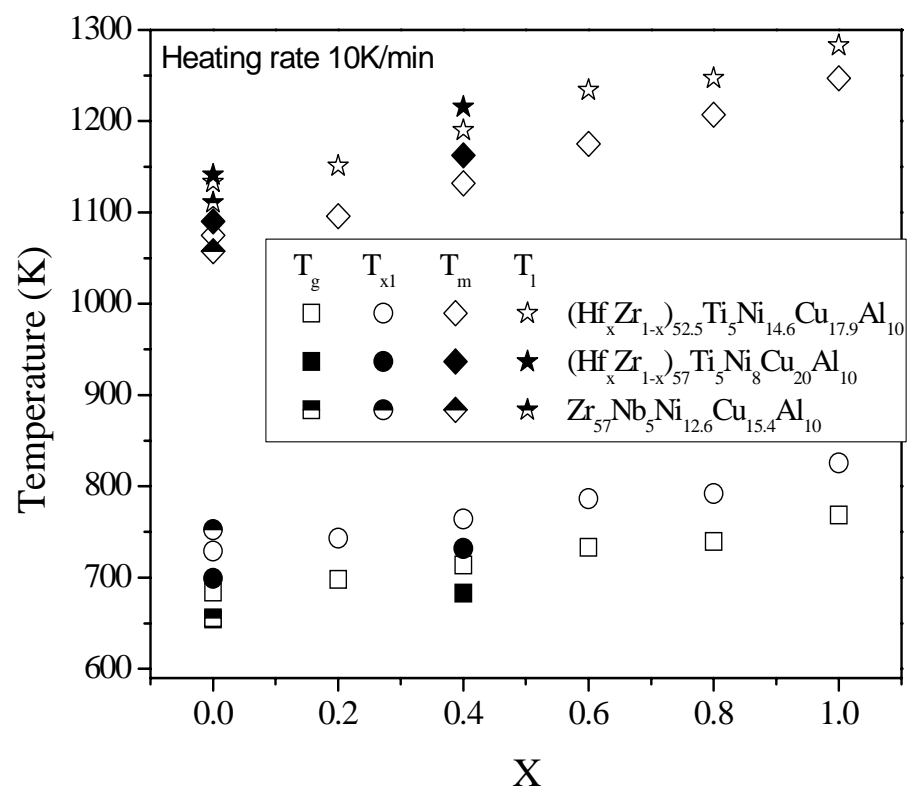

Figure 2.5. Relationship between Transition temperatures and Hf content for ZrHf-based BMGs 


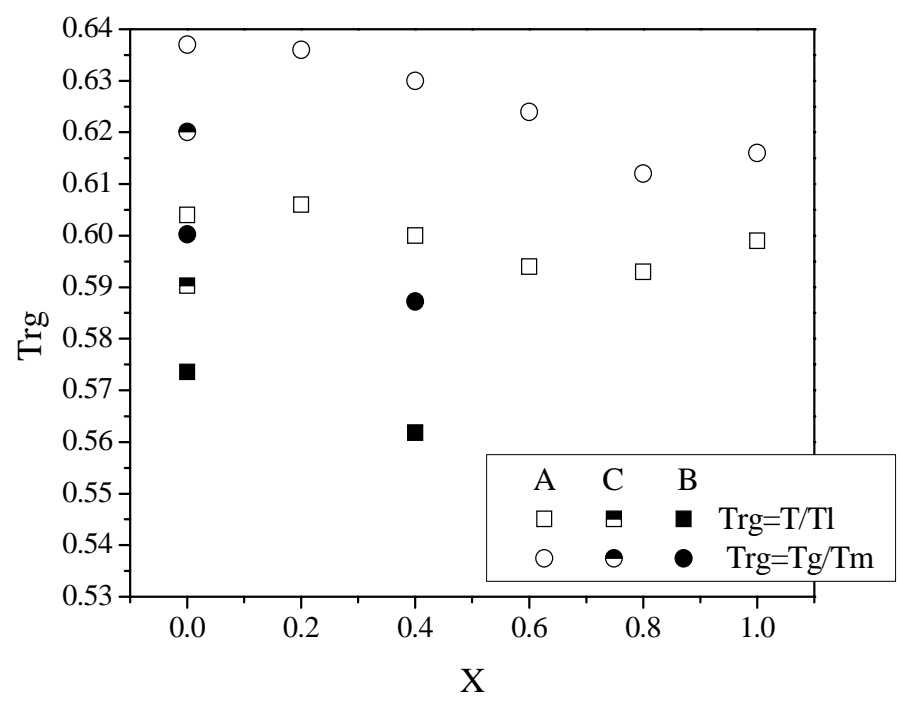

Figure 2.6 Reduced temperature indicating the glass forming ability (GFA) as a function of $\mathrm{Hf}$ content in $\mathrm{ZrHf}-\mathrm{based} \mathrm{BMGs}\left(\mathrm{A}:\left(\mathrm{Hf}_{\mathrm{x}} \mathrm{Zr}_{1-\mathrm{x}}\right)_{52.5} \mathrm{Ti}_{5} \mathbf{N i}_{14.6} \mathrm{Cu}_{17.9} \mathrm{Al}_{10}\right.$ $\left(x=0,0.2,0.4,0.6,0.8\right.$ and 1.0); $\mathrm{B}:\left(\mathrm{Hf}_{\mathrm{x}} \mathrm{Zr}_{1-\mathrm{x}}\right)_{57} \mathrm{Ti}_{5} \mathrm{Ni}_{8} \mathrm{Cu}_{20} \mathrm{Al}_{10}(\mathrm{x}=0,0.2,0.4) ; \mathrm{C}$ : $\left.\mathrm{Zr}_{57} \mathrm{Nb}_{5} \mathrm{Ni}_{12.6} \mathrm{Cu}_{15.4} \mathrm{Al}_{10}\right)$

By plotting $\ln \left(\frac{B}{T^{2}}\right)$ vs. $-\frac{1}{R \cdot T}$ (Eq. (2.1)), the activation energy $\Delta E_{a}$ for each transition is then obtained through a linear fitting slope. Figure 2.7 exhibits the relationship between $\ln \left(\frac{B}{T^{2}}\right)$ and $-\frac{1}{R \cdot T}$ in a $\mathrm{Zr}_{52.5} \mathrm{Ti}_{5} \mathrm{Ni}_{14.6} \mathrm{Cu}_{17.9} \mathrm{Al}_{10} \mathrm{BMG}$ and the activation energy for those reactions identified in the DSC curves are also obtained as indicated by the slope values. Figure 2.8 exhibits the dependence of the activation energy for the glass transition and the first crystallization reaction on $\mathrm{Hf}$ content. At high $\mathrm{Hf}$ contents in $\left(\mathrm{Hf}_{\mathrm{x}} \mathrm{Zr}_{1-\mathrm{x}}\right)_{52.5} \mathrm{Ti}_{5} \mathrm{Ni}_{14.6} \mathrm{Cu}_{17.9} \mathrm{Al}_{10}(\mathrm{x}=0.8$ and 1$)$, the activation energy of the glass transition increases while the activation energy of the first crystallization reaction does not show significant change. Note that $T_{l}$ and $T_{m}$ reflect the bonding force among the components and recall the increasing $T_{g}$ with increasing Hf content. Therefore, it may indicate that the higher kinetic stability of 
the glass transition with Hf content may mainly result from the higher bonding force or dense packed structure with Hf addition.

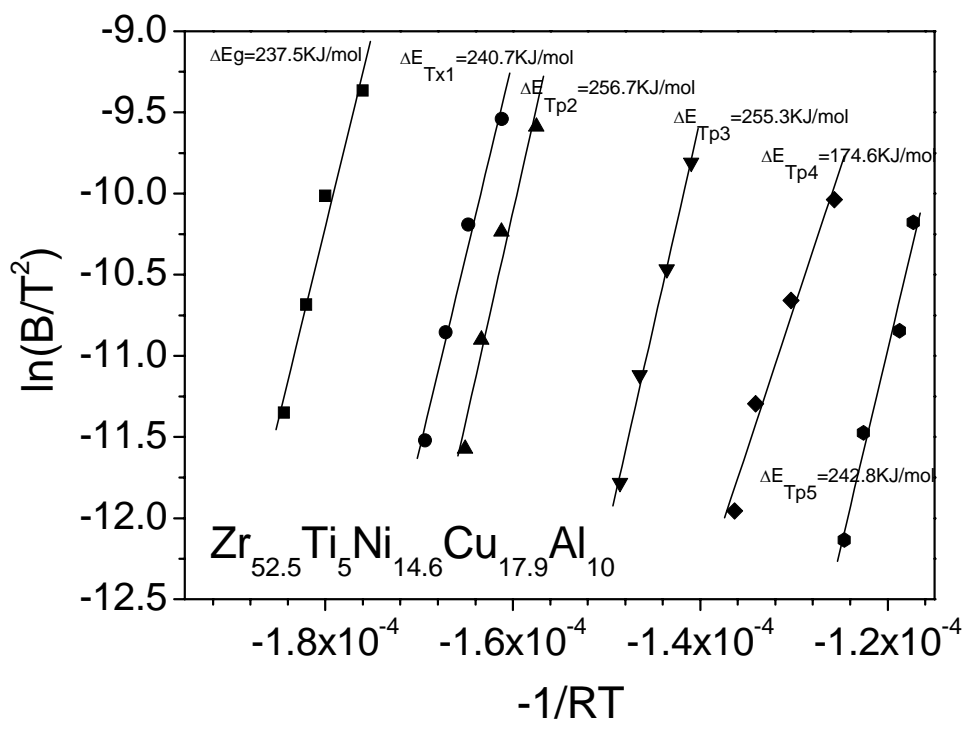

Figure 2.7 Activation energy of various transitions calculated from Kissinger analysis

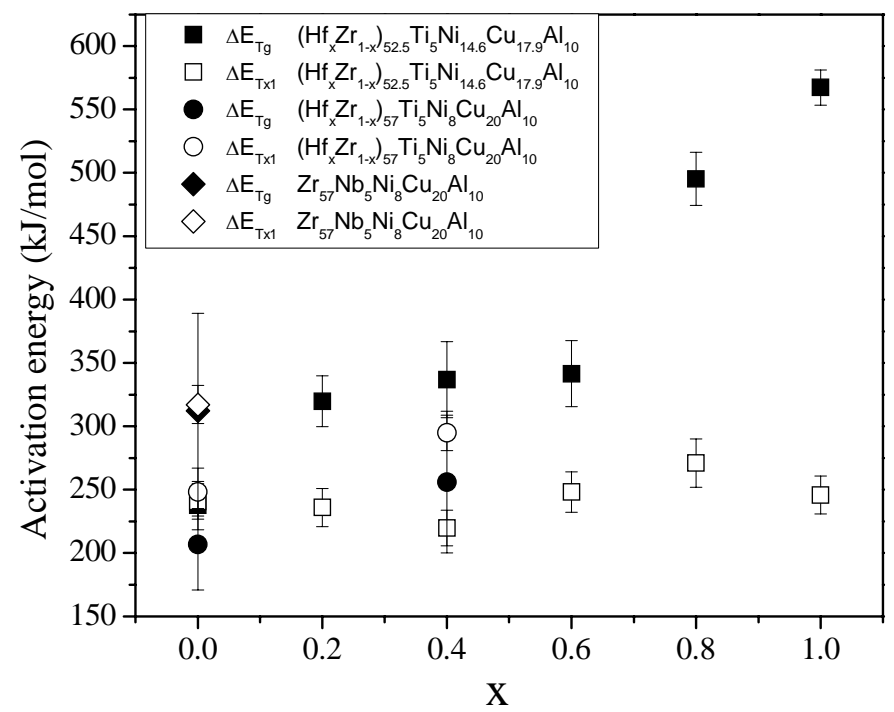

Figure 2.8 Dependence of activation energy of glass transition and crystallization on Hf content

In summary, with Hf addition, the glass transition temperature, the first crystallization 
temperature, the melting temperature and the liqudus temperature increase while the GFA indicated by the reduced glass transition temperature decreases slightly. The Hf addition also results in a higher kinetic stability for the glass transition characterized by an increasing activation energy of the glass transition with Hf content. However, the activation energy of the first crystallization reaction does not change with $\mathrm{Hf}$ content.

\subsection{Nano-indentation tests on BMGs}

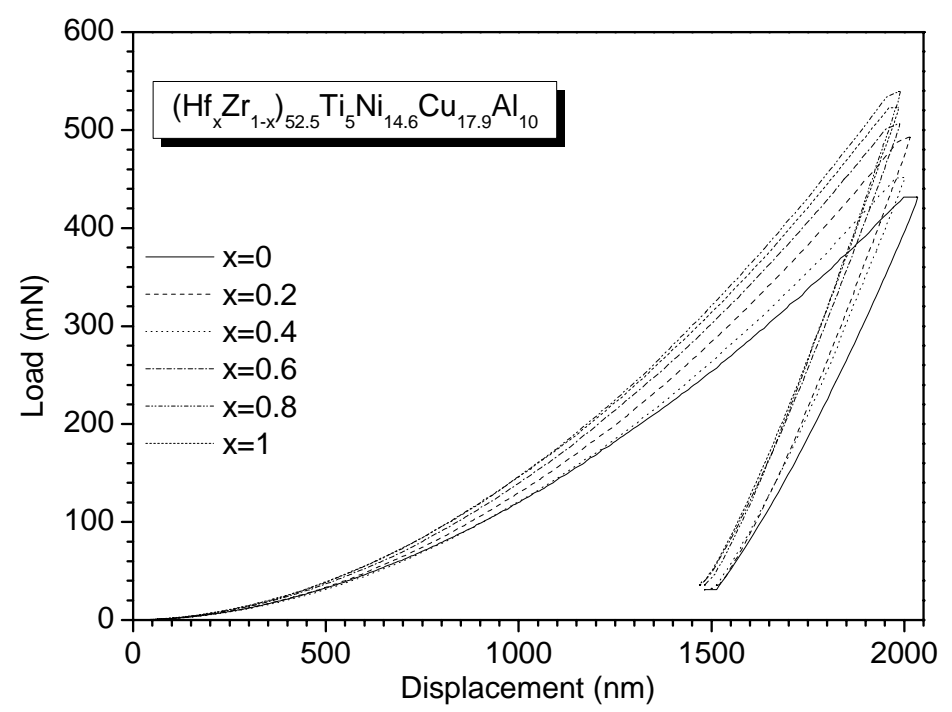

Figure 2.9 Typical load-displacement (p-h) curves of as-cast amorphous alloys measured during nano-indentation test.

The mechanical properties of these alloys (hardness and modulus) were measured by nano-indentation tests with a Berkovich indenter. Representative nano-indentation load-displacement (p-h) curves for $\left(\mathrm{Hf}_{\mathrm{x}} \mathrm{Zr}_{1-\mathrm{x}}\right)_{52.5} \mathrm{Ti}_{5} \mathrm{Ni}_{8} \mathrm{Cu}_{20} \mathrm{Al}_{10}$ BMGs are presented in Figure 2.9. The compositional dependence of the load-displacement curves is clearly seen in this figure. With increasing Hf content, the maximum load for an indentation 
depth of $2000 \mathrm{~nm}$ tend to increase from 451 to $540 \mathrm{mN}$, as summarized in Table 2. A slight decrease of maximum load for $\mathrm{Hf}_{52.5} \mathrm{Ti}_{5} \mathrm{Ni}_{14.6} \mathrm{Cu}_{17.9} \mathrm{Al}_{10}$ compared with $\left(\mathrm{Hf}_{0.8} \mathrm{Zr}_{0.2}\right)_{52.5} \mathrm{Ti}_{5} \mathrm{Ni}_{14.6} \mathrm{Cu}_{17.9} \mathrm{Al}_{10}$, as well as $\left(\mathrm{Hf}_{0.4} \mathrm{Zr}_{0.6}\right)_{57} \mathrm{Ti}_{5} \mathrm{Ni}_{8} \mathrm{Cu}_{20} \mathrm{Al}_{10}$ compared with $\mathrm{Zr}_{57} \mathrm{Ti}_{5} \mathrm{Ni}_{8} \mathrm{Cu}_{20} \mathrm{Al}_{10}$ and $\left(\mathrm{Hf}_{0.2} \mathrm{Zr}_{0.8}\right)_{57} \mathrm{Ti}_{5} \mathrm{Ni}_{8} \mathrm{Cu}_{20} \mathrm{Al}_{10}$ is probably due to a small variation in alloy composition at the region of the nano-indentation. The increasing indentation load with an increase in Hf content indicates that the material tends to be harder and stiffer with the substitution of Hf for Zr. Moreover, about 70\% of the displacement (indentation depth) remained after unloading and is accommodated plastically in all these alloys. This indicates that severe plastic deformation can be achieved under indentation tests compared to the conventional tensile or compressive tests that fail to accommodate such large inelastic strains. Also note that the p-h curves are relatively smooth and do not explicitly reveal the serrated flow that is typically associated with the initiation of an isolated shear band [10, 11]. This might be either caused by the high strain rates imposed on the sample or due to a lack of adequate instrument resolution to capture the load-drops at the onset of shear band initiation.

Table 2.2 Mechanical properties of ZrHf-based amorphous alloys

\begin{tabular}{cccccc}
\hline Composition & $\begin{array}{c}\mathrm{E} \\
(\mathrm{GPa})\end{array}$ & $\begin{array}{c}\text { Hardness } \\
(\mathrm{GPa})\end{array}$ & $\begin{array}{c}\text { Max Load } \\
(\mathrm{mN})\end{array}$ & $\begin{array}{c}\mathrm{Hv} \\
(\mathrm{GPa})\end{array}$ & $\begin{array}{c}\sigma_{\mathrm{y}} \\
(\mathrm{MPa})\end{array}$ \\
\hline $\mathrm{Zr}_{57} \mathrm{Ti}_{5} \mathrm{Ni}_{8} \mathrm{Cu}_{20} \mathrm{Al}_{10}$ & $85 \pm 1$ & $5.7 \pm 0.1$ & $467 \pm 3$ & $5.1 \pm 0.1$ & $1644 \pm 22$ \\
$\left(\mathrm{Hf}_{0.2} \mathrm{Zr}_{0.8}\right)_{57} \mathrm{Ti}_{5} \mathrm{Ni}_{8} \mathrm{Cu}_{20} \mathrm{Al}_{10}$ & $87 \pm 1$ & $5.5 \pm 0.2$ & $483 \pm 5$ & $4.7 \pm 0.1$ & $1781 \pm 13$ \\
$\left(\mathrm{Hf}_{0.4} \mathrm{Zr}_{0.6}\right)_{57} \mathrm{Ti}_{5} \mathrm{Ni}_{8} \mathrm{Cu}_{20} \mathrm{Al}_{10}$ & $94 \pm 1$ & $6.0 \pm 0.1$ & $414 \pm 8$ & $5.2 \pm 0.1$ & $1799 \pm 101$ \\
$\mathrm{Zr}_{52.5} \mathrm{Ti}_{5} \mathrm{Ni}_{14.6} \mathrm{Cu}_{17.9} \mathrm{Al}_{10}$ & $93 \pm 2$ & $6.2 \pm 0.2$ & $433 \pm 4$ & $5.0 \pm 0.2$ & $1743 \pm 32$ \\
$\left(\mathrm{Hf}_{0.2} \mathrm{Zr}_{0.8}\right)_{52.5} \mathrm{Ti}_{5} \mathrm{Ni}_{14.6} \mathrm{Cu}_{17.9} \mathrm{Al}_{10}$ & $108 \pm 3$ & $7.1 \pm 0.3$ & $486 \pm 7$ & $5.3 \pm 0.1$ & $1935 \pm 20$ \\
$\left(\mathrm{Hf}_{0.4} \mathrm{Zr}_{0.6}\right)_{52.5} \mathrm{Ti}_{5} \mathrm{Ni}_{14.6} \mathrm{Cu}_{17.9} \mathrm{Al}_{10}$ & $113 \pm 2$ & $7.2 \pm 0.2$ & $474 \pm 2$ & $5.5 \pm 0.1$ & $1845 \pm 23$ \\
$\left(\mathrm{Hf}_{0.6} \mathrm{Zr}_{0.4}\right)_{52.5} \mathrm{Ti}_{5} \mathrm{Ni}_{14.6} \mathrm{Cu}_{17.9} \mathrm{Al}_{10}$ & $110 \pm 3$ & $7.5 \pm 0.3$ & $507 \pm 5$ & $5.8 \pm 0.2$ & $2028 \pm 25$ \\
$\left(\mathrm{Hf}_{0.8} \mathrm{Zr}_{0.2}\right)_{52.5} \mathrm{Ti}_{5} \mathrm{Ni}_{14.6} \mathrm{Cu}_{17.9} \mathrm{Al}_{10}$ & $124 \pm 2$ & $8.0 \pm 0.3$ & $536 \pm 4$ & $6.0 \pm 0.2$ & $2042 \pm 39$ \\
$\mathrm{Hf}_{52.5} \mathrm{Ti}_{5} \mathrm{Ni}_{14.6} \mathrm{Cu}_{17.9} \mathrm{Al}_{10}$ & $128 \pm 4$ & $7.8 \pm 0.3$ & $525 \pm 4$ & $6.1 \pm 0.2$ & $2086 \pm 23$ \\
$\mathrm{Zr}_{57} \mathrm{Nb}_{5} \mathrm{Ni}_{12.6} \mathrm{Cu}_{15.4} \mathrm{Al}_{10}$ & $89 \pm 1$ & $5.7 \pm 0.1$ & $451 \pm 6$ & $4.9 \pm 0.1$ & $1740 \pm 40$ \\
\hline
\end{tabular}




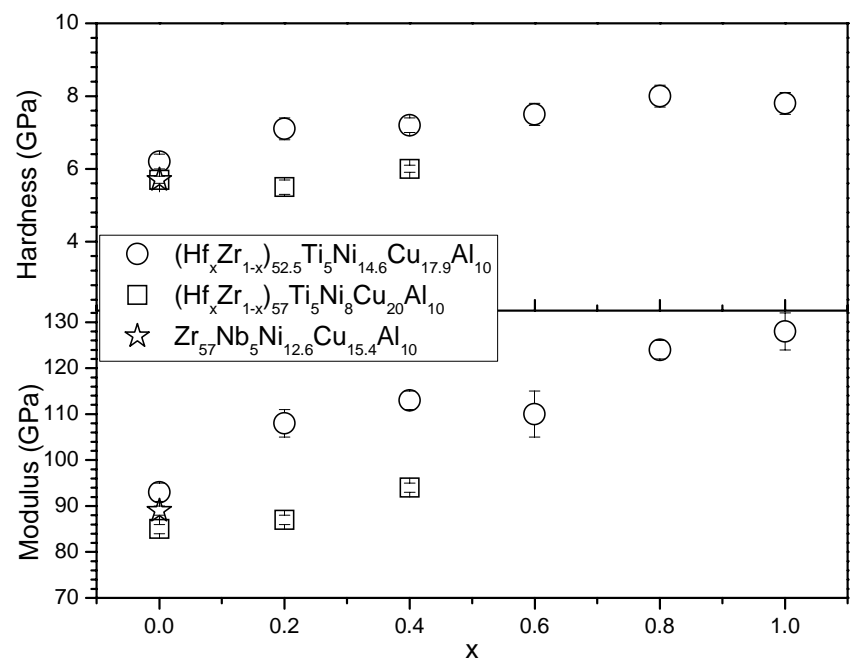

Figure 2.10 Dependence of hardness and modulus on Hf content

Figure 2.10 displays plots of hardness and modulus as a function of Hf composition for all the HfZr-based BMGs. Generally, both the hardness and the modulus increase with increasing Hf content (see Table 2.2). The minor fluctuation observed in the data may be attributed to the following reasons. First, although the XRD shows the amorphous state of the alloys, in practice it is difficult to achieve a completely homogeneous glassy state. Some compositional variation is unavoidable in the amorphous matrix due to the cooling rate change along the cross section. Second, in the nano-indentation measurements, the indenter is impressed into a micron-sized area and is sensitive to such minor compositional disturbances. Hence fluctuation of the data reflected in the nano-indentation results is reasonable. 

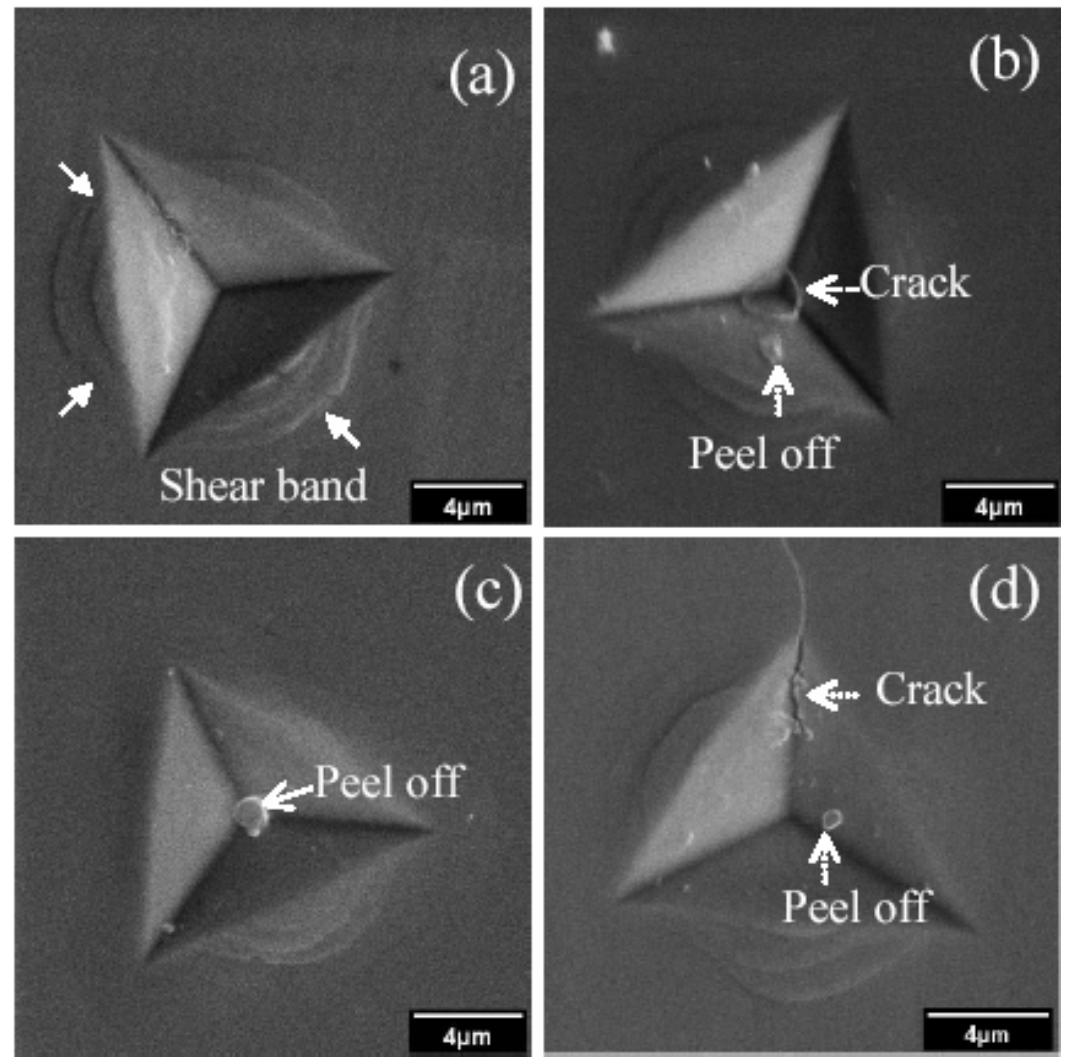

Figure 2.11 SEM images of evolved deformation features after nano-indentation at $2000 \mathrm{~nm}$ depth

A typical SEM image in Figure 2.11(a) shows an indent from a $2000 \mathrm{~nm}$ deep nano-indentation. The characteristic annular patterns of shear bands around the indent, as marked by the arrows, indicate severely localized plastic deformation was achieved by the formation of shear bands. As the indentation depth increased, isolated shear bands initiate from sharp edges or corners to relax the stress concentration and then continue to grow into annular bands to accommodate the plastic deformation. The asymmetric nature of the shear bands along each side of the indent might be caused either by the inhomogeneous compositional distribution around the indent area or the non-uniform stress distribution (e.g., due to a slight inclination of the loading surface). Although the annular shear bands inside the indents are not clearly discerned from the 
Figure 2.11, Vaidyanathan et al [12] were able to observe such shear bands in some magnified images in similar structures. Meanwhile, annular cracks at the center of some indents were found as shown in Figure 2.11(b). Such cracks were possibly formed by the development of the shear bands initiated at an early stage of indentation under increasing loading. Upon continued loading, these shear bands or cracks can further spread into the amorphous matrix and may intercept with each other underneath the indenter causing a 'peel-off' of the material. Figure 2.11(c) indeed displays such a circular peel-off in the center of an indent. More peel-offs were also seen with in the indented area that may have been induced by the development of shear bands. In only one indent, a crack along the edge has been observed as shown in Figure 2.11(d), where the crack extends along the edge to the amorphous matrix. Although the reasons for this crack initiation are not fully understood at this time, it is perceived that microstructural flaws such as crystallites or voids etc. may be responsible for its formation.

As mentioned earlier, the mechanical properties as measured by nano-indentation improve considerably with increasing Hf content. Insight into a compositional hardening mechanism may assist in the design of high strength amorphous alloys such as the ones produced here. In the present work, the bonding forces among constitutive elements may mainly account for the hardening effect. Recall that with rising Hf content $T_{g}$ and $T_{1}$ increase. Considering that $T_{g}$ and $T_{1}$ of glassy alloys reflect the bonding force among the constituent elements [13], a stronger bonding nature between Hf and other constituent elements would reasonably be assumed. It is well 
known that the bonding force among the constitutive elements in materials can be represented by their modulus. Here the modulus increase in nano-indentation test, shown in Figure 2.12 as a function of temperature, does reflect the stronger bonding force among the constitutive elements with Hf substitution for Zr. Moreover, the crystalline phases formed upon heating to the first crystallization peak temperature, are $\mathrm{Cu}_{2} \mathrm{Zr}$ and $\mathrm{Zr}_{2} \mathrm{Ni}$ for $\mathrm{Zr}_{52.5} \mathrm{Ti}_{5} \mathrm{Ni}_{14.6} \mathrm{Cu}_{17.9} \mathrm{Al}_{10}$ versus $\mathrm{Al}_{16} \mathrm{Hf}_{6} \mathrm{Ni}_{7}$ and $\mathrm{Cu}_{2} \mathrm{Hf}$ for $\mathrm{Hf}_{52.5} \mathrm{Ti}_{5} \mathrm{Ni}_{14.6} \mathrm{Cu}_{17.9} \mathrm{Al}_{10}$ [8], indicative of a structural transformation due to stronger bonding of Hf with other elements. Therefore, it is concluded that the better mechanical properties originate from the strong bonding nature among constituent elements with the replacement of Zr by Hf.

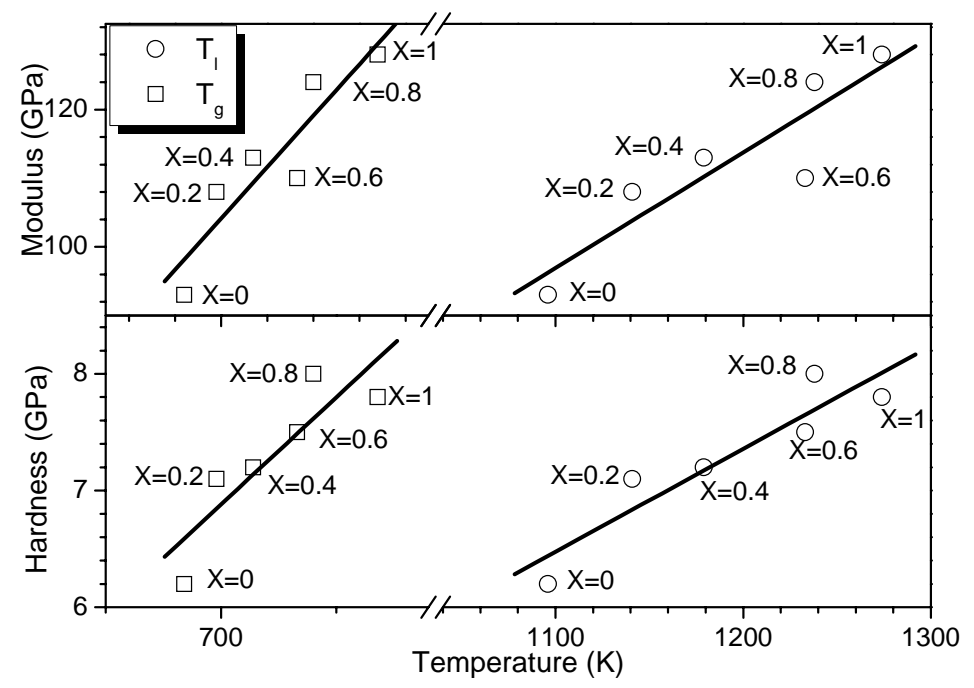

Figure 2.12 Relationship between modulus, hardness and glass transition temperature $\left(T_{g}\right)$ as well as liquidus temperature $\left(T_{1}\right)$ of $\left(\mathrm{Hf}_{\mathrm{X}} \mathrm{Zr}_{1-\mathrm{x}}\right)_{52.5} \mathrm{Ti}_{5} \mathrm{Ni}_{14.9} \mathrm{Cu}_{17.9} \mathrm{Al}_{10}$ based BMGs. 


\subsection{Conclusions}

The crystallization behavior and mechanical properties of bulk $(\mathrm{HfxZr1-x})_{52.5} \mathrm{Ti}_{5} \mathrm{Ni}_{14.6} \mathrm{Cu}_{17.9} \mathrm{Al}_{10}(\mathrm{x}=0,0.2,0.4,0.6,0.8,1), \mathrm{Zr}_{57} \mathrm{Nb}_{5} \mathrm{Ni}_{12.6} \mathrm{Cu}_{15.4} \mathrm{Al}_{10}$ and $\left(\mathrm{Hf}_{\mathrm{x}} \mathrm{Zr}_{1-\mathrm{x}}\right)_{57} \mathrm{Ti}_{5} \mathrm{Ni}_{8} \mathrm{Cu}_{20} \mathrm{Al}_{10}(\mathrm{x}=0,0.2,0.4)$ amorphous alloys were studied by thermal analysis and nano-indentation tests. Thermal analysis showed that glass transition temperature $T_{g}$, onset temperature of first crystallization $T_{x 1}$, and the supercooled liquid region $\Delta T_{x}$ increase with increasing $\mathrm{Hf}$ content while the reduced glass transition temperature $T_{\mathrm{rg}}$ decreases. Hardness and modulus were found to be enhanced with Hf substitution for Zr. SEM observation revealed that the plastic deformation was achieved by intense shear banding. The increasing mechanical strength with Hf content is attributed to a local change of the amorphous structure with a change in the composition.

\section{Reference}

1. Peker A, Johnson WL, Appl. Phys. Lett., 1993; 63:2342.

2. Zhang T, Inoue A, Masumoto T, Mater. Trans. JIM, 1991; 32:1005.

3. Lin XH, Johnson WL, Rhim WK, Mater. Trans. JIM, 1997; 38:473.

4. Xing LQ, Ochin P, Harmelin M, Faudot F, Bigot J, Chevalier JP, Mater. Sci \& Eng 1996; A220:155.

5. Xing LQ, Ochin P, Harmelin M, Faudot F, Bigot J, J Non-Cryst. Solids, 1996; 205-207:597.

6. Gu X, Xing LQ, Hufnagel TC. J Non-cryst. Solids, 2002; 311:77.

7. Gu X, Jiao T, Kecskes J, Woodman RH, Fan C, Ramesh KT, Hufnagel TC, J Non-cryst. Solids, 2003; 317:112.

8. Gu X, PhD Thesis, Johns Hopkins University, Baltimore, Maryland, 2003.

9. Kissinger HE, Analytical Chemistry, 1957; 29:1703.

10. Schuh CA, Nieh TG. Acta Mater, 2003; 51:87

11. Golovin YI, Ivolgin VI, Khonik VA, Kitagawa K, Tyurin AI, Scripta Mater, 2001; 
$45: 947$

12. Vaidyanathan R, Dao M, Ravichandran G, Suresh S. Acta Mater, 2001; 49:3781

13. Chen HS, Rep. Prog Phys, 1980; 43:353 


\section{Chapter 3. Investigation of Shear Band Evolution in BMGs Beneath Quasistatic Vickers Indentations}

\subsection{Introduction}

Experimental evidence has shown that plastic deformation in amorphous alloys at room temperature is accommodated through the development of multiple shear bands [1-3]. The indentation test is still an attractive technique to study the deformation behavior of amorphous alloys for the following reasons. First, indentation tests, being not particular about sample size, are easy to perform. Second, the plastic deformation in the indented material is constrained locally around the indent, which facilitates the study of plastic flow of the amorphous alloys surrounding and underneath the indentation. In addition, the direct comparison of instrumented indentation results with tensile and compressive responses has [4-6] further validated the indentation technique as an effective probe for understanding the physics of plastic deformation in amorphous alloys.

The popular instrumented nano-indentation technique has played a major role in elucidating the mechanisms of plastic flow in amorphous alloys, which include the relationship between hardness and yield strength, discrete plasticity and microstructural changes under indentation [7-10]. One of the interesting results is the discrete plasticity, which was identified as discrete pop-ins or flow serrations in the load-displacement curves. Wright et al. [6] speculated that the 'pop-ins' are the result of rapid strain accommodation by individual shear bands emitted discretely in sequence. Some researchers have noted the correlation between the number of shear bands and the 'pop-ins' in load-displacement curves [4]. In reality, these so-called shear bands are the slip-steps left by the propagation of shear bands on the observed 
surface. In the present chapter, the 'slip-steps' of the shear bands are loosely referred to as shear bands. However, detailed quantitative investigations of this correlation between the slip-steps and the pop-ins remain to be seen. Moreover, the number of circle-like slip-steps, surrounding either the Berkovich or Vickers indents on a top surface of the specimen [1,11], is far less than the number of serration flows (if each 'pop-in' corresponds to an individual shear band initiation [4,12]). These results may indicate that (1) most of the plastic deformation is accommodated by shear bands formed underneath the indents and only a few of these shear bands extend onto the indentation surface, (2) most of the shear bands locate inside these sharp indents and their slip-steps are later smoothened by the indenter surfaces during the loading process, and (3) these slip-steps are too small to be easily identified by the methods employed in these studies.

So far, only a small number of papers have reported the shear bands formation underneath indents $[13,14]$. Donovan [13] observed that the plastic zone beneath the indentation in $\mathrm{Pd}_{40} \mathrm{Ni}_{40} \mathrm{P}_{20}$ metallic glass was mainly characterized by the radial incipient cracks and the curving Hartmann lines. In Jana et al. [14], several sets of slip-steps from shear bands were noticed by using a sharp indent under a load of 5Kg. The patterns close to the indenter are akin to the slip-line field patterns in plasticity theory. However, the large semicircular slip-steps observed in experiments are beyond the predictive capability of the slip-line theory. This limitation may be due to the complex stress state beneath the indenter as opposed to the plane-strain condition presumed in the slip-line theory and the effects from the existence of a free surface.

For these reasons, the current study is devoted to a systematic investigation of microstructural changes of the amorphous alloy beneath a Vickers indentation 
subjected to a range of loads with varying durations. To explore the possible factors that affect shear band formation, the following considerations are incorporated into the experimental design and sample selection. First, to eliminate the effects of pre-existing nano-crystals (mainly precipitated during BMG preparation) on shear band formation, $\mathrm{Zr}_{57} \mathrm{Nb}_{5} \mathrm{Ni}_{12.6} \mathrm{Cu}_{15.4} \mathrm{Al}_{10}$ bulk amorphous alloy (Vit106), whose reduced glass transition temperature $T_{\mathrm{rg}}$ is 0.62 , is utilized in the current investigation [11,15]. Second, to elucidate the shear bands (slip-steps) pattern beneath the indentation, Vickers indentations are performed along the bonded interface of a cylindrical specimen. The specimen is then split apart for observation of the shear bands beneath the indentations. Third, to clarify the slip-step pattern evolution beneath the indenter, indentations are performed under gradually increasing loads and the orientation of the indenter is varied with respect to the interface.

\subsection{Experiments}

The bonded interface approach for observation of deformation patterns underneath indentation are employed as follows. A cylindrical sample is cut into two halves and the cut surfaces is polished to mirror finish. They are then bonded together with rapid glue and clamped together tightly with specially designed clamp. The bonded specimen is then mounted into a mixture of epoxide resin and epoxide hardener. After curing, the top surface of the sample is polished to mirror finish for indentation tests.

A Leco Vicker's hardness tester is employed for quasi-static indentation tests. To monitor the load-time relationship during the indentation, a high frequency ( 200kHz) Kistler load cell with a load resolution of $0.1 \mathrm{~N}$ is placed under the sample. The total indentation cycle duration (consisting of loading, holding and unloading) is varied from 5 s to 30s. Normally, the maximum load is reached in much less than 1 second 
even for the $1000 \mathrm{~g}$ loading. Typical loading rates range from $10.7 \mathrm{~N} / \mathrm{s}$ to $26.9 \mathrm{~N} / \mathrm{s}$ for the selected loads. The load is then held constant for certain amount of time and then the sample is unloaded. Indentations are also performed along the interface with the diagonal of the indenter oriented either parallel to the interface or at $45^{\circ}$ to the interface, as shown in Figure 3.1.

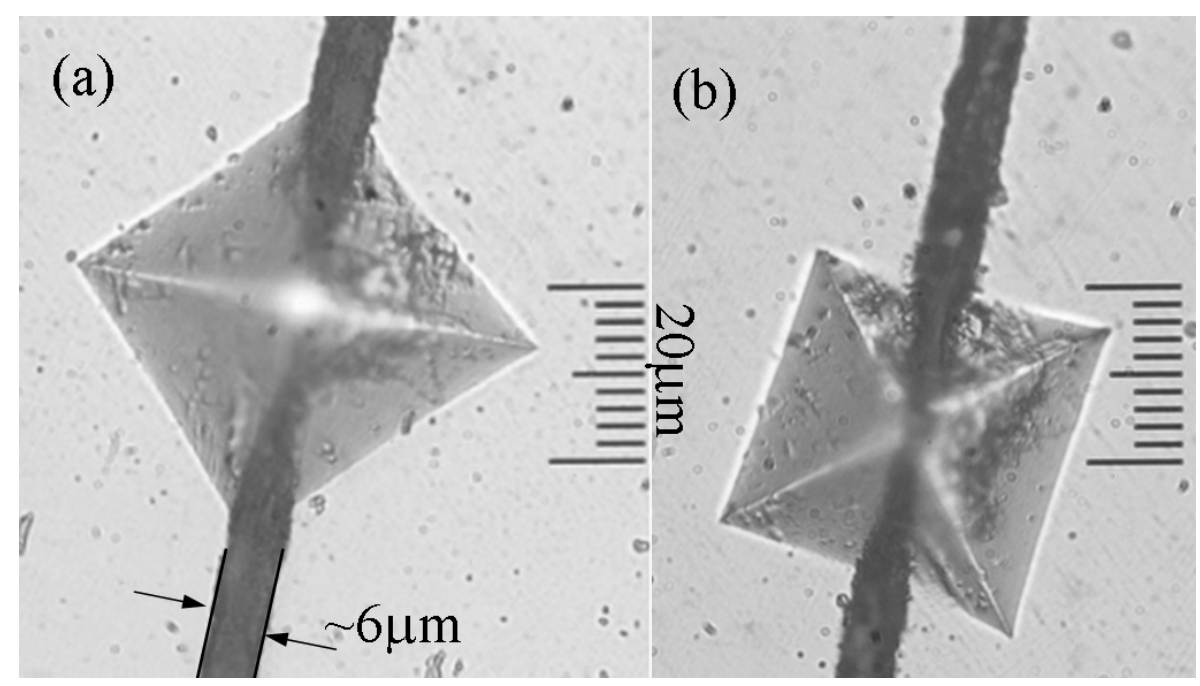

Figure 3.1. Vickers indentation along the interface at different orientations: (a) interface parallel to the indenter diagonal and (b) interface at $45^{\circ}$ to the indenter diagonal.

To illustrate the effects of magnitude and duration of the indentation load on the hardness, indentations are also performed on the top surface away from the interface. At each selected load and time duration, at lease five indentations are carried out to determine the average hardness. After the indentation tests, the samples are placed in an acetone bath for 24 hours to remove the surrounding epoxide resin and the rapid glue along the interface. An optical microscope and a scanning electron microscope (SEM) are used to observe the shear bands patterns surrounding and beneath the indentation. 


\section{3. $\quad$ Results}

\subsubsection{Indentation on flat surface}

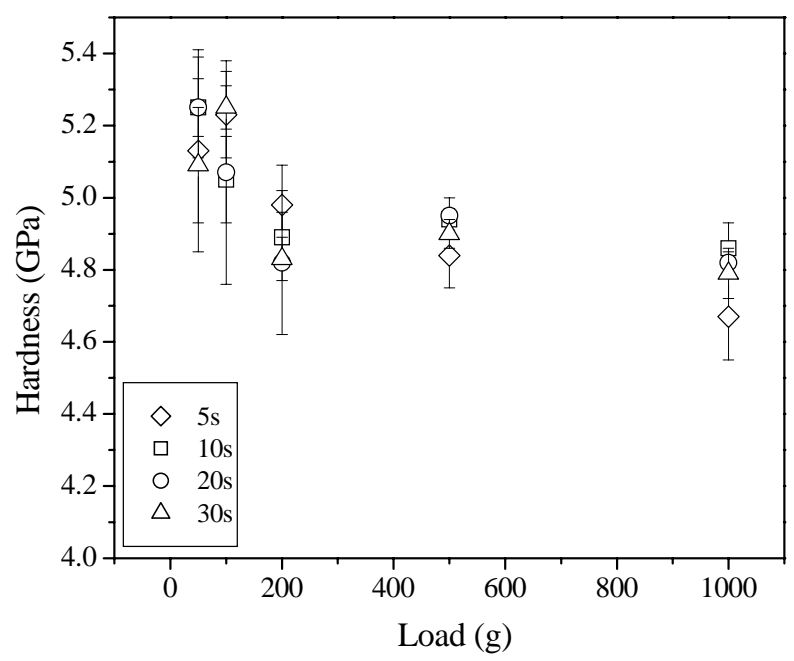

Figure 3.2. Variation of Vickers hardness with load and loading time duration.

The hardness measured on the top surface away from the interface at selected loads and time durations is shown in Figure 3.2. A slight decrease in hardness with increasing load is observed. However, at a given load, no evidence of variation in hardness value with increasing indentation duration was detected, which indicates that the plastic deformation under indentation was accomplished well within the time duration of less than 5 seconds (the smallest duration employed in the test). Typical indentation images on the top surface away from the interface are shown in Figure 3.3. At a small load of $10 \mathrm{~g}$, slip-steps of shear bands partially surrounding some edges of the indentation are clearly observed on the top surface in Figure 3.3(a). Some partially-developed slip-steps are also observed initiating from some corners of the indent and disappearing into the amorphous matrix. At a larger load of 500g, curved slip-steps are occasionally observed only around one of the indent edges. In many cases, slip-steps cannot be detected outside the indent. Note that in Figure 3.3(b), some slip-steps seem to intersect with others. As will be explained later, these 
slip-steps may be associated with secondary or tertiary shear bands induced at large loads.

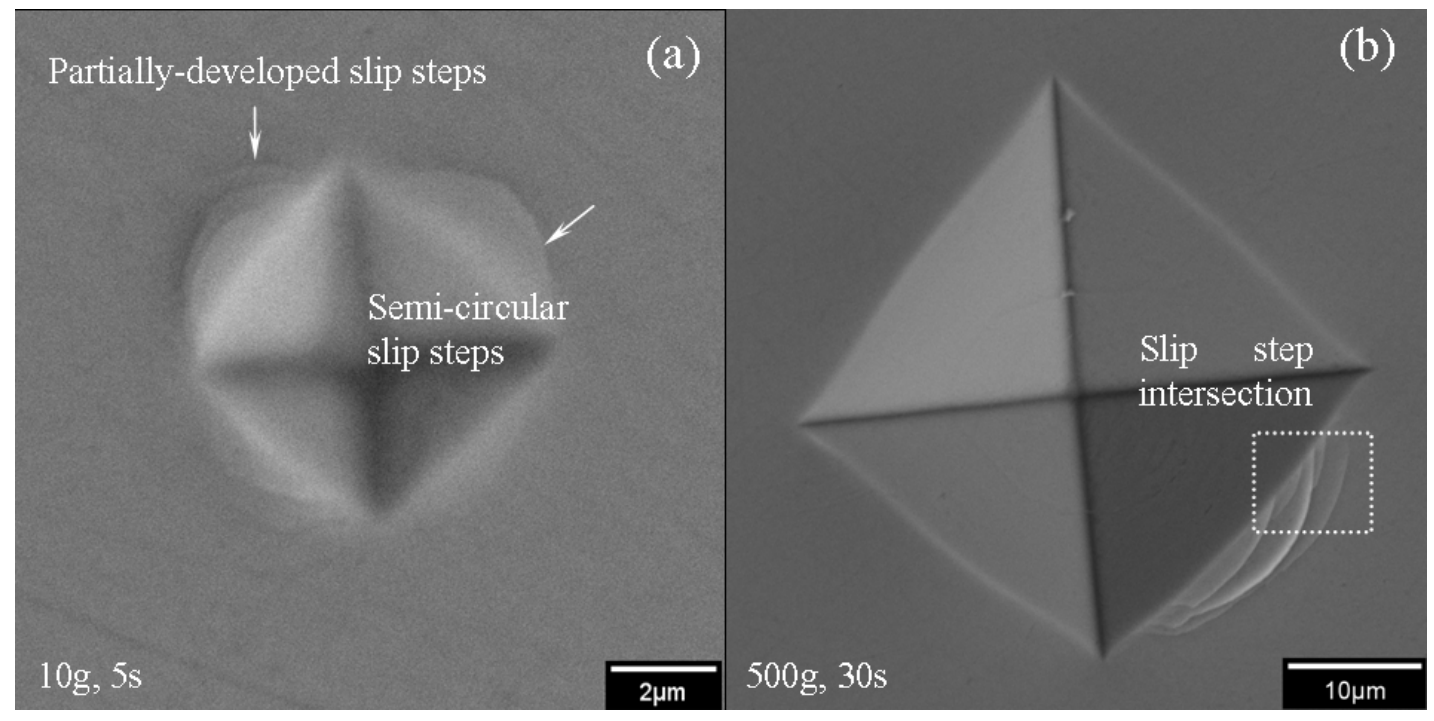

Figure 3.3. Slip-step patterns resulting from shear bands propagation surrounding the Vickers indentation.

\subsubsection{Indentation along the interface}

Figure 3.1 indicates a typical indentation on a specimen along the interface. It is seen that a fairly close bond is formed between the two halves where the width of the interface is measured to be around $6 \mu \mathrm{m}$ and the size of the indentations (under a load of $200 \mathrm{~g}$ for the left image and $100 \mathrm{~g}$ for the right image) is observed to be significantly larger than the width of the interface. The confinement provided by the epoxide resin matrix surrounding the bonded sample holds the two halves together and does not allow separation even under an indentation load of 1000g. Figure 3.4 reveals the half indent at a load of $200 \mathrm{~g}$ and duration of $5 \mathrm{~s}$ on the top surface of one of the half samples after debonding, where the indenter diagonal is oriented parallel to the interface. A slightly out of plane protrusion $(\sim 3 \mu \mathrm{m})$ at the center of the indent is observed, which implies a plastic flow normal to the bonded interface under the indentation. Recall that the width of interface is $\sim 6 \mu \mathrm{m}$ (Figure 3.2) and, hence, the 
$3 \mu \mathrm{m}$ protrusion indicates that (1) the soft adhesive material in the interface does not provide rigid boundary condition but allows a plastic displacement of the material flow normal to the plane of the interface and (2) the constraint from the other half of the bonded specimen can only be effective when the displacement reaches half of the width of the interface.

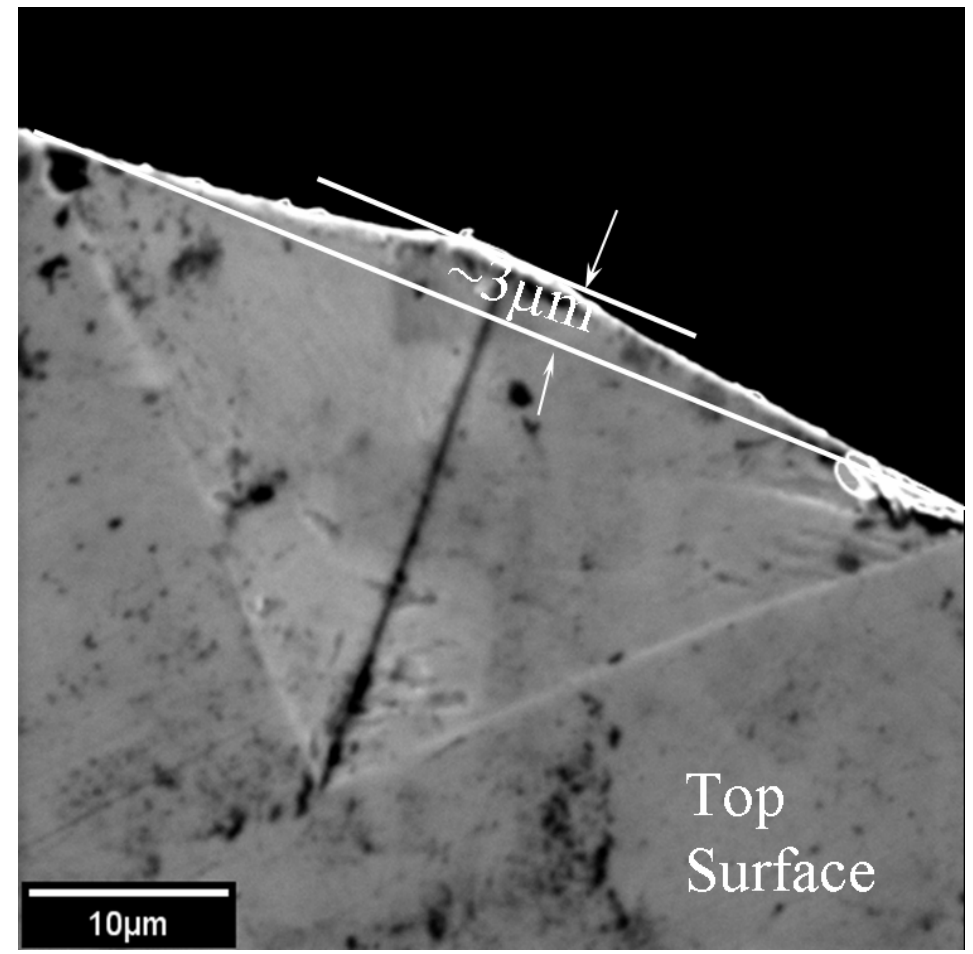

Figure 3.4. Half indent revealing materials flow normal to the plane of interface.

Figure 3.5 illustrates the evolution of deformation pattern on the vertical surfaces of the bonded sample indented at increasing loads and with the indenter diagonal oriented along the interface. In all the figures, a layered bulge at the tip of the indent is observed, which corresponds to the protrusion observed from the top surface in Figures 3.1 and 3.4. As mentioned earlier, the layered bulges are caused mainly by the existence of 'non-rigid surface' along the interface and consequently, the material flows toward the interface. Notice from Figure 3.5 that the depth of the bulge below 
the indentations increases from around $2.6 \mu \mathrm{m}$ to $6.4 \mu \mathrm{m}$ when the load increases from $10 \mathrm{~g}$ to $1000 \mathrm{~g}$. Immediately surrounding the bulge, several serrated semi-circular slip-steps due to shear bands are observed. Beyond the serrated slip-steps, numerous smooth semi-circular slip-steps of shear bands with spacing of 200 300nm are seen when the load was increased above 50g. These serrated and the smooth semi-circular slip-steps together are named 'primary shear bands' in order to distinguish them from other slip-steps due to shear bands that form at higher loads ( $>50 \mathrm{~g})$. The number of the slip-steps from these primary shear bands increases dramatically with increasing load, but the spacing between them seems to remain constant. Interestingly, the slip-steps of these semi-circular primary shear bands seem to vanish as they approach the indentation surface (see Figure 3.5 (f)). The reason for this behavior will be explored in the next section. In all of the above indentations, it is noted that the lateral size of the region containing these primary shear bands does not extend beyond the diagonal size of the indent on the top surface. Therefore, typically no slip-steps of the shear bands are seen to extend beyond the diagonal of the indentation on the top surface as illustrated earlier in Figure 3.3.

Above 100g loading, two additional sets of the slip-steps patterns occur inside the zone of primary shear bands, as shown in Figures 3.5 (c) and (d). They are named secondary and tertiary shear bands. The secondary shear bands either emanate radially (called secondary radial shear bands in Figures 3.5 (e) and (f)) from the tip of the indent (bulge area) or initiate along the top indentation surface (called secondary surface shear bands in Figure 3.5 (f)). The tertiary shear bands develop inside but close to the boundary of the primary shear bands region as shown in Figure 3.5 (e). They intersect with both primary and secondary radial shear bands but seldom approach the top surface of the indent. 


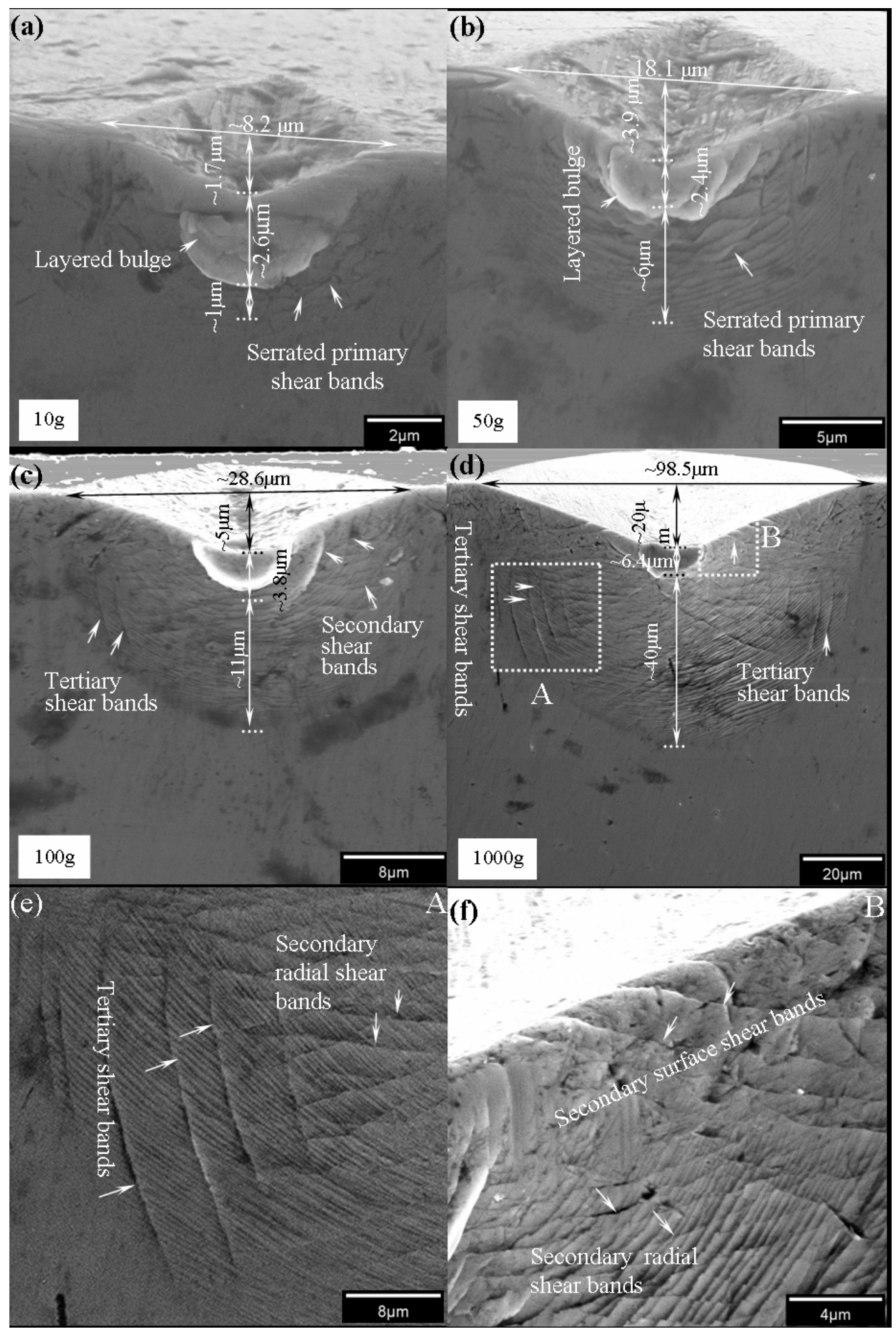

Figure 3.5. Evolution of shear band patterns with load beneath the Vickers indentation when the indenter diagonal is aligned parallel to the interface. 

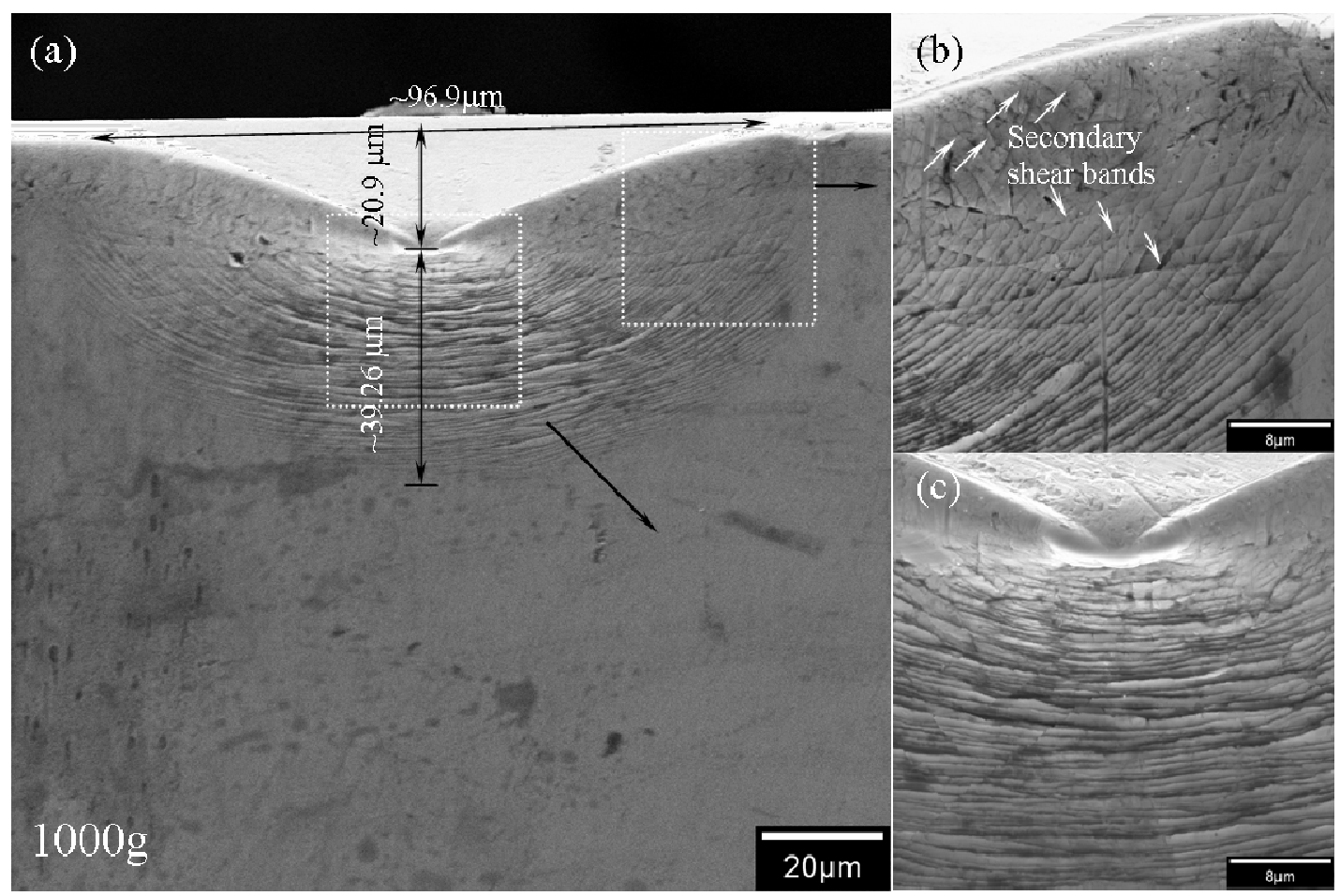

Figure 3.6. Shear band pattern beneath a Vickers indentation when the indenter diagonal is aligned at $45^{\circ}$ to the interface.

Figure 3.6 reveals the evolved shear bands pattern at a $1000 \mathrm{~g}$ load when one of the indenter boundaries is aligned parallel to the interface. Similar to the previous orientation, the slip-steps of the semi-circular primary shear bands as well as the radial and surface shear bands are seen. However, the slip-steps of the tertiary shear bands do not appear even at a load of 1000g. Moreover, the central layered bulge is also significantly smaller as shown in Figure 3.6 (c), when compared with the previous micrographs shown in Figure 3.5. This might be due to the fact that the sharp edges of the pyramid are away from the interface and therefore the intensity of deformation is less severe. Lack of tertiary shear band traces also further verifies that the intensity of deformation in this orientation is significantly less severe. Based on the above observations, it is reasonable to deduce that a hemispherical region of shear bands with different patterns is formed beneath the indentation. 


\subsection{Discussions}

In many previous studies of Vickers indentations on amorphous alloys of different compositions [14, 17, 18], it was noted that a few slip-steps of shear bands were observed on the top surface surrounding the indents. Similarly a few of slip-steps of shear bands were also observed surrounding the Berkovich indents $[1,11]$. This may indicate that whether the shear bands could propagate onto the top surface is not only dependent on the indenter shape but also on the load and the material microstructure (even for amorphous alloys, the local microstructural variation still exists, such as ordering in short range or middle range).

Beneath the Vickers indentation, the deformation patterns have been clearly illustrated in Figures 3.5 and 3.6. However, the bonded interface does not provide continuous elastic constraint for the plastic flow, and hence may produce a deformation zone which is different in size and shape from what would occur in a continuous bulk solid. Through extensive studies on various materials, Mulhearn [19] concluded that the relaxation of the constraint may affect the extent of the deformed zone and the strain gradient, but not the contours of the equivalent strain. Based on this premise, the current observation of shear band patterns could be considered to represent the deformation behavior beneath the indenter in the bulk solid. The von Mises equivalent stress contours, analyzed by a finite element model [20] beneath a pyramidal indenter for various materials, also have patterns similar to the semi-circular slip-steps of shear bands (primary shear bands) observed in the current study. However, the formations of both the secondary and the tertiary shear bands under elevated loads have not been 
predicted by the finite element model.

Slip-line field models and expanding cavity models are widely used to describe the plastic flow of the material beneath an indenter. From the current observations, few slip-steps of the shear bands reach the top surface, which indicates that the rigid plastic slip-line field models may not account for the deformation behavior of the amorphous material under consideration. Furthermore, the evolution of additional shear band patterns with increasing load also implies the limitation of the application of slip-line field model in present observations. In a simple stress state, such as uniaxial compression or pure bending, shear bands along certain angle relative to the loading axis are favorably formed to accommodate the local plastic strain [2, 21]. The subsequent plastic deformation at increasing loads is generally accommodated by branching of shear bands and cracking. However, the complex stress state of indentation tests causes various sets of shear bands at different orientations and locations beneath the indentation, instead of shear band branching and cracking. Similar to analytical models that try to explain formation of several indentation crack systems such as radial, median and lateral cracking in brittle solids [22], it seems reasonable to correlate the spatial location and orientation of these shear band patterns under different loads with the stress components in the indented specimen. Therefore, a modified expanding cavity model (ECM) based on the Durcker-Prager yield criterion [23] is employed to analyze the deformation behavior of the indented material beneath a Vickers indentation. To simplify the analysis of various stress components, the deformation is assumed to be axisymmetric. Although this is not 
fully in accordance with actual deformation under a Vickers indenter, the intent is to identify the relevant stress components that are responsible for the observed slip-step patterns of the shear bands.

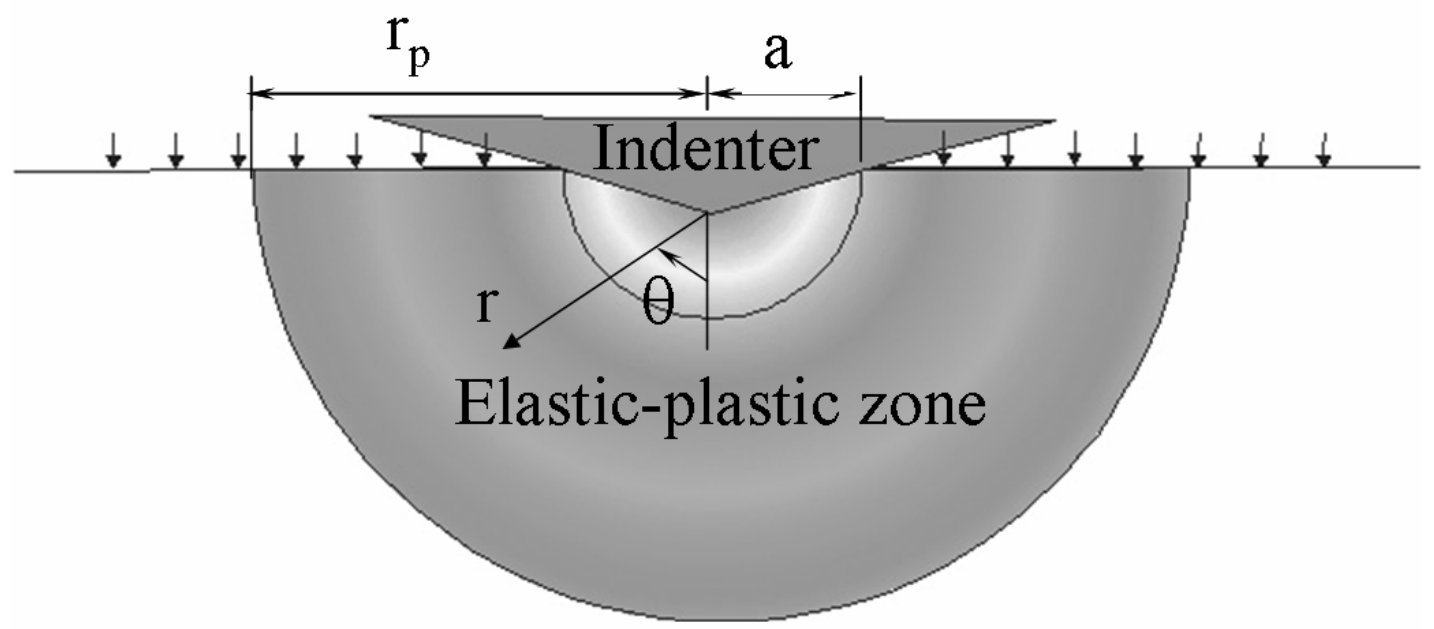

Elastic zone

Figure 3.7. Schematic of the modified expanding cavity model.

Figure 3.7 shows the schematic of the elastic-plastic region beneath an indentation described by the expanding cavity model. The Drucker-Prager yield function (e.g., [23]) may be represented in spherical coordinates $(r, \theta, \varphi)$ by

$\sigma_{\theta \theta}-\sigma_{r r}+\frac{1}{3}\left(\sigma_{r r}+2 \sigma_{\theta \theta}\right) \tan \alpha=\left(1-\frac{1}{3} \tan \alpha\right) \sigma_{y}^{c}$

where $\alpha$ is the pressure sensitivity index which depends on the yield stress in uniaxial compression $\sigma_{y}^{c}$ and the yield stress in uniaxial tension $\sigma_{y}^{t}$. Assuming that the Drucker-Prager circular cone coincides with the outer apexes of the Coulomb-Mohr hexagon, $\alpha$ can be estimated as ([24,25]) 
$\alpha=\operatorname{Arctan}\left[\frac{3\left(\sigma_{y}^{c}-\sigma_{y}^{t}\right)}{\sigma_{y}^{c}+2 \sigma_{y}^{t}}\right]$

The values of $\sigma_{y}^{c}$ and $\sigma_{y}^{t}$ in Eq.(3.2) for the sample material are listed in Table 3.1 [2].

Table 3.1. Properties of $\mathrm{Zr}_{57} \mathrm{Nb}_{5} \mathrm{Ni}_{12.6} \mathrm{Cu}_{15.4} \mathrm{Al}_{10}$ bulk metallic glass [2]

\begin{tabular}{l|ll}
\hline Property & & Value \\
\hline Elastic Modulus (GPa) & $\mathrm{E}$ & 86.7 \\
Bulk Modulus (GPa) & $\mathrm{K}$ & 118 \\
Shear Modulus (GPa) & $\mathrm{G}$ & 30.8 \\
Yield Strength (MPa) & $\sigma_{\mathrm{y}}{ }^{\mathrm{c}}$ & 1800 \\
& $\sigma_{\mathrm{y}}{ }^{\mathrm{t}}$ & 1200 \\
& $\rho$ & 6.8 \\
Density $\left(\mathrm{g} / \mathrm{cm}^{3}\right)$ & $\mathrm{v}$ & 0.38 \\
\hline
\end{tabular}

Referring to Narasimhan [23], the stress components and the radial displacement in the elastic region $\left(r_{p} \leq r<\infty\right)$ and the plastic region $\left(a \leq r<r_{p}\right)$, where $a$ is the equivalent indent contact radius and $r_{p}$ is the radius of the plastic region (see Figure 3.8), are given as follows:

In the elastic region $\left(r_{p} \leq r<\infty\right)$,

$$
\begin{aligned}
& \sigma_{r r}=-\frac{2}{3} \sigma_{y}^{c}\left(1-\frac{1}{3} \tan \alpha\right)\left(\frac{r_{p}}{r}\right)^{3} \\
& \sigma_{\theta \theta}=\frac{1}{3} \sigma_{y}^{c}\left(1-\frac{1}{3} \tan \alpha\right)\left(\frac{r_{p}}{r}\right)^{3} \\
& u_{r}=\frac{1}{3 E} \sigma_{y}^{c}\left(1-\frac{1}{3} \tan \alpha\right)(1+v) \frac{r_{p}^{3}}{r^{2}}
\end{aligned}
$$

In the plastic region $\left(a \leq r<r_{p}\right)$,

$$
\sigma_{r r}=-D \sigma_{y}^{c}\left(\frac{r_{p}}{r}\right)^{2 q}+\frac{B}{q} \sigma_{y}^{c}
$$




$$
\begin{aligned}
& \sigma_{\theta \theta}=D(q-1) \sigma_{y}^{c}\left(\frac{r_{p}}{r}\right)^{2 q}+\frac{B}{q} \sigma_{y}^{c} \\
& u_{r}=\frac{\sigma_{y}^{c}}{E}\left[M r_{p}\left(\frac{r_{p}}{r}\right)^{2 q-1}-L r_{p} \eta_{\theta}\left(\frac{r_{p}}{r}\right)^{s-1}+(1-2 v) \frac{B}{q} r\right]
\end{aligned}
$$

where $v$ is the Poisson's ratio and $B, q, D, L$ and $M$ are defined as

$$
\begin{aligned}
& B=\frac{1-\frac{1}{3} \tan \alpha}{1+\frac{2}{3} \tan \alpha}, \quad q=\frac{\tan \alpha}{1+\frac{2}{3} \tan \alpha}, \quad D=\frac{B}{q}+\frac{2}{3}\left(1-\frac{1}{3} \tan \alpha\right), \quad \eta_{\theta}=\frac{1}{2}+\frac{\tan \alpha}{3} \\
& L=\frac{2(2 q-3)(1-v)}{3-4 q\left(\frac{1}{2}+\frac{\tan \alpha}{3}\right)} D q, \quad M=L\left(\frac{1}{2}+\frac{\tan \alpha}{3}\right)+(1-v)(q-1) D+v D
\end{aligned}
$$

In the above analysis, the traction outside the indentation zone on the top surface of the specimen is not zero-valued, as shown in Figure 3.8. This is one main limitation of the expanding cavity models when applied directly to the indentation problem. Chiang et al. [22] proposed to eliminate the non-zero normal stress field acting on the top surface by superposing inverse Boussinesq's point force elasticity solution [26]. They argued that the elastic superposition on the elastic-plastic stress fields is self-consistent due to the spherical symmetry of the plastic zone as well as the elastic-plastic boundary.

The stresses induced within the plastic zone by the surface forces result in the modification of the stress magnitudes in Eq. (3.3) and Eq. (3.4) inside elastic and plastic zones. The stresses created by the surface forces have a general form [26] $\sigma_{m m}=\int_{V_{e l}} G_{m m} \sigma_{n}^{e l} d A+\int_{V_{p l}} G_{m m} \sigma_{n}^{p l} d A$ 
where $\sigma_{n}^{e l}$ and $\sigma_{n}^{p l}$ are the normal stresses on the specimen surface within the elastic and the plastic zones, respectively. The subscript $\mathrm{mm}$ can be either $r r, \phi \phi, \quad z z$ or $r z$ (the components in the cylindrical coordinate system $(\rho, \phi, z))$ and $G_{m m}$ are the point force functions given by ([26])

$$
\begin{aligned}
& G_{\rho \rho}=\frac{1}{2 \pi}\left[(1-2 v)\left(\frac{1}{\rho^{2}}-\frac{z}{r \rho^{2}}\right)-\frac{3 z \rho^{2}}{r^{5}}\right] \\
& G_{\phi \phi}=-\frac{1}{2 \pi}(1-2 v)\left(\frac{1}{\rho^{2}}-\frac{z}{r \rho^{2}}-\frac{z}{r^{3}}\right) \\
& G_{z z}=-\frac{1}{2 \pi} \frac{3 z^{3}}{r^{5}} \\
& G_{r z}=-\frac{1}{2 \pi} \frac{3 \rho z^{2}}{r^{5}}
\end{aligned}
$$

Transforming the above expressions into the spherical coordinates $(r, \theta, \varphi)$ and using $r^{2}=\rho^{2}+z^{2}$, one can obtain

$$
G_{r r}=G_{\rho \rho} \sin ^{2} \theta+G_{z z} \cos ^{2} \theta+2 G_{\rho z} \sin \theta \cos \theta
$$$$
G_{\theta \theta}=G_{\rho \rho} \cos ^{2} \theta+G_{z z} \sin ^{2} \theta-2 G_{\rho z} \sin \theta \cos \theta
$$

$G_{\varphi \varphi}=G_{\phi \phi}$

The formulas listed above will be used to numerically determine the stress components in the plastic zone, which will be used to explain the formation of various shear bands.

\subsubsection{Geometry of deformation region beneath the Vickers indentation}

Generally, shear bands initiate and propagate to accommodate the local plastic strain. The current observations reveal that the plastic deformation through the formation of 
various shear bands is mainly confined within a hemi-spherical region beneath the indenter. For some crystalline materials, the different sub-regions based on the characteristic plastic strain could be quantitatively distinguished [27, 28]. It is hard to subdivide the plastic zone based on plastic strain in the current observations because of the lack of work hardening in amorphous alloys. However, the plastic zone characterized by various shear bands has been clearly detected, which is essential to determine the size of the deformation zone underneath the indentation.

Following Johnson's expanding cavity model [26, 29], the radial displacement of the core boundary is assumed to accommodate the volume of material displaced by the indenter. Thus, the ratio of the plastic zone radius $\left(r_{p}\right)$ to contact area radius $(a)$ can be expressed as the following [26, 29]:

$\frac{r_{p}^{3}}{a^{3}}=\frac{E}{6(1-v)^{*} \sigma_{y}^{c}} \cot \beta+\frac{2}{3} \frac{1-2 v}{1-v}$

where $E$ is the Young's modulus and $\beta=70.3^{\circ}$, the equivalent half included angle of the indenter referred to [30]. Generally, the true contact area size can be extracted directly from the load-depth curve in an instrumented indentation test. To facilitate the analysis based on the expanding cavity model, an alternative way of estimating the size of contact area is employed. Based on the definition of the Meyer hardness $H=\frac{P_{\max }}{A_{\text {cont }}}$, where $P_{\max }$ and $A_{\text {cont }}$ are, respectively, the maximum load and the projected area of the indenter. The radius $a$ of the projected area (see Figure 3.8) can be obtained as $a=\sqrt{\frac{P_{\max }}{\pi H}}$. 
Thus, the radius of the plastic zone can be estimated using Eq. (3.9) as:

$r_{p}=\sqrt{\frac{P_{\max }}{\pi H}}\left\{\frac{E}{6(1-v)^{*} \sigma_{y}^{c}} \cot (\beta)+\frac{2}{3} \frac{1-2 v}{1-v}\right\}^{\frac{1}{3}}$

The calculated size of the indentation as a function of load based on Eq. (3.10) is shown in Figure 3.8 along with the experimentally measured radius of the plastic region from Figure 3.5. In addition to the overall size of the plastic zone containing the shear bands, the bulge radius as well as the indentation depth from several other experiments is also indicated in Figure 3.8 as a function of load. Because the hardness decreases with increasing load, an average Vickers Hardness of 4.97GPa (from Figure 3.2) is employed to facilitate the calculation. A good agreement is seen at loads up to $500 \mathrm{~g}$. At a load of $1000 \mathrm{~g}$, the measured plastic region is slightly larger than that predicted by the current model (i.e., Eq. (3.10)). This deviation is probably due to the use of the average hardness value as opposite to the measured value under the load of $1000 \mathrm{~g}$.

Giannakopoulos and Suresh [27] analyzed elastic-plastic properties of materials under instrumented indentation and proposed the following equation for the hemi-spherical plastic zone:

$r_{p}=\sqrt{\left(0.3 P_{\max }\right) / \sigma_{y}^{c}}$

Based on indentation mechanics for single crystals, Zielinski et al. [31] proposed another equation for estimating plastic zone size as

$r_{p}=\sqrt{\left(3 P_{\max }\right) /\left(2 \pi \sigma_{y}^{c}\right)}$ 


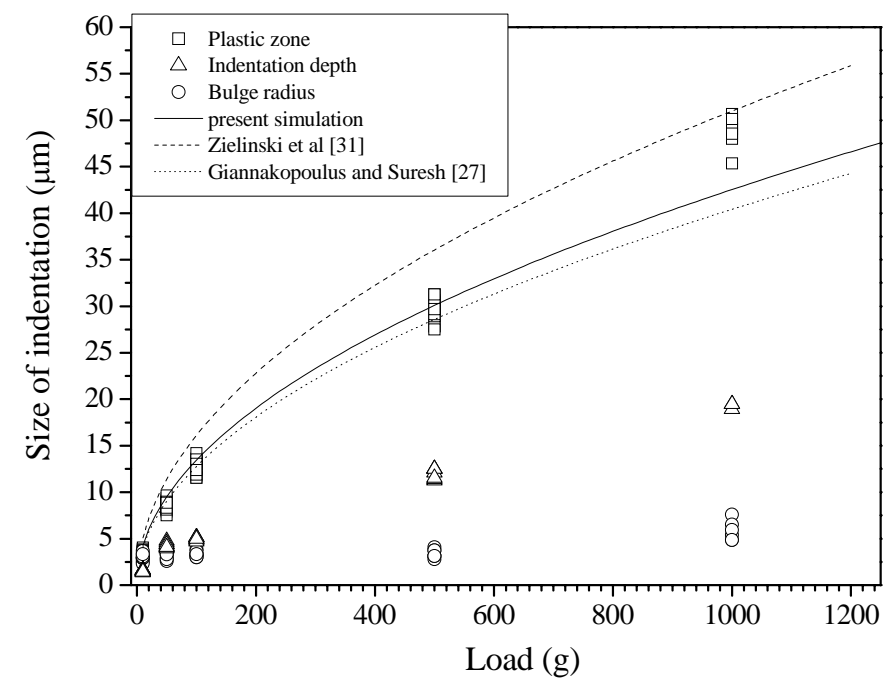

Figure 3.8. Comparison of the experimentally measurement plastic zone size with other models. The bulge radius and residual indentation depth measured from Figure 3.8 are also included.

The estimates from both Eqs. (3.11) and (3.12) are also plotted in Figure 3.8. Clearly, the prediction by the current model falls in between those by the above two models, and the current model seems to provide a slightly better estimation than the above two models. Moreover, the prediction by Eq. (3.11) are better for loads below 500g, and the predictions using Eq. (3.12) seems to be closer to the experimental results for loads beyond 500g. Similar trend for plastic zone size with increasing load $\left(r_{p} \propto P_{\max }^{0.5}\right)$ has also been reported recently [16].

\subsubsection{Evaluation of stress field beneath the indentation}

Although severe plastic deformation characterized by the distribution of various slip-steps of shear bands have been observed as shown in Figures 3.5 and 3.6, it is still difficult to identify the origin of each set of shear bands. In general, under quasi-static uniaxial compression or pure bending, shear bands form at certain angle relative to the loading axis. Branching of shear bands and even cracking have also been observed to 
occur at higher indentation loads [2, 32]. In the current indentation tests, instead of shear band branching and cracking, additional sets of shear bands at different orientations and locations are developed inside the plastic zone to accommodate the intense plastic strain beneath the indentation. Therefore, it seems that different stress components may primarily be responsible for different sets of shear bands. Most recently, a unified failure criterion was proposed, by Zhang et al. [33], to account for the different fracture behavior of BMGs, metals, and brittle materials based on the ratio ( $\alpha=\frac{\tau_{0}}{\sigma_{0}}$ ) between the critical shear fracture stress $\tau_{0}$ and the critical normal fracture stress $\sigma_{0}$. As summarized in their paper, normal tensile stress always plays some roles in the tensile fracture behavior. Reference [21] also summarizes the fracture angles for different BMGs under compressive loading, where the deviation of the fracture angles from $45^{\circ}$ was referred to as the influence of normal stress in addition to shear stress on fracture. In the current situation, due to the non-uniform distribution of the stress beneath the indentation, it is reasonable to propose that the stress components may dominate certain shear bands formation in some regions.

The distribution of the three normal stress components $\left(\sigma_{r r}, \sigma_{\theta \theta}, \sigma_{\phi \phi}\right)$ and the resulting maximum shear stress components $\left(\tau_{1}^{c r}=\frac{1}{2}\left(\sigma_{\theta \theta}-\sigma_{r r}\right)\right.$ and $\left.\tau_{2}^{c r}=\frac{1}{2}\left(\sigma_{\phi \phi}-\sigma_{r r}\right)\right)$ underneath the indentation can be determined numerically through Eqs. (3.3-3.6) and (3.8). The resulting normalized stress components ( $\sigma_{r r} / p$, $\tau_{1}^{c r} / p$ and $\tau_{2}^{c r} / p$ ) are plotted as a function of angle $\theta$ and radial distance $r$ (see Figure 3.7) in Figure 3.9. In the following, it is assumed that the shear bands are formed when one of the stress components reaches a critical value at room 
temperature. Upon deciding the dominant stress component for each shear band pattern, both the absolute value of each of the stress components and the ratio between the two shear stress components and the radial stress, at certain location beneath the indentation are considered to explain the formation of shear bands.

Inside the plastic zone, the modified ECM model reveals that the radial component $\sigma_{r r}$, normal to the spherical zone of the elastic-plastic boundary, is always negative, as shown in Figure 3.9 (a). The magnitude of $\sigma_{r r}$ is the highest near the core area $(r=a)$ and decreases gradually from the core to the elastic-plastic boundary ( $r=r_{p}$ ). Close to the core, $\sigma_{r r}$ first reach the yield stress when the load is large enough. Note that at a small indentation load of $10 \mathrm{~g}$, only primary shear bands are observed (Figure 3.5 (a)) and the plastic zone containing these primary shear bands grows with increasing load. Thus, the formation of primary shear bands can be reasonably attributed to this radial stress component. Moreover, the ratio between the shear stress components and the radial stress close to the core area $(\sim 0.35)$ also indicates that radial stress may also contribute to the initiation of shear bands in that region. Furthermore, $\sigma_{r r}$ decreases quickly in magnitude near the top surface $\left(\theta \rightarrow 90^{\circ}\right.$ ) because of the relaxation of the surface forces. So this may illustrate why only a few primary shear bands can propagate to the top surface in our observation from Figures 3.3 and 3.5 (f).

Upon increasing the load, two maximum critical shear stress components $\tau_{1}^{c r}=\frac{1}{2}\left(\sigma_{\theta \theta}-\sigma_{r r}\right)$ and $\tau_{2}^{c r}=\frac{1}{2}\left(\sigma_{\phi \phi}-\sigma_{r r}\right)$ may reach shear yield stress $\tau_{\mathrm{y}}\left(\right.$ i.e., $\tau_{\mathrm{y}}=$ $0.5 \sigma_{\mathrm{y}}$ ) as shown in Figure 3.9 (b) and (c). It is seen that these two stress components 
do not vary significantly in magnitude from $r=a$ to $r=r_{p}$ as compared to $\sigma_{r r}$ in Figure 3.9 (a). However, a clear variation of the magnitude of these two stress components near the core area $(r=a)$ is seen with $\theta$, i.e., $\tau_{2}^{c r}$ decreases rapidly when $\theta>60^{\circ}$, whereas $\tau_{1}^{c r}$ displays a peak value in the range $50^{\circ}<\theta<70^{\circ}$. It is reasonable to assume that shear bands caused by these shear stress components may reveal a different pattern as compared to the primary shear bands caused by the radial stress component. Thus, the secondary and the tertiary shear bands may possibly be caused by either or both of these two shear stress components.
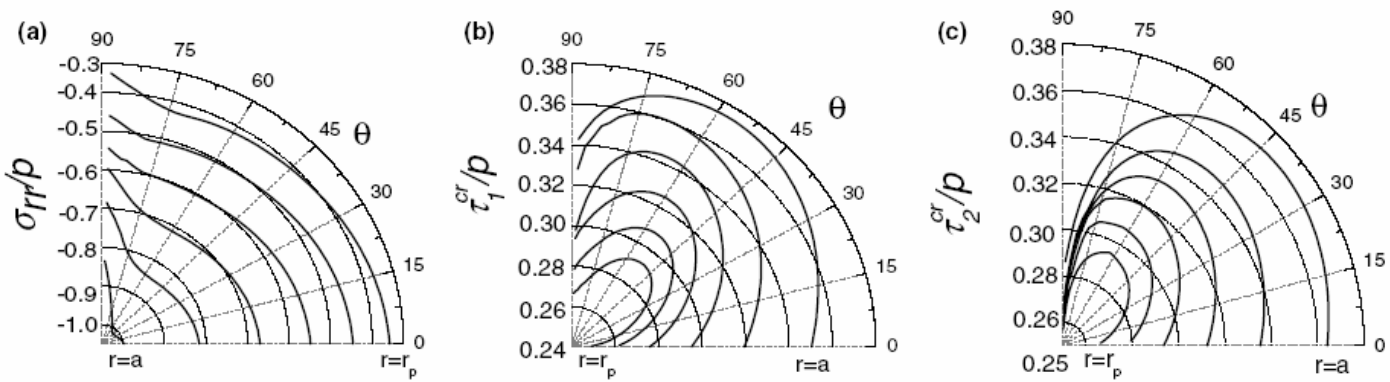

Figure 3.9. Distribution of the normalized stress components beneath the indentation. Variation of (a) radial stress, (b) and (c) the maximum shear stress as a function of angle between the radius and the vertical direction defined in Figure 3.7.

One of the characteristics of the secondary radial shear bands is that they extend from the core and cut across the entire elastic-plastic zone. Here, the minor variation in magnitude of certain shear stress component inside the plastic zone might account for the extension of the secondary radial shear bands. However, the assumption of parallel shear bands formation due to $\tau_{1}^{c r}$ and/or $\tau_{2}^{c r}$ leads to a controversy. Unlike the secondary radial shear bands, these secondary surface parallel shear bands (close to top surface) hardly extend across the whole plastic region. Recall that the confinement at the interface is non-rigid and hence the peripheral zone surrounding the indenter edge may not be accurately analyzed using the ECM. Giannakopoulos 
and Suresh [27] suggested a plastic cutting region close to the indentation edge, in which slip-line models, instead of expanding cavity models, are deemed to be more appropriate. Jana and co-workers [14, 16, 32] also found similar parallel secondary shear bands near the indentation edge, and suggested that the slip-line field analysis could be used to account for the shear band patterns.

Beyond a load of $100 \mathrm{~g}$, three sets of slip-step patterns are observed in the current experiments as shown in Figure 3.5(c). The slip-steps associated with the tertiary shear bands form mainly around the periphery of the elastic-plastic boundary between $50^{\circ}$ and $70^{\circ}$ (see Figure 3.5 (e)). These patterns may also be illustrated by the maximum critical shear stress component $\tau_{1}^{c r}$ (Figure 3.9 (b)), which reaches its peak value in the above range and thus could possibly explain their formation.

In Figure 3.9 (c), $\tau_{2}^{\text {cr }}$ decreases significantly when $\theta$ ranges from $65^{\circ}$ to $90^{\circ}$. Consequently, $\tau_{2}^{c r}$ seems to more likely account for the secondary radial shear bands because of the smaller value close to the top surface and a larger value at $\theta$ below $70^{\circ}$. But few secondary radial shear bands can be observed right beneath the indenter, because of the dense primary shear bands in that range relax most of the local severe plastic strain. Thus the above approach based on the stress components seems to logically explain the formation of various sets of shear bands.

Although the ECM was used here to explain the stress components responsible for each set of shear bands, the model has many limitations. First, from this model, the authors can only obtain the distribution of different stress components underneath the indentation which may dominate in the formation of a specific set of shear bands but 
it is not possible to determine the slip plane of the shear bands caused by each of the stress components. Recall that the primary shear bands continue to form as the load continues to increase. Formation of each shear band alters the stress state beneath the indentation. This modification of stress field continues with the formation of new sets of secondary and tertiary shear bands. The current modified ECM model, based on continuum elastic-plastic theory, does not directly account for such discrete stress release effects when shear bands are formed. Moreover, the sharp-edge effects associated with a Vickers indenter are also not taken into account. From Figure 3.7, it appears that the absence of tertiary shear bands could be attributed to the less severe stress state when the indenter diagonal is aligned $45^{\circ}$ relative to the interface than that observed when the indenter diagonal is aligned parallel to the interface, as shown in Figure 3.6. This model fails to capture such orientation effect due to the axisymmetric assumption. Also the evolution of shear bands is proposed purely based on the variation in the magnitude of stress components within the plastic zone without any reference to a criterion for shear band initiation. Despite these limitations, the model provides a fairly good estimation of the plastic zone size (Figure 3.8) and also furnishes a simple explanation for exploring the formation of various sets of shear bands based on the evolving stress state beneath the indentation.

\subsection{Conclusions}

A bonded interface technique is successfully used to investigate the formation of various sets of shear bands beneath a Vickers indentation in BMGs. At small indentation load, only semi-circular primary shear bands surrounding the indent are 
observed. With increasing load secondary and tertiary shear bands are developed inside this plastic region. A modified ECM was used to predict the size of the plastic zone as a function of load. This model provides a good estimate of the plastic zone size compared to other models available in the literature. Based on the stress distribution inside the hemispherical plastic zone, the radial stress component has been identified to be responsible for primary semi-circular shear bands formation, and shear stress components for secondary and tertiary shear band formation.

\section{Reference}

1. Vaidyanathan R., Dao M., Ravichandran G., Suresh S., Acta Mater. 2001;49:3781

2. Conner R.D., Yi Li, W.D.Nix, Johnson W.L., Acta Mater. 2004;52:2429

3. Xing L.-Q., Li Y., Ramesh K.T., Li J., Hufnagel T.C., Phys. Rev. B 2001;64:180201

4. Golovin Y.I., Ivogin V.I., Khonik V.A., Kitagawa K., Tyurin A.I., Scripta Mater. 2001; 45:947

5. Schuh C.A., Argon A.S., Nieh T.G., Wadsworth J., Phil Mag.A 2003;83:2585

6. Wright W.J., Saha R., Nix W.D., Mater. Trans. 2001;42:642

7. Schuh C.A., Nieh T.G., J Mater. Res. 2004;19:46

8. Schuh C.A., Nieh T.G., Acta Mater. 2003;51:87

9. Bei H., Lu Z.P., George E.P., Phys. Rev. Lett. 2004;93:125504

10. Jiang W.H., Pinkerton F.E., Atzmon M., J. Appl. Phys. 2003;93:9287

11. Zhang H.W., Subhash G., Kecskes L.J., Dowding R.J., Scripta Mater. 2003;49:447

12. Wang J.G., Choi B.W., Nieh T.G., Liu C.T., J. Mater. Res. 2000;15:798

13. Donovan P.E. J. Mater. Sci. 1989;24:523

14. Jana S., Ramamurty U., Chattopadhyay K., Kawamura Y., Mater Sci.\&Eng. A 2004;375-377:1191

15. Gu X., Xing L.Q., Hufnagel T.C., J. Non-cryst. Solids 2002;311:77

16. Ramamurty U., Jana S., Kawamura Y., Chattopadhyay K., Acta Mater. 2005;53:705

17. Inoue A., Shen B.L., Koshiba H., Kato H., Yavari A.R., Acta Mater. 2004;52:1631

18. Hajlaoui K., Benameur T., Vaughan G., Yavari A.R., Scripta Mater. 2004;51:843 
19. Mulhern T.O., J. Mech. Phys. Solids 1959;7:85

20. Giannkopoulos A.E., Larsson P.-L., Vestergaad R., Int. J. Solids Structures 1994;31:2679

21. Zhang Z.F., He G., Eckert J., Schultz L., Phys. Rev. Lett. 2004;91:045505

22. Chiang S.S., Marshall D.B., Evans A.G., J.. Appl. Phys. 1982;53:298.

23. Narasimhan R., Mechanics of Materials, 2004;36:633

24. Khan A.S., Huang S.J., 1995. Continuum Theory of Plasticity, John Wiley \& Sons, New York

25. Chen W.F., Han D.J., 1988. Plasticity for Structural Engineers, Springer Verlag, Berlin

26. Johnson K.L., 1985. Contact mechanics, Cambridge University Press, Cambridge

27. Giannakopulos A.E., Suresh S., Scr.Mater. 1999;40:1191

28. Chaudhri M.M., Acta Mater. 1998;46:3047

29. Johnson K.L., J. Mech. Phys. Solids 1970;18:115

30. Li M., Chen W.M., Liang N.G., Wang L.D., J. Mater. Res. 2004;19:73

31. Zielinski W., Huang H., Gerberich W.W., J. Mater Res. 1993;8:1300

32. Jana S., Bhowmick R., Kawamura Y., Chattopadhyay K., Ramamurty U., Intermetallics, 2004;12:1097

33. Zhang Z.F., Eckert J., Phys. Rev. Lett. 2005;94:094301 


\section{Chapter 4. Evaluation of Hardness-Yield-Strength Relationships for Bulk Metallic Glasses}

\subsection{Introduction}

Research on bulk metallic glasses (BMGs) has attracted considerable attention on account of their unique combination of mechanical properties, such as higher ratios of yield strength and hardness to Young's modulus, and a large elastic strain [1-3]. Numerous experimental studies on BMGs, including their behaviour under instrumented indentation, compression, tension, bending and fatigue have been widely reported [4-8]. Numerical $[9,10]$ and analytical [11,12] models have also been proposed to gain insight into the deformation behaviour of these materials.

Unlike conventional mechanical tests under uniaxial or bending loads, indentation tests are quite easy to perform and have much fewer restrictive requirements for sample size and specimen preparation. Therefore, indentation tests, especially the instrumented indentation, have been widely used to study the deformation behaviour of BMGs $[4,13,14]$. For traditional metallic crystalline solids (which deform predominantly by dislocation motion), the relationship between hardness $H$ and yield strength $\sigma_{y}$ was first proposed by Tabor [15] as

$$
H=K \sigma_{y}
$$

where $K$, commonly referred to as the constraint factor in the literature [15], generally depends on the indenter shape and the mechanical properties of the indented 
materials. As a rule of thumb, $K \approx 3$ is commonly used for metallic crystalline materials. In addition to Tabor's equation, various models based on indenter geometries and the material properties have been proposed. For indentation on rigid perfectly plastic materials, slip-line field theory has been widely used for strength estimation [16]. These models generally provide a simple linear relationship between $H$ and $\sigma_{y}$ based on indenter geometry. Through a detailed numerical study on various conical indenters, Lockett's results are conveniently summarized in [17] as:

$H=\frac{\sigma_{y}}{\sqrt{3}}(1.41+2.72 \theta)$

where $\theta$ is the half apex angle of the cone-shaped indenter. To approximate a Vickers indenter, the equivalent half angle is normally chosen to be $70.3^{\circ}$, which gives a value of $H / \sigma_{y} \approx 2.73$ for rigid plastic materials.

The available experimental data on BMGs reveals that these materials deform akin to elastic perfectly plastic materials $[18,19]$. For such non-strain hardening materials, finite-element analysis by Dao et al revealed a simple relationship between hardness and yield strength as [20]:

$H=\frac{2 N_{1}}{B} \sigma_{y}\left[N_{2}+\ln \left(\frac{E_{r}}{\sigma_{y}}\right)\right]$

where $N_{1}$ and $N_{2}$ are computationally derived constants related to indenter geometry. For a Vickers indenter $N_{1}=7.143$ and $N_{2}=-1$, and for a Berkovich indenter $N_{1}=6.618$ and $N_{2}=-0.875 . E_{r}$ is the reduced modulus given by 
$\frac{1}{E_{r}}=\frac{1-v^{2}}{E}+\frac{1-v_{i}^{2}}{E_{i}} . E$ and $v$ are the Young's modulus and Poisson's ratio of the specimen and the subscript $i$ indicates the indenter. The constant $B$ depends on the ratio $H / \sigma_{y}$ and the indenter geometry. For typical ZrHf-based BMGs, the ratio $\frac{E_{r}}{\sigma_{y}}$ is approximately 57 , calculated and chosen from data for ZrHf-based BMGs shown in Table 4.1. (In this study, $\sigma_{y}$ is assumed to be the compressive yield strength for calculation of $\frac{E_{r}}{\sigma_{y}}, \frac{E}{\sigma_{y}}$ and $\frac{H}{\sigma_{y}}$ if not explicitly specified). Based on the ratio of residual indentation depth to the maximum indentation depth during nano-indentation on BMGs [21], B can be estimated to be 15 for a sharp indenter [22]. Thus, from Eq. (3) the ratio between the hardness and the yield strength for ZrHf-based BMGs is given by $\frac{H}{\sigma_{y}} \approx 2.9$ for Vickers indentation and $\frac{H}{\sigma_{y}} \approx 2.8$ for Berkovich indentation.

Another popular approach for the analysis of indentation tests is the expanding-cavity model (ECM), which also gives simple expressions for the $H-\sigma_{y}$ relationship for a wide range of materials. Under the assumption of quasi-static expansion of an internally pressurized spherical cavity, Marsh derived the following expression for hardness [23]:

$H=\frac{2 \sigma_{y}}{3}\left\{1+\ln \left[\frac{E}{3(1-v) \sigma_{y}}\right]\right\}$

In general, the value of $\frac{E}{\sigma_{y}} \approx 55$ and $v=0.37$ are commonly used for most 
ZrHf-based amorphous materials [21,24]. $\frac{H}{\sigma_{y}}$ is then predicted to be around 2.84 for these materials.

Johnson [25,26] extended the expanding-cavity model by taking into account the indenter geometry and assuming an incompressible hemispherical hydrostatic core in the indented region. Here, the hardness is given as

$H=\frac{4}{3} \sigma_{y}+\frac{2}{3} \sigma_{y} \ln \left(\frac{1}{3} \frac{E}{\sigma_{y}} \cot \theta\right)$

For a Vickers indenter, the above equation results in a constraint factor $\frac{H}{\sigma_{y}}$ of around 2.59 for ZrHf-based BMGs.

Clearly, when the above relationships are applied to BMGs, there is considerable deviation in the predicted value of $H / \sigma_{y}$. Although all the above models reveal a simple proportionality between hardness and yield strength, there is no relative and comprehensive comparison between these models and the widely available experimental data on different BMG compositions. It is also worth mentioning that the experimentally obtained proportionality constants between hardness and yield strength for a wide range of BMGs reveal that this constraint factor ranges from 2.1 to 4.2 [27], indicating the limitation of the above models when applied to BMGs.

In this chapter, the various models describing the relationships between $H$ and $\sigma_{y}$ are first compared with the experimental data generated on ZrHf-based BMGs. A recently modified ECM [28] is further extended to obtain a relationship between the 
Table 4.1. Mechanical properties of various BMG compositions

\begin{tabular}{|c|c|c|c|c|c|c|}
\hline Alloy & $\sigma_{y}^{c} \quad(\mathrm{GPa})$ & $\begin{array}{c}E \\
(\mathrm{GPa})\end{array}$ & $\begin{array}{c}H^{\dagger} \\
(\mathrm{GPa})\end{array}$ & $E / \sigma_{y}^{c}$ & $\begin{array}{l}H^{\prime} \\
\sigma_{y}^{c}\end{array}$ & Ref. \\
\hline $\mathrm{Zr}_{57} \mathrm{Ti}_{5} \mathrm{Ni}_{8} \mathrm{Cu}_{20} \mathrm{Al}_{10}$ & $1.64 \pm 0.02$ & $85 \pm 1$ & $4.6 \pm 0.1$ & 52 & 2.8 & {$[21] \&$} \\
\hline $\mathrm{Hf}_{11.4} \mathrm{Zr}_{45.6} \mathrm{Ti}_{5} \mathrm{Ni}_{8} \mathrm{Cu}_{20} \mathrm{Al}_{10}$ & $1.78 \pm 0.01$ & $87 \pm 1$ & $4.7 \pm 0.1$ & 49 & 2.6 & {$[29] \&$} \\
\hline $\mathrm{Hf}_{22.8} \mathrm{Zr}_{34.2} \mathrm{Ti}_{5} \mathrm{Ni}_{8} \mathrm{Cu}_{20} \mathrm{Al}_{10}$ & $1.80 \pm 0.10$ & $94 \pm 1$ & $5.2 \pm 0.1$ & 52 & 2.9 & [47] \\
\hline $\mathrm{Zr}_{52.5} \mathrm{Ti}_{5} \mathrm{Ni}_{14.6} \mathrm{Cu}_{17.9} \mathrm{Al}_{10}$ & $1.74 \pm 0.03$ & $93 \pm 2$ & $5.0 \pm 0.2$ & 53 & 2.9 & .. \\
\hline $\mathrm{Hf}_{10.5} \mathrm{Zr}_{42} \mathrm{Ti}_{5} \mathrm{Ni}_{14.6} \mathrm{Cu}_{17.9} \mathrm{Al}_{10}$ & $1.94 \pm 0.02$ & $108 \pm 3$ & $5.3 \pm 0.1$ & 56 & 2.7 & .. \\
\hline $\mathrm{Hf}_{21} \mathrm{Zr}_{31.5} \mathrm{Ti}_{5} \mathrm{Ni}_{14.6} \mathrm{Cu}_{17.9} \mathrm{Al}_{10}$ & $1.85 \pm 0.02$ & $113 \pm 2$ & $5.5 \pm 0.1$ & 61 & 3.0 & $\cdot$. \\
\hline $\mathrm{Hf}_{31.5} \mathrm{Zr}_{21} \mathrm{Ti}_{5} \mathrm{Ni}_{14.6} \mathrm{Cu}_{17.9} \mathrm{Al}_{10}$ & $2.03 \pm 0.03$ & $110 \pm 3$ & $5.8 \pm 0.2$ & 54 & 2.9 & $\cdot \cdot$ \\
\hline $\mathrm{Hf}_{42} \mathrm{Zr}_{10.5} \mathrm{Ti}_{5} \mathrm{Ni}_{14.6} \mathrm{Cu}_{17.9} \mathrm{Al}_{10}$ & $2.04 \pm 0.04$ & $124 \pm 2$ & $6.0 \pm 0.2$ & 61 & 2.9 & .. \\
\hline $\mathrm{Hf}_{52.5} \mathrm{Ti}_{5} \mathrm{Ni}_{14.6} \mathrm{Cu}_{17.9} \mathrm{Al}_{10}$ & $2.09 \pm 0.02$ & $128 \pm 4$ & $6.1 \pm 0.2$ & 61 & 2.9 & \\
\hline $\mathrm{Zr}_{57} \mathrm{Nb}_{5} \mathrm{Ni}_{12.6} \mathrm{Cu}_{15.4} \mathrm{Al}_{10}$ & $1.74 \pm 0.04$ & $89 \pm 1$ & $4.9 \pm 0.1$ & 49 & 2.7 & \\
\hline$\left(\mathrm{Al}_{0.84} \mathrm{Y}_{0.09} \mathrm{Ni}_{0.05} \mathrm{Co}_{0.02}\right)_{95} \mathrm{Sc}_{5}$ & 1.51 & 78 & 4.4 & 52 & 2.9 & [38] \\
\hline$\left(\mathrm{Al}_{0.85} \mathrm{Y}_{0.08} \mathrm{Ni}_{0.05} \mathrm{Co}_{0.02}\right)_{95} \mathrm{Sc}_{5}$ & 1.45 & 75 & 4.0 & 52 & 2.8 & [38] \\
\hline $\mathrm{Co}_{78} \mathrm{Si}_{10} \mathrm{~B}_{12}$ & 3.00 & 88 & 8.9 & 30 & 3.0 & [39] \\
\hline $\mathrm{Cu}_{60} \mathrm{Hf}_{25} \mathrm{Ti}_{15}$ & $1.92^{\mathrm{T}} / 2.01^{*}$ & 124 & 6.7 & 62 & 3.2 & [40] \\
\hline $\mathrm{Cu}_{60} \mathrm{Hf}_{30} \mathrm{Ti}_{10}$ & 2.00 & 119 & 6.3 & 60 & 3.2 & [40] \\
\hline $\mathrm{Cu}_{47.5} \mathrm{Zr}_{47.5} \mathrm{Al}_{5}$ & 1.55 & 87 & - & 56 & - & [41] \\
\hline $\mathrm{Fe}_{80} \mathrm{~B}_{20}$ & 3.40 & 167 & 10.6 & 49 & 3.1 & [39] \\
\hline $\mathrm{Fe}_{80} \mathrm{P}_{13} \mathrm{C}_{7}$ & 3.04 & 118 & 7.5 & 39 & 2.5 & [39] \\
\hline $\mathrm{Fe}_{78} \mathrm{~B}_{10} \mathrm{Si}_{12}$ & 3.33 & 118 & 8.9 & 35 & 2.7 & [39] \\
\hline$\left(\mathrm{Fe}_{0.75} \mathrm{~B}_{0.2} \mathrm{Si}_{0.05}\right)_{96} \mathrm{Nb}_{4}$ & 3.16 & 180 & 10.5 & 56 & 3.3 & [42] \\
\hline$\left.\left(\mathrm{Fe}_{0.9} \mathrm{Co}_{0.1}\right)_{0.75} \mathrm{~B}_{0.2} \mathrm{Si}_{0.05}\right)_{96} \mathrm{Nb}_{4}$ & 3.82 & 190 & 11.3 & 50 & 3.0 & [42] \\
\hline$\left.\left(\mathrm{Fe}_{0.8} \mathrm{Co}_{0.2}\right)_{0.75} \mathrm{~B}_{0.2} \mathrm{Si}_{0.05}\right)_{96} \mathrm{Nb}_{4}$ & 4.05 & 205 & 12.0 & 51 & 3.0 & [42] \\
\hline$\left.\left(\mathrm{Fe}_{0.7} \mathrm{Co}_{0.3}\right)_{0.75} \mathrm{~B}_{0.2} \mathrm{Si}_{0.05}\right)_{96} \mathrm{Nb}_{4}$ & 4.10 & 210 & 12.2 & 51 & 3.0 & [42] \\
\hline$\left.\left(\mathrm{Fe}_{0.6} \mathrm{Co}_{0.4}\right)_{0.75} \mathrm{~B}_{0.2} \mathrm{Si}_{0.05}\right)_{96} \mathrm{Nb}_{4}$ & 4.10 & 210 & 12.3 & 51 & 3.0 & [42] \\
\hline$\left.\left(\mathrm{Fe}_{0.5} \mathrm{Co}_{0.5}\right)_{0.75} \mathrm{~B}_{0.2} \mathrm{Si}_{0.05}\right)_{96} \mathrm{Nb}_{4}$ & 4.07 & 210 & 12.0 & 51 & 2.9 & [42] \\
\hline $\mathrm{Ni}_{78} \mathrm{Si}_{10} \mathrm{~B}_{12}$ & 2.45 & 78 & 8.4 & 32 & 3.4 & [39] \\
\hline $\mathrm{Ni}_{45} \mathrm{Ti}_{20} \mathrm{Zr}_{25} \mathrm{Al}_{10}$ & 2.37 & 114 & 7.8 & 50 & 3.4 & [43] \\
\hline $\mathrm{Ni}_{40} \mathrm{Cu}_{6} \mathrm{Ti}_{16} \mathrm{Zr}_{28} \mathrm{Al}_{10}$ & 2.18 & 111 & 7.6 & 51 & 3.5 & [43] \\
\hline $\mathrm{Ni}_{40} \mathrm{Cu}_{5} \mathrm{Ti}_{17} \mathrm{Zr}_{28} \mathrm{Al}_{10}$ & 2.30 & 134 & 8.4 & 58 & 3.7 & [43] \\
\hline $\mathrm{Ni}_{40} \mathrm{Cu}_{5} \mathrm{Ti}_{16.5} \mathrm{Zr}_{28.5} \mathrm{Al}_{10}$ & 2.30 & 122 & 7.8 & 53 & 3.4 & [43] \\
\hline $\mathrm{Ni}_{39.8} \mathrm{Cu}_{5.97} \mathrm{Ti}_{15.92} \mathrm{Zr}_{27.86} \mathrm{Al}_{9.95} \mathrm{Si}_{0.5}$ & 2.32 & 117 & 8.1 & 50 & 3.5 & [43] \\
\hline $\mathrm{Zr}_{41.25} \mathrm{Ti}_{13.75} \mathrm{Ni}_{10} \mathrm{Cu}_{12.5} \mathrm{Be}_{22.5}$ & 1.90 & 96 & 5.2 & 51 & 2.7 & [37] \\
\hline $\mathrm{Zr}_{54.4} \mathrm{Cu}_{25.6} \mathrm{Fe}_{8} \mathrm{Al}_{12}$ & 1.69 & - & 5.5 & - & 3.3 & [44] \\
\hline $\mathrm{Zr}_{58} \mathrm{Cu}_{22} \mathrm{Fe}_{8} \mathrm{Al}_{12}$ & 1.63 & - & 5.3 & - & 3.3 & [44] \\
\hline $\mathrm{Zr}_{61.6} \mathrm{Cu}_{18.4} \mathrm{Fe}_{8} \mathrm{Al}_{12}$ & 1.56 & - & 5.1 & - & 3.3 & [44] \\
\hline $\mathrm{Pd}_{80} \mathrm{Si}_{20}$ & 1.34 & 67 & 3.2 & 50 & 2.4 & [39] \\
\hline $\mathrm{Pd}_{40} \mathrm{Ni}_{40} \mathrm{P}_{20}$ & $1.46^{\mathrm{T}} / 1.78^{*}$ & 108 & 5.3 & 68 & 3.0 & {$[30,45]$} \\
\hline $\mathrm{Pd}_{77.5} \mathrm{Cu}_{6} \mathrm{Si}_{16.5}$ & $1.44^{\mathrm{T}} / 1.54^{*}$ & 88 & 4.9 & 61 & 3.4 & {$[30,45]$} \\
\hline $\mathrm{Pt}_{57.5} \mathrm{Cu}_{14.7} \mathrm{Ni}_{5.3} \mathrm{P}_{22.5}$ & 1.40 & 94.8 & - & 68 & - & {$[46]$} \\
\hline
\end{tabular}

*: Superscript $\mathrm{T}$ indicates tensile yield strength. ${ }^{\dagger}$ :Vickers Hardness 
hardness and the yield strength of BMGs and then validated with the above experimental data. This model is then compared to previously described models (Eqs. (4.1) to (4.5)) and comparisons will be drawn regarding the limitations of each model. Experimental data available on other BMG compositions reported elsewhere by other researchers will then be used to compare the model predictions.

\subsection{Theoretical framework}

Amorphous alloys are known to exhibit elastic perfectly plastic response during uniaxial loading. Limited plastic strain has been widely reported for various compositions of BMGs and therefore these materials are normally believed to be elastic perfectly plastic materials [29,30]. It is commonly accepted that the plastic deformation behaviour of these quasi-brittle materials are pressure-sensitive (i.e., the yield strength differs under compression and tension), and such behaviour has been characterized by a pressure sensitivity index, denoted by $\alpha$ [10,31]. Accordingly, Mohr-Coloumb and Drucker-Prager yield criteria are widely recommended and used to study the yield behaviour of BMGs $[10,32,33]$. Thus, in contrast to metallic crystalline materials, the indentation hardness of BMGs must also include the effect of the pressure sensitivity index $\alpha$, which is the focus of the current theoretical framework. A modified expanding-cavity model (ECM), based on the Drucker-Prager yield criterion, was recently used by Zhang et al [28] to account for the indentation behaviour of $\mathrm{Zr}_{57} \mathrm{Nb}_{5} \mathrm{Ni}_{12.6} \mathrm{Cu}_{15.4} \mathrm{Al}_{10}$ amorphous alloys (Vitreloy 106) and good agreement between the experimental observation and the model prediction was obtained. Compared to the hexagon yield surface set by the Mohr-Coulomb criterion, 
the smooth circular cone yield surface defined by the Drucker-Prager criterion facilitates analytical derivation for complex deformation condition in situations such as indentation. Therefore, the Drucker-Prager criterion is more appropriate for parametric study. Encouraged by this result, the authors extend this approach to derive the $\frac{H}{\sigma_{y}}$ relationship.

The Drucker-Prager yield function (see for example [31]) is represented by

$\Phi\left(\sigma_{i j}\right)=\sigma_{e}+\sigma_{m} \tan \alpha-\left(1-\frac{1}{3} \tan \alpha\right) \sigma_{y}^{c}=0$

where $\sigma_{m}=\frac{1}{3} \sigma_{k k}$ and $\sigma_{e}=\sqrt{3 J_{2}^{\prime}}$ are the hydrostatic stress and Mises equivalent stress, respectively. $\sigma_{k k}$ is the first invariant of the stress tensor $\left(\sigma_{k k}=\sigma_{1}+\sigma_{2}+\sigma_{3}\right)$ and $J_{2}^{\prime}$ is the second invariant of the deviatoric stress tensor $\left(J_{2}{ }^{\prime}=\frac{1}{3}\left[\left(\sigma_{1}-\sigma_{2}\right)^{2}+\left(\sigma_{2}-\sigma_{3}\right)^{2}+\left(\sigma_{3}-\sigma_{1}\right)^{2}\right]\right)$, where $\sigma_{1}, \quad \sigma_{2}$ and $\sigma_{3}$ are the principal stresses. $\alpha$ is the pressure sensitivity, index which depends on the yield stress in uniaxial compression $\sigma_{y}^{c}$ and in uniaxial tension $\sigma_{y}^{t}$, and when $\tan \alpha=0$ the Drucker-Prager criterion reduces to the Von-Mises criterion. Assuming that the Drucker-Prager circular cone coincides with the outer apexes of the Coulomb-Mohr hexagon, $\alpha$ can be estimated as a function of both the compression and tension yield strengths $([34,35])$

$\alpha=\operatorname{Arctan}\left[\frac{3\left(\sigma_{y}^{c}-\sigma_{y}^{t}\right)}{\sigma_{y}^{c}+2 \sigma_{y}^{t}}\right]$

The friction coefficient $\beta$ in Mohr-Coulomb criterion for $\mathrm{Zr}_{59} \mathrm{Cu}_{20} \mathrm{Al}_{10} \mathrm{Ni}_{8} \mathrm{Ti}_{3}$ BMG is dependent on the stress state, $\beta=0.324$ for compression and $\beta=0.07$ for 
tension [19]. In present model, the pressure sensitivity index $\alpha$ unites the effects from both tension and compression. Because the stress state in the indented materials is not purely hydrostatic immediately beneath the indenter, the expanding-cavity model predicts lower hardness than that measured experimentally. Therefore, as proposed by Johnson [25,26] and Narasimhan [31], the indentation pressure can be approximated to the stress component along the $z$-axis in a cylindrical coordinate system $(r, \theta, z)$ as follows:

$\sigma_{z z} \cong-(p+\hat{\sigma})$

$\sigma_{r r}=\sigma_{\theta \theta} \cong-\left(p-\frac{\hat{\sigma}}{2}\right)$

where the mean contact pressure $p$ inside the cavity and $\hat{\sigma}$ are defined as:

$$
\begin{aligned}
& p=D \sigma_{y}^{c}\left(\frac{r_{p}}{a}\right)^{2 q}-\frac{B}{q} \sigma_{y}^{c} \\
& \hat{\sigma}=\frac{2 \sigma_{y}^{c}}{3}\left[1+\tan \alpha\left(\frac{p}{\sigma_{y}^{c}}-\frac{1}{3}\right)\right]
\end{aligned}
$$

where $r_{p}$ and $a$ are the radius of the plastic region along the $z$-axis and the equivalent indent contact radius, respectively. $B, \quad q$ and $D$ are defined as

$$
B=\frac{1-\frac{1}{3} \tan \alpha}{1+\frac{2}{3} \tan \alpha}, q=\frac{\tan \alpha}{1+\frac{2}{3} \tan \alpha}, \text { and } D=\frac{B}{q}+\frac{2}{3}\left(1-\frac{1}{3} \tan \alpha\right)
$$

As suggested by Johnson [25], i.e. assuming the indentation hardness $H$ to be equal to the stress component $\sigma_{z z}$, Eq. (4.8a) can be written as: 
$H=\left(1+\frac{2}{3} \tan \alpha\right) p+\frac{2}{3} \sigma_{y}^{c}\left(1-\frac{1}{3} \tan \alpha\right)$

Substituting $p$ from Eqs. (4.9) and (4.11) into Eq. (4.12), the relationship between the hardness and the yield strength can be expressed as a function of the pressure sensitive index $\alpha$, and the ratio between the plastic zone radius and the contact radius $\frac{r_{p}}{a}[25,26]$, i.e.,

$$
\frac{H}{\sigma_{y}^{c}}=\left(\frac{1-\frac{1}{3} \tan \alpha}{\tan \alpha}\right)\left[\left(1+\frac{2}{3} \tan \alpha\right)^{2}\left(\frac{r_{p}}{a}\right)^{2 q}-1\right]
$$

Following Johnson's expanding-cavity model $[25,26]$, the radial displacement of the plastic core boundary is assumed to accommodate the volume of material displaced by the indenter. Thus, the ratio of the plastic zone radius to contact area radius can be expressed as a function of material properties $\left(E, \sigma_{y}^{c}\right.$ and $\left.v\right)$ as well as the indenter geometry (equivalent half apex angle of the indenter $\theta$ ) by:

$\frac{r_{p}^{3}}{a^{3}}=\frac{E}{6(1-v) \cdot \sigma_{y}^{c}} \cot \theta+\frac{2}{3} \frac{1-2 v}{1-v}$

Combining Eq. (4.13) and Eq. (4.14), it can be seen that the relationship between hardness and yield strength is not only a function of the materials properties ( $E, \sigma_{y}^{c}$ and $v$ ) and the indenter geometry ( $\theta$ ) but also the pressure sensitivity index $\alpha$. As mentioned above, the Drucker-Prager criterion reduces to Von-Mises criterion if $\tan \alpha=0$. Then, the constraint factor $H / \sigma_{y}^{c}$ will reduce to Johnson's model as given in Eq.(4.5) (The derivation can be done based on Eqs.(4.9-4.12) or refer to [31] for detail). While the Tabor relationship (Eq. (4.1)) is primarily phenomenological, 
Eqs. (4.2)-(4.5) consider both the indenter geometries and the materials properties, and Eq. (4.13) extends to include the pressure sensitivity index. In this paper, a comparison of all the above model predictions with the available experimental data on a wide range of BMG compositions is performed. In addition, ten different compositions of ZrHf-based metallic glasses are also used to generate hardness and yield strength data to make comparisons between the above model predictions and the experimental results.

\subsection{Experimental Procedure}

Amorphous $\left(\mathrm{Hf}_{\mathrm{x}} \mathrm{Zr}_{1-\mathrm{x}}\right)_{52.5} \mathrm{Ti}_{5} \mathrm{Ni}_{14.6} \mathrm{Cu}_{17.9} \mathrm{Al}_{10} \quad(\mathrm{x}=0, \quad 0.2, \quad 0.4, \quad 0.6, \quad 0.8, \quad 1)$, $\left(\mathrm{Hf}_{\mathrm{x}} \mathrm{Zr}_{1-\mathrm{x}}\right)_{57} \mathrm{Cu}_{20} \mathrm{Ni}_{8} \mathrm{Al}_{10} \mathrm{Ti}_{5}(\mathrm{x}=0,0.2,0.4)$ and $\mathrm{Zr}_{57} \mathrm{Cu}_{15.4} \mathrm{Ni}_{12.6} \mathrm{Al}_{10} \mathrm{Nb}_{5}$ alloys, of $3 \mathrm{~mm}$ diameter were prepared by arc melting and mould casting as described in reference [24]. The as-cast condition of these alloys was verified to be fully amorphous by X-ray diffraction (XRD) analysis, differential scanning calorimetry (DSC) and transmission electron microscopy (TEM). These results were presented in previous chapters and also in [21, 36].

Specimens for indentation tests were prepared by cutting the as-cast metallic glass rods into $3 \mathrm{~mm}$ long cylinders using electrical discharge machining and by subsequent mechanical polishing to a mirror finish. Static indentation tests were performed under a Leco micro-hardness tester with a Vickers indenter at a load of $500 \mathrm{~g}$. The hardness was then determined from averaging ten measurements.

To determine the yield strength, quasi-static uniaxial compression tests were 
conducted using a servo-hydraulic MTS machine on cylindrical specimens of length $3.6 \mathrm{~mm}$ and diameter $3 \mathrm{~mm}$, at a crosshead speed of $0.1 \mathrm{~mm} / \mathrm{min}$, resulting in a strain rate on the order of $10^{-4} / \mathrm{s}$ in the specimen. The yield strength was determined by averaging data from three tests.

\subsection{Comparison of Models}

The relevant properties (compressive yield strength $\sigma_{y}^{c}$, Vickers hardness $H$, elastic modulus $E$ ) for various ZrHf-based BMGs are shown in Table 4.1. In this table, the ratio of hardness to compressive yield strength from the above experimental data is also listed. The constraint factor for these BMGs ranges from 2.6 to 3.0. Although the values of $\frac{E}{\sigma_{y}}$ and $\frac{E_{r}}{\sigma_{y}}$ for various ZrHf-based BMG compositions range between 49-61 and 51-63, respectively, because the emphasis in this paper is on comparison of the $H$ vs. $\sigma_{y}$ relationship as predicted by various models, approximate median value of $\frac{E}{\sigma_{y}} \approx 57$ and $\frac{E_{r}}{\sigma_{y}} \approx 57$ are used in all models. Figure 4.1 gives a comparison of the $H-\sigma_{y}$ relationship from the models presented in Eqs. (4.1)-(4.5) and (4.13) along with the experimental data on ZrHf-based BMGs. 


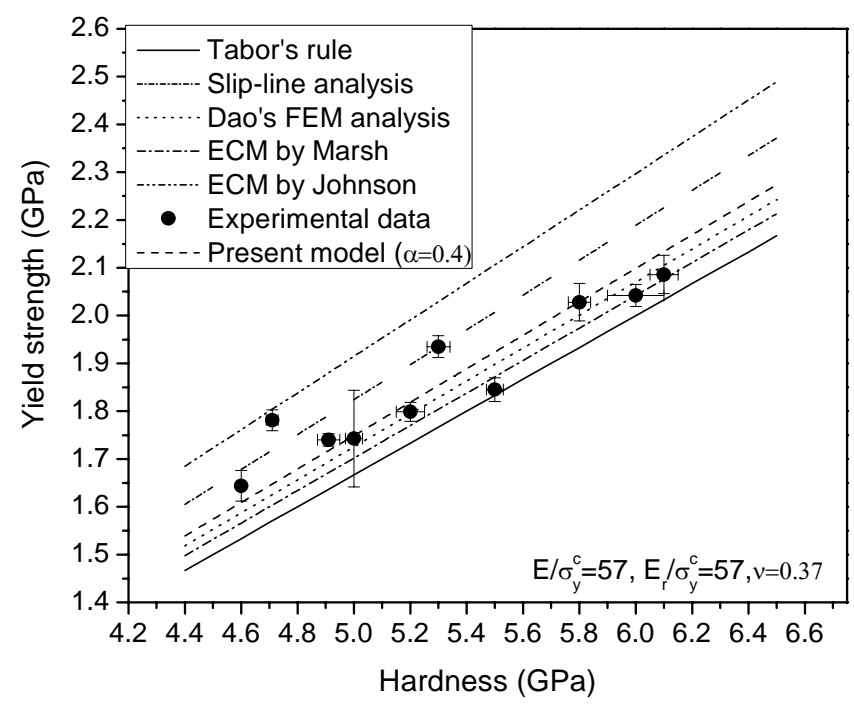

Figure 4.1. Comparison of various yield strength and hardness relationships with experimentally determined values on ZrHf-based BMGs.

Note that all the models predict an almost linear relationship between hardness and yield strength for fixed value of $\frac{E}{\sigma_{y}}$ and $\frac{E_{r}}{\sigma_{y}}$. A constant value of $v=0.37$ is assumed for these BMGs although it may vary for different BMG compositions (see references in Table 4.1). All the experimental data fall in between the Tabor estimation and the ECM prediction by Johnson. Although Johnson's model considers the effects from both the material properties and the indenter geometry (the present model can also be reduced to Johnson's model as mentioned in the previous section), the predicted yield strengths are significantly higher than all other models (i.e. a smaller ratio of $\frac{H}{\sigma_{y}}$ or in other words an underestimate of the constraint factor). The yield strengths by the Dao's numerical analysis (Eq. 4.3) and the Marsh's expanding-cavity model (Eq. 4.4) also seem to give better agreement with most of the 
experimental data. The data on ZrHf-based BMGs are also reasonably well modelled with the current modified expanding-cavity model for $\alpha=0.4$. Also, note that the model has the flexibility to estimate the tensile and the compressive yield strengths from the $H-\sigma_{y}$ relationship of BMGs when these strengths are difficult to determine experimentally. This flexibility is achieved by varying $\alpha$ and matching the experimental data to the model predictions. Therefore, in the following, we investigate the influence of $\alpha$ and expand the experimental data to other BMG compositions so as to investigate the predictive ability of the model.

Figure 4.2 reveals the dependence of $\frac{H}{\sigma_{y}}$ on the proportionality ratio $\frac{r_{p}}{a}$ and the pressure sensitivity index $\alpha$ from the current model (Eq.(4.13) and (4.14)). The ratio of hardness to yield strength increases with increasing values of $\frac{r_{p}}{a}$ and $\alpha$. Although it is still difficult to determine experimentally the exact value of $\frac{r_{p}}{a}$ in Eq.(4.13), a rough estimate based on the authors' experimental observations on the plastic zone developed in indentation studies is employed in the present work. The plastic zone measurements were made using a bonded interface technique on split specimens on which Vickers indentations were performed along the interface [28]. For metallic glasses, the plastic zone is normally characterized by various sets of slip-steps of shear bands. The plastic zone depth $r_{p}$ and the contact radius $a$ of the indentation can be measured through observations on the vertical surfaces of the split specimens along the indentation direction; see Figure 4.3. For ZrHf-based BMGs under Vickers 
indentation, $\frac{r_{p}}{a}$ values ranging from around 1.30 to 1.50 , have been measured. Because the distance from the centre to the edge of the indentation varies with the orientation of the Vickers indenter, an equivalent radius is calculated by utilizing the projected indentation imprint area on the top surface to be equal to the area of a circle with radius $a_{e q}$. Thus the ratio $\frac{r_{p}}{a_{e q}} \approx 1.68 \sim 1.93$ is obtained. Simultaneously, Eq. (4.14) also provides some theoretical estimation of the ratio $\frac{r_{p}}{a}$. With the known modulus, yield strength (Table 4.1) and Poisson's ratio $(v=0.37)$ of ZrHf-based BMGs, it is deduced that $\frac{r_{p}}{a} \approx 1.70 \sim 1.88$, which agrees reasonably well with the data derived from direct observations. These latter values are utilized on the $x$-axis in Figure 4.2. It appears that the pressure sensitivity indices of these materials vary in a range from about 0.25 to 0.55 . Vaidynathan et al [10] suggested a pressure sensitivity index $\alpha \sim 0.27$ in their finite-element analysis of indentation on Vitreloy 1 , attempting to provide a good match with their experimental results. (Note that a Mohr-Coulomb friction coefficient $\beta \sim 0.13$ is assumed in their paper, which is equivalent to the value $\alpha \sim 0.27$.) Considering the rough approximation of the ratio $\frac{r_{p}}{a}$, the range of values used for $\alpha$ in Figure 4.2 would be reasonable. 


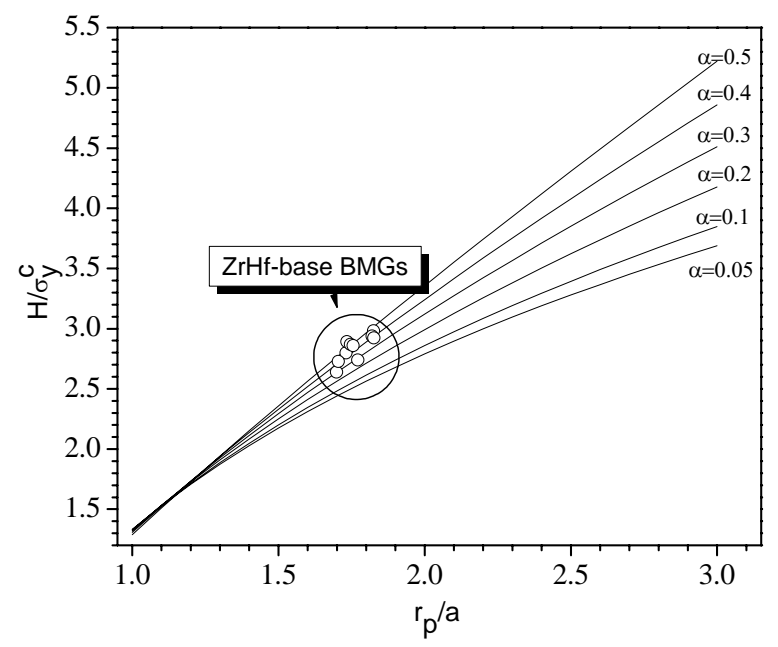

Figure 4.2. The dependence of the constraint factor $\frac{H}{\sigma_{y}^{c}}$ on the ratio of $\frac{r_{p}}{a}$ for various values of $\alpha$.

As mentioned above, the calculated ratio $\frac{r_{p}}{a}$ is quite close to the results obtained by direct observation, which provides an acceptable approximation to estimating the relationship between hardness and yield strength for ZrHf-based BMGs. An alternative approach of approximating the constraint factor is to combine Eq. (4.13) and (4.14). Figure 4.4 illustrates the estimated yield strengths for $\frac{E}{\sigma_{y}}=57$ and $v=0.37$ at various values of $\alpha$. Typically, the values of $\frac{E}{\sigma_{y}}$ for ZrHf-based BMGs fall between 49 and 61 and so the chosen value $\frac{E}{\sigma_{y}}$ of 57 is in mid-range and seems to give a better fit to the experimental data. The experimental results for Vit-1, Vit-105 and Vit-106 [35] are also marked in the figure; these fall right in or close to the predicted range. 


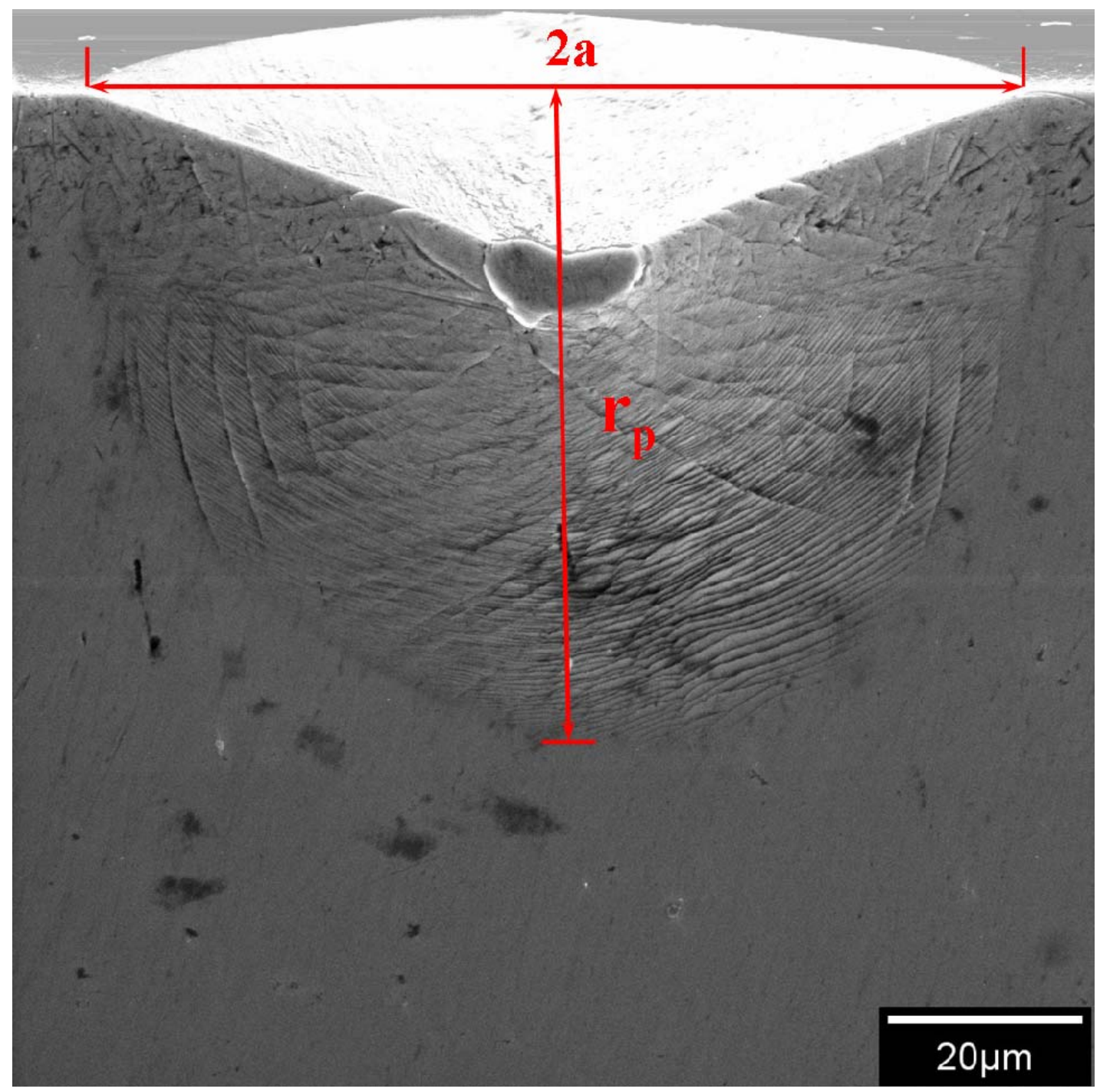

Figure 4.3. Experimental observation of the deformation structure beneath a Vickers indentation. 


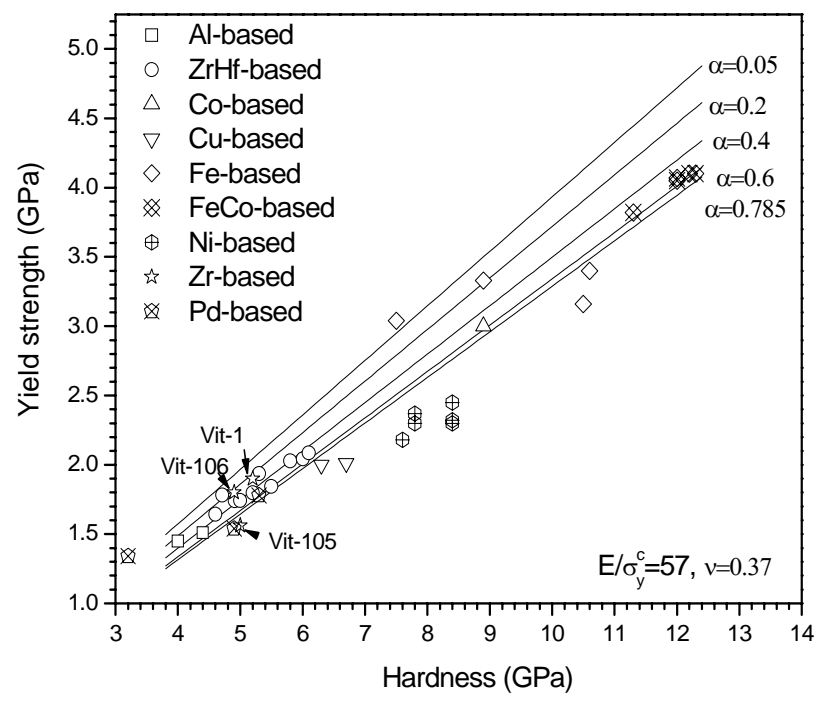

Figure 4.4. Comparison of predictions from the modified expanding-cavity model with experimental data for various BMG compositions.

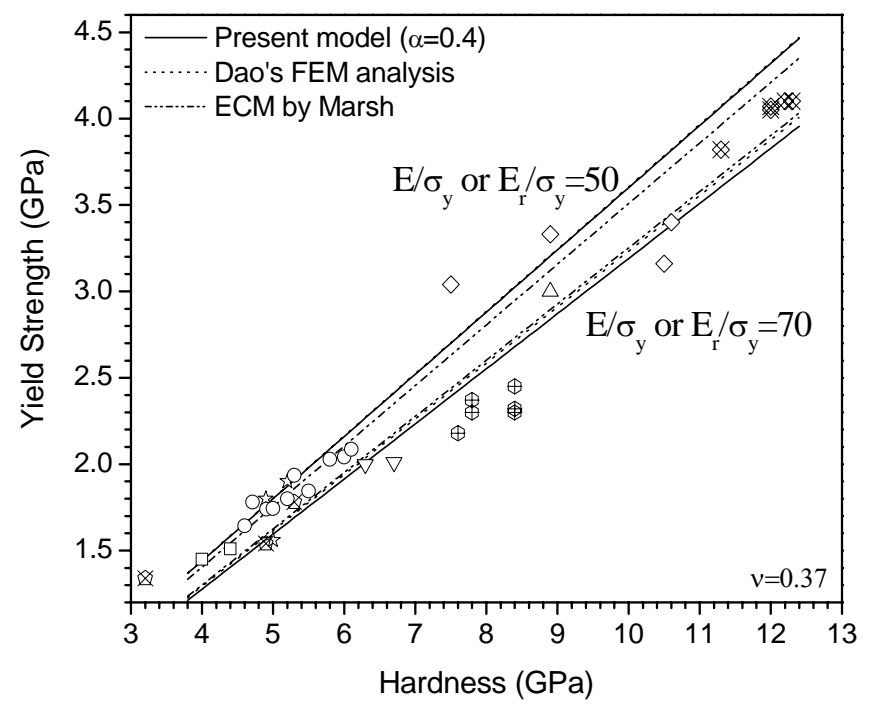

Figure 4.5. Comparison of predictions from the modified expanding-cavity model with experimental data when $\frac{E}{\sigma_{y}}$ was varied from 50 to 70 . The predictions from Dao's FEM analysis and the ECM by Marsh have also been plotted for comparison. (Refer to Figure 4.4 for identification of the compositions as corresponding to each symbol.) 
Data from other BMG compositions (i.e. Al-based, Co-based, Cu-based, Fe-based, Ni-based and Pd-based amorphous alloys), collected from the literature [30,37-46] are also plotted on the same figure. All these data are shown in Table 4.1. Clearly, the proposed model seems to make reasonable predictions for the hardness-yield strength relationship for the majority of the compositions shown here. Data on Cu-based, Ni-based and some of Fe-based metallic glasses do not seem to follow the model prediction well. One of the reasons for the lack of good correlation is possibly that the assumed ratio of $\frac{E}{\sigma_{y}}$ and the Poisson ratio $v$ are different for each BMG composition. For example, for $\mathrm{Pd}_{40} \mathrm{Ni}_{40} \mathrm{P}_{20}$ and $\mathrm{Pd}_{77.5} \mathrm{Cu}_{6} \mathrm{Si}_{16.5} \mathrm{BMGs}, \frac{E}{\sigma_{y}}$ equals 68 and 61 respectively; however for $\mathrm{Ni}_{45} \mathrm{Ti}_{20} \mathrm{Zr}_{25} \mathrm{Al}_{10} \mathrm{BMGs}$, it is only 50 . To study the effects of the magnitude of $\frac{E}{\sigma_{y}}$ on the results, its value was varied from 50 to 70 . Figure 4.5 exhibits the dependence of the predicted strengths for different $\frac{E}{\sigma_{y}}$ at fixed $\alpha=0.4$ and $v=0.37$. Clearly, the data from Ni-based BMGs still fall outside the predicted range for the chosen values of $\frac{E}{\sigma_{y}}$ value. Predictions from Dao's FEM analysis (Eq.3) and the ECM model by Marsh (Eq.(4.4)) are also plotted in Figure 4.5. Note that the results from these models are close to those of current model. Similarly, the Poisson ratio $v$ may also have some effect on these estimations. Simulations with $v$ increasing from 0.33 to 0.41 revealed only a small variation in the results of the current model. Therefore, it seems that none of the chosen models can fully predict the constraint factor for all the BMG compositions. 
Recall that Eq.(4.14) provides only a rough estimate of the ratio between the radius of the plastic zone radius and the radius of the contact area based on the assumption that the radial displacement of the plastic core boundary is to accommodate the volume of material displaced by the indenter. As is well known, pile-up and sink-in always surround the indentations for BMGs and each BMG composition may have different responses to indentations. Thus, Eq. (4.14) may have to be modified to account for such phenomena.

\subsection{Conclusions}

Comparison of various hardness-yield-strength relationships currently available in the literature for BMGs has been presented. It was shown that the Tabor's relationship and the ECM by Johnson do not provide good agreement with results for $\mathrm{Zr}$-Hf BMGs.

A theoretical analysis of the relationships between the hardness and the yield strength for ZrHf-based BMGs within the framework of the expanding-cavity model is provided. The relationship not only considers the material properties $\left(\frac{E}{\sigma_{y}}\right.$ and $\left.v\right)$ and the indenter geometry $\theta$, but also the pressure sensitivity index $\alpha$.

The current model predictions along with those of Dao (Eq.4.3) and Marsh (Eq.4.4) have been shown to provide good agreement with the experimental data for a wide range of BMG compositions.

\section{References}

1. Johnson WL, MRS Bull, 1999; 10:42 
2. Inoue A, Bulk amorphous alloys: Preparation and Fundamental Characteristics. (Trans Tech Publication, Switzerland), 1998

3. Inoue A, Acta Mater, 2000;48:279

4. Golovin YI, Ivolgin VI, Khonik VA, Kitagawa K, Tyurin AI, Scripta Mater, 2001;45:947

5. Subhash G., Dowding R, Kecskes L, Mater Sci Eng, 2002;A334:33

6. Xing L-Q, Li Y, Ramesh KT, Li J, Hufnagel TC, Phys. Rev. B, 2001;64:180201

7. Conner RD, Li Y, Nix WD, Johnson WL, Acta Mater, 2004;52:2429

8. Gilbert C J, Schroeder V, Ritchie RO, Metal \&Mater Trans.,1999;A30:1739

9. Patnaik MNM, Narasimhan R, Ramamurty U, Acta Mater,2004;52:3335

10. Vaidyanathan R, Dao M, Ravichandran G, Suresh S, Acta Mater,2001;49:3781

11. Zhang ZF, He G, Eckert J, Schultz L, Phys Rev Lett, 2003;91:045505

12. Zhang ZF, Eckert J, Phys Rev Lett,2005;94:094301

13. Schuh CA, Nieh TG, Acta Mater,2003;51:87

14. Wang JG, Choi BW, Nieh TG, J Mater Res, 2000;15:913

15. Tabor D, The hardness of Metals. Oxford University Press, London, UK,1951

16. Locktt FJ, J Mech Phys Solids, 1963;11:345

17. Schuh CA, Argon AS, Nieh TG, Wadsworth J, Philos Mag A, 2003;83:2585

18. Mukai T, Nieh T G, Kawamura Y, Inoue A, Higashi K, Scripta Mater, 2002;46:43

19. Zhang ZF, Eckert J, Schultz L, Acta Mater, 2003;51:1167

20. Dao M, Chollacoop N, VanVliet KJ, Venkatesh TA, Suresh S, Acta Mater, 2001;49: 3899

21. Zhang HW, Subhash G., Kecskes LJ, Dowding RJ, Scripta Mater, 2003;49:447

22. Giannakopoulos AE, Suresh S, Scripta Mater, 1999;40:1191

23. Marsh DM, Proc Roy Soc (Lond.), 1964;A279:420

24. Gu X, Xing LQ, Hufnagel TC. J Non-cryst. Solids,2002;311:77

25. Johnson KL, 1985. Contact mechanics, Cambridge University Press, Cambridge

26. Johnson KL, J. Mech. Phys. Solids, 1970;18:115

27. Schuh CA, Nieh T.G., J Mater. Res, 2004;19:46

28. Zhang HW, Jing XN, Subhash G, Kecskes LJ, Dowding RJ, Acta Mater, 2005;53: 3849

29. Li H, Subhash G, Kecskes LJ, Dowding RJ, Scripta Mater, 2003;11:1087

30. Donovan PE, Stobbs WM. Acta Metall, 1981;29:1419 
31. Narasimhan R., Mech Mater, 2004;36:633

32. Donovan PE, Acta Metall, 1989;37:445

33. Giannakopoulos AE, Larsson PL, Mech Mater, 1997;25:1

34. Khan A.S., Huang S.J., Continuum Theory of Plasticity, (John Wiley \& Sons, New York) 1995

35. Chen W.F., Han D.J., Plasticity for Structural Engineers, (Springer Verlag, Berlin),1988

36. Zhang HW, Subhash G, Kecskes LJ, Dowding RJ (unpublished)

37. Conner RD, Dandliker RB, Johnson WL, Acta Mater, 1998;46:6089

38. Inoue A, Sobu S, Louzguine D, Kimura H, Sasamori K, J Mater Res, 2004;19:1539

39. Luborsky FE ed., Amorphous Metallic Alloys, (Butterworths Monographs in Materials), 1983

40. Inoue A, Zhang W, Zhang T, Kurosaka K, J Mater Res, 2001;16: 2836

41. Das J, Tang M, Kim KB, Theissmann R, Baier F, Wang WH, Eckert J, Phys Rev Lett, 2005;94:205501

42. Inoue A, Shen BL, Chang CT, Acta Mater, 2004;52:4093

43. Xu DH, Duan G, Johnson WL, Garland C, Acta Mater, 2004;52:3493

44. Jin KF, Loffler JF, Appl. Phys Lett, 2005;86:241909

45. Donovan PE, J Mater Sci, 1989;24:523

46. Schroers J, Johnson WL, Phys Rev Lett, 2004;93:255506

47. Zhang H.W., Subhash G., Jing X.N., Kecskes L.J., Dowding R.J., Philosophical Magazine Letters, 2006;V86:333 


\section{Chapter 5. Experimental Investigation of Dynamic Response and Shear Band Evolution in ZrHf-based BMGs}

\subsection{Introduction}

The plastic properties for a vast majority of engineering materials are strongly dependent on the applied strain rate. For example, metals exhibit an increase in yield strength [1,2] and ceramics display an increase in fracture strength and fracture toughness with increasing strain rate $[3,4]$. For metallic glasses, no conclusive agreement on their rate sensitivity has been reached. Bruck et al. [5], Subhash et al. [6] and Lu et al. [7] reported insensitivity of the compressive yield strength to strain rate for Vitreloy-1 $\left(\mathrm{Zr}_{41.2} \mathrm{Ti}_{13.8} \mathrm{Cu}_{12.5} \mathrm{Ni}_{10} \mathrm{Be}_{22.5}\right)$. On the other hand, negative rate sensitivity in compression (i.e., a decrease in compressive yield/fracture strength with strain rate) has been reported by Mukai et al. [8] on $\mathrm{Pd}_{40} \mathrm{Ni}_{40} \mathrm{P}_{20}$, by Hufnagel et al. [9] on $\mathrm{Zr}_{57} \mathrm{Ti}_{5} \mathrm{Cu}_{20} \mathrm{Ni}_{8} \mathrm{Al}_{10}$, and by Gu et al. [10] and Li et al. [11] on $\mathrm{Zr} / \mathrm{Hf}$ based metallic glasses. This disagreement may be due to the variations in composition of BMGs, specimen size, experimental limitations and probably due to limited number of test specimen employed in these investigations.

Although static indentations [12-15] have been extensively employed, few studies are focused on indentations at high strain rates. A dynamic indentation technique based on modified split Hopkinson pressure bar [16] has been successfully used earlier to analyze dynamic indentation response of various metals and ceramics by Subhash and coworkers $[17,18]$, where the positive rate sensitivity of indentation hardness, similar 
to that of uniaxial yield stress, has been verified. The method is akin to the traditional static indentation technique in terms of load measurement and hardness determination, and therefore can easily facilitate comparison of static and dynamic hardness values in materials. Dynamic indentations have been performed on three ZrHf-based bulk metallic glasses and their rate sensitivity of indentation hardness has been obtained. Slip steps of shear bands pattern beneath and surrounding the indentations have been identified and compared to those developed under static indentation.

\subsection{Experimental Procedure}

Cylindrical ingots of $\mathrm{Zr}_{57} \mathrm{Ti}_{5} \mathrm{Cu}_{20} \mathrm{Ni}_{8} \mathrm{Al}_{10}, \quad \mathrm{Zr}_{34.2} \mathrm{Hf}_{22.8} \mathrm{Ti}_{5} \mathrm{Cu}_{20} \mathrm{Ni}_{8} \mathrm{Al}_{10}$ and $\mathrm{Zr}_{57} \mathrm{Cu}_{15.4} \mathrm{Ni}_{12.6} \mathrm{Al}_{10} \mathrm{Nb}_{5}$ alloys of $3 \mathrm{~mm}$ in diameter and $3 \sim 3.6 \mathrm{~mm}$ in length were prepared for indentation tests by polishing the flat surfaces using standard metallographic techniques. Dynamic indentations were carried out on a dynamic indentation tester shown schematically in Figure 5.1 [19]. It consists of a long rod with a momentum trap (MT) assembly $[19,20]$ at one end and a Vickers indenter at the other end. A high frequency $(200 \mathrm{kHz})$ load cell that captures the indentation load is mounted on a rigid base. The BMG specimen is placed with one flat surface against the load cell and another flat surface in contact with the indenter tip. A striker bar of the same diameter as incident bar and of length of $254 \mathrm{~mm}$ is launched from a gas gun at a predetermined velocity to impact the incident bar at the MT end. The impact generates a compressive stress pulse of amplitude proportional to the striker velocity. 


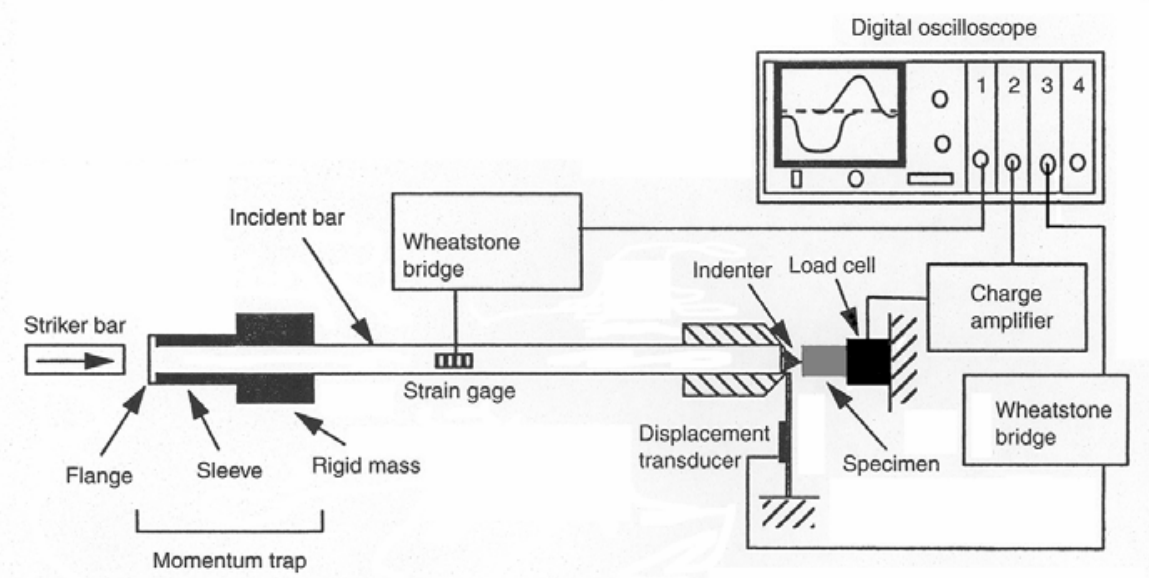

Figure 5.1. Experimental Setup for dynamic indentation hardness measurements

The MT assembly also introduces a tensile pulse of similar duration into the incident bar. The MT assembly ensures that only a single compressive pulse reaches the indenter thus causing a single indentation of duration around $100 \quad \mathrm{~s}$ and then moves the indenter away from the specimen $[16,19]$ due to successive wave reflections that are tensile while traveling towards the indenter. The load history for each indentation is captured by a digital oscilloscope. A metallic strip with a bonded strain gage acts as a displacement transducer with its free end moving in unison with the indenter during the indentation test to provide indenter depth $v$ s. time signature. The loading duration for all the tests ranges approximately from 90 to $130 \mu$ s and the indentation load ranges from around $6 \mathrm{~N}$ to $90 \mathrm{~N}$ ( $\sim 0.61 \mathrm{kgf}$ to $\sim 9.2 \mathrm{kgf}$ ), as shown in Figure 5.2 . The maximum indentation depth measured from the displacement transducer ranges from $\sim 50 \mu \mathrm{m}$ to $\sim 200 \mu \mathrm{m}$ for various indentations. 


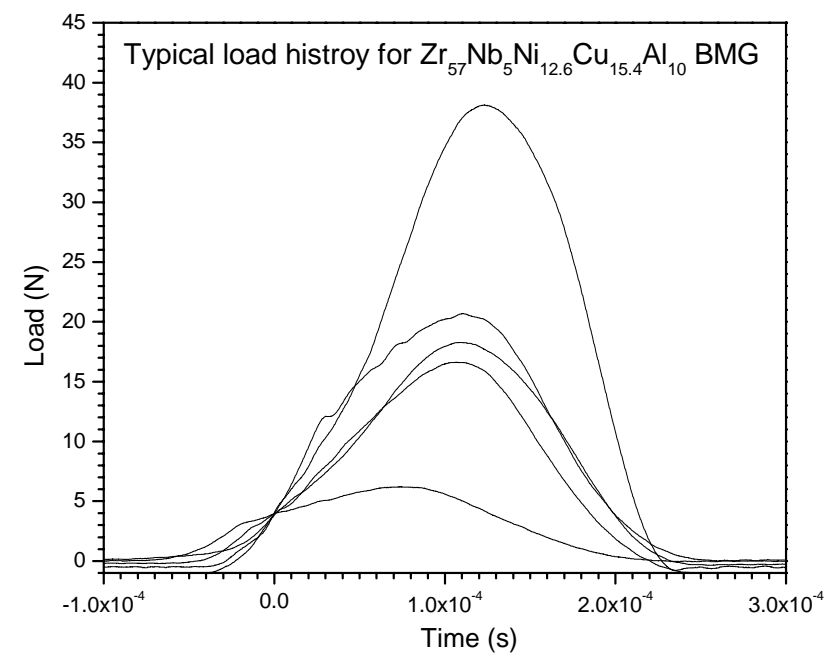

\section{Figure 5.2. Typical loading history of dynamic indentation tests}

In an indentation test, the strain rate is not constant during the indentation process.

The strain rate $\dot{\varepsilon}$ varies temporally and spatially within the indentation influenced region. During the early phase of indentation, the strain rate of deformation is high due to the sharp indenter tip penetrating at high velocity into a small region. As the depth of indentation increases, the strain rate decreases gradually because the area resisting the indenter increases and the velocity of the indenter decrease. Thus, the strain rate $\dot{\varepsilon}$ is non-uniform throughout the indentation region. Therefore, an average indentation strain rate $\dot{\varepsilon}$ is employed to characterize this dynamic process by dividing the average indentation velocity $\bar{v}_{i}$ (estimated from displacement-time history captured by the displacement transducer, see reference [19, 20]) with the measured average diagonal size $d_{o}$ of the projected indentation area on the specimen. With the measured $d_{o}$ and $\bar{v}_{i}$, the average indentation strain rate $\dot{\varepsilon}$ was calculated to vary from around 1000/s to 7000/s. Employing the identical definition to static 
Vickers hardness determination, the dynamic indentation hardness can be calculated from $H_{d}=1.8544 \frac{P_{\max }}{d_{0}{ }^{2}}$, where $P_{\max }$ is the maximum indentation load measured from the load cell signals (the peak value of each measurement shown in Figure 5.2).

In the current investigation, the dynamic hardness values were compared to static hardness values at similar load levels. Typical static indentation hardness $H_{s}$ measurements were performed at maximum loads $P_{\max }$ of $500 \mathrm{~g}, 1000 \mathrm{~g}, 5000 \mathrm{~g}$ and $10000 \mathrm{~g}$ for 10 seconds. On average 10 tests were performed at each load level. However, the dynamic indentations can be performed at any intermediate load level by simply varying the striker bar velocity. Because the available commercial static indentation hardness tester provides only a limited number of load values at which hardness can be obtained, a regression curve was fit through the measured hardness so as to determine the static hardness value at any load comparable to the load level in each dynamic indentation. The ratio between dynamic indentation hardness $\left(H_{d}\right)$ and static indentation hardness $\left(H_{s}\right)$ at the same load, denoted as the normalized dynamic indentation hardness $\left(H_{d N}\right)$, is thus obtained.

Two specimen configurations were used: (i) cylindrical specimens to determine dynamic indentation hardness and its rate sensitivity and to characterize the deformation features on the indentation surface and (ii) bonded split specimens to characterize the deformation patterns beneath the indentations. The latter specimen configuration was successfully used by Zhang et al [15] and Jana et al [12-14] to determine shear band patterns beneath a static Vickers indentation. In this method, a 
cylindrical specimen is cut in half vertically and the split specimens are polished and bonded together. The top surface of the bonded specimen is then polished to obtain a flat surface. Indentations are then performed along the bonded interface with the diagonal of the indenter aligned along the interface. The deformation structure beneath each indentation is observed after de-bonding the specimen. Characterization of the deformation structures under dynamic indentations on both top surface and vertical surface was performed using a scanning electron microscope (SEM). These deformation features were later compared to those developed under static indentations.

\section{3. $\quad$ Results}

The comparison between static hardness and dynamic hardness as a function of load is shown in Figure 5.3. It is noted that: (i) the static hardness is significantly greater than the dynamic hardness for all the three BMG compositions, (ii) the static hardness is load dependent, i.e., $H_{s}$ is high at lower loads and tends to stabilize to a lower value at higher loads and (iii) there is a large scatter in the dynamic hardness values compared to the static hardness values. In the current technique, loads below $500 \mathrm{~g}$ could not be achieved due to the limitation in the dynamic hardness tester. The observed scatter in the dynamic hardness values $\left(H_{d}\right)$ is typical in dynamic indentations, especially for quasi-brittle or brittle materials [18, 19]. 


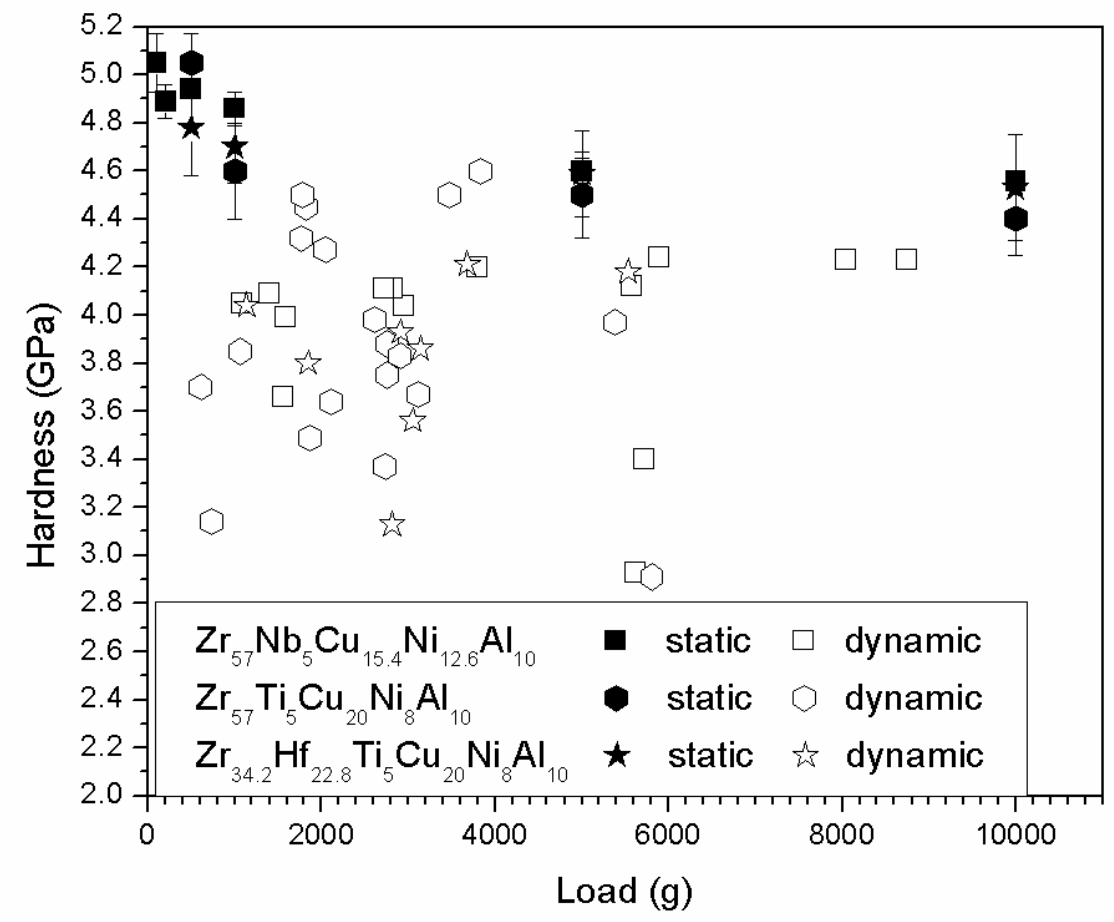

Figure 5.3. Variation of static hardness and dynamic hardness for various ZrHf-based BMGs with load

To further rationalize the hardness as a function of indentation strain rate $\dot{\varepsilon}$, an average strain rate measure is defined based on the indenter velocity and the size of indentation diagonal $[19,20]$ as described before. The normalized dynamic hardness $H_{d N}$ (i.e., $H_{d} / H_{s}$ ) at the same load level is then plotted as a function of $\dot{\varepsilon}$ in Figure 5.4. Clearly, the normalized dynamic hardness is less than unity reflecting a strain rate softening of hardness in these alloys. This result is consistent with the reported decrease in dynamic yield strength or fracture strength by Hufnagel et al in $\mathrm{Zr}_{57} \mathrm{Ti}_{5} \mathrm{Cu}_{20} \mathrm{Ni}_{8} \mathrm{Al}_{10}$ [9], and $\mathrm{Gu}$ et al [10] and Li et al [11] in ZrHf-based BMGs, as indicated in Figure 5.4. 


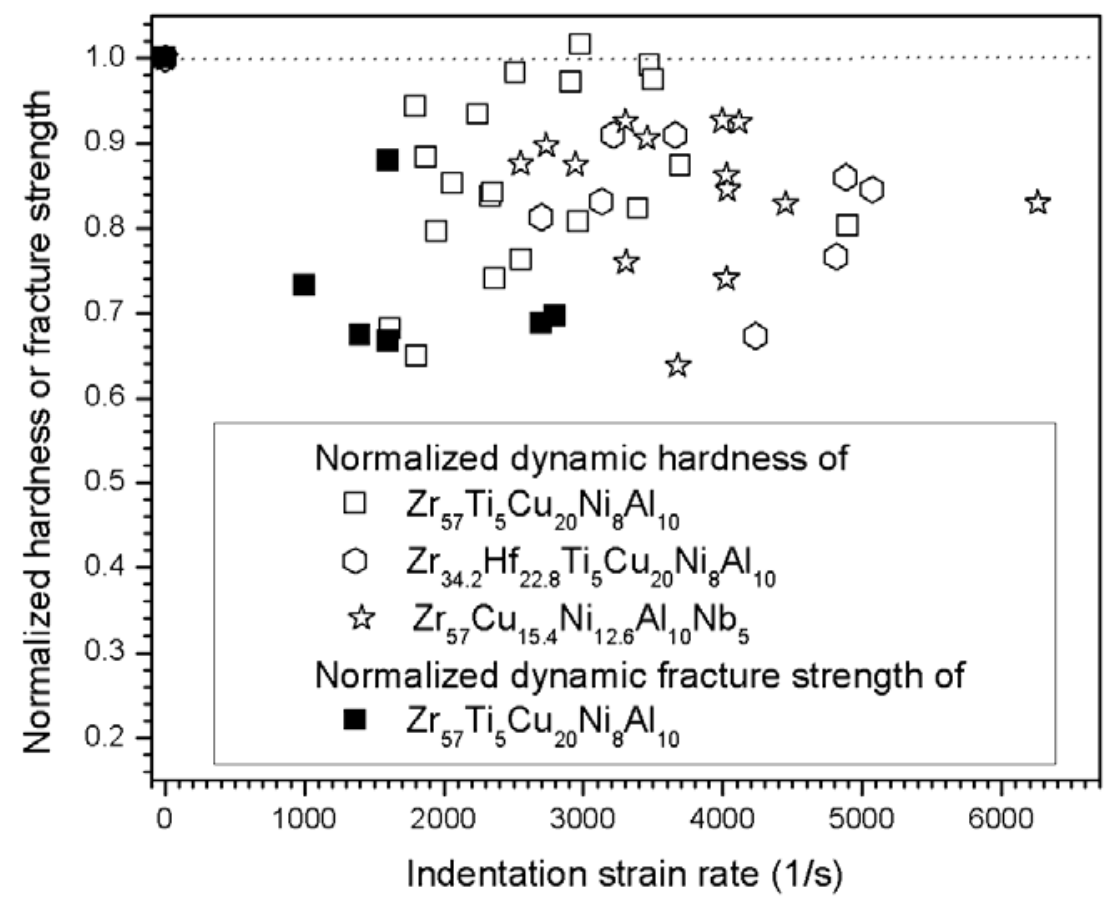

Figure 5.4. Variation of normalized hardness and fracture strength of various ZrHf-based BMGs with strain rate

Typical indentation images on the top surface of $\mathrm{Zr}_{57} \mathrm{Nb}_{5} \mathrm{Ni}_{12.6} \mathrm{Cu}_{15.4} \mathrm{Al}_{10}$ for $\mathrm{a}$ dynamic load of $9.4 \mathrm{~kg}$ are shown in Figure 5.5, where a static indentation image at $10 \mathrm{~kg}$ is also presented for comparison. Inside the dynamic indentation numerous deformation features such as slip steps of shear bands and even cracks have been observed. These deformation features appear to vary depending on the nature of stress concentration at various locations of the Vickers indentation. Right beneath the tip of the indenter where stress intensity is maximum, rough facets characterized by 'lip-like’ or 'coin-like’ cracks have been observed. In the vicinity of the indentation edges, numerous short and parallel slip steps of shear bands inclined at an angle to the edge can be detected. Inside the four flat surfaces of the indentation where stress 
intensity is minimal, semi-circular slip steps and cracks have been identified. No such severe deformation features were detected inside the indented region of the static indentations. Few shear bands are occasionally seen around the indentation. Some pileup may also be possible along the edges of static indentation.

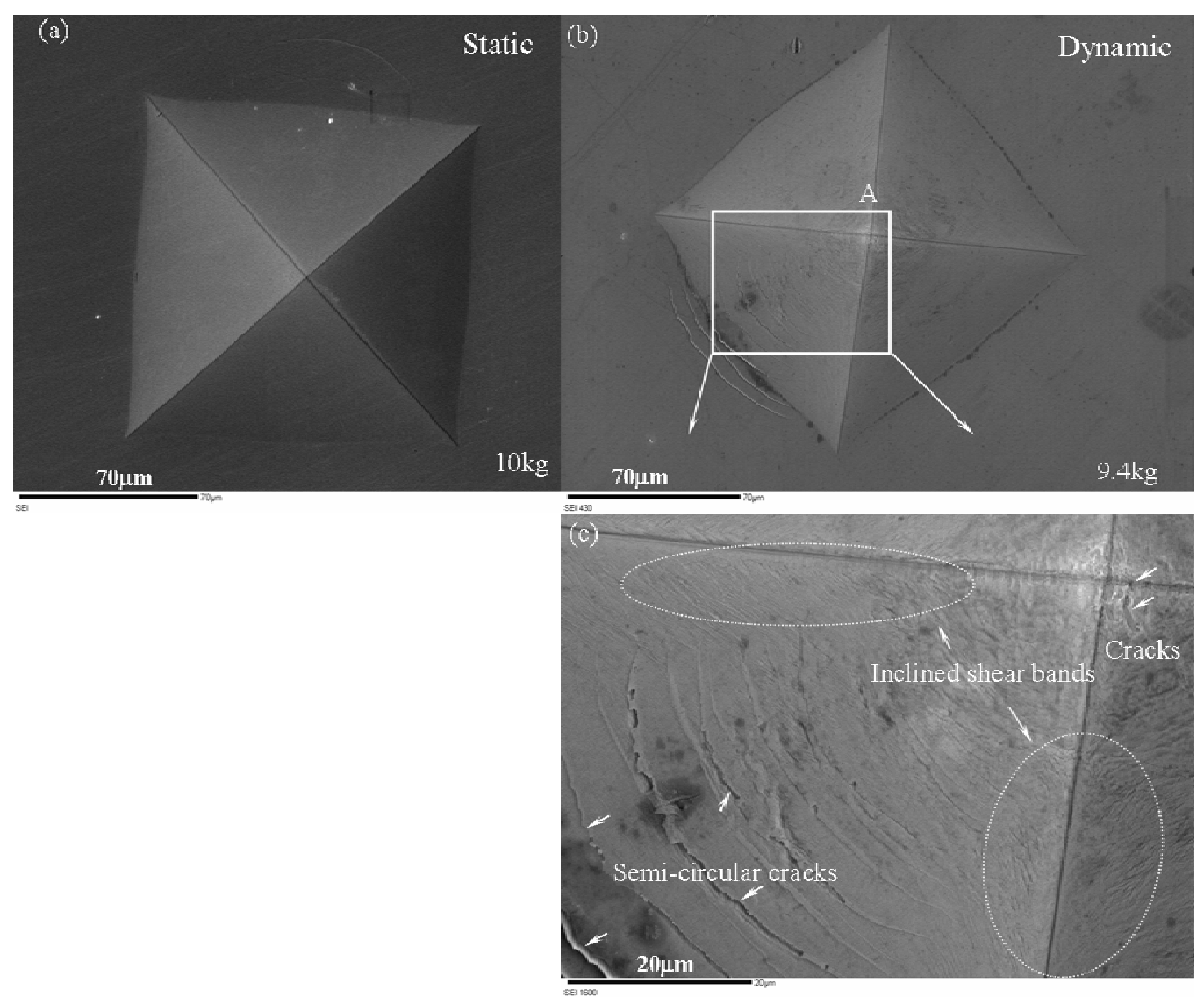

Figure 5.5. Deformation structure resulting from shear band evolution surrounding (a) static Vickers indentation, (b) dynamic Vickers indentation and (c) magnified area inside dynamic Vickers indentation

The above crack pattern in BMGs under dynamic indentations is different from the cracks that occur along the edges and corners during static and dynamic Vickers indentations on brittle materials $[18,19]$. Such cracks have been known to result in lower hardness as they accommodate larger amounts of deformation. But this is an experimental artifact because it occurs due to the geometric stress concentration 
imposed by the indenter shape. In our experiments on BMGs, cracking occurred along the circular bands on the flat surfaces of indentation where no geometric stress concentration exists. Therefore, the operating mechanism should be different as discussed in next session.

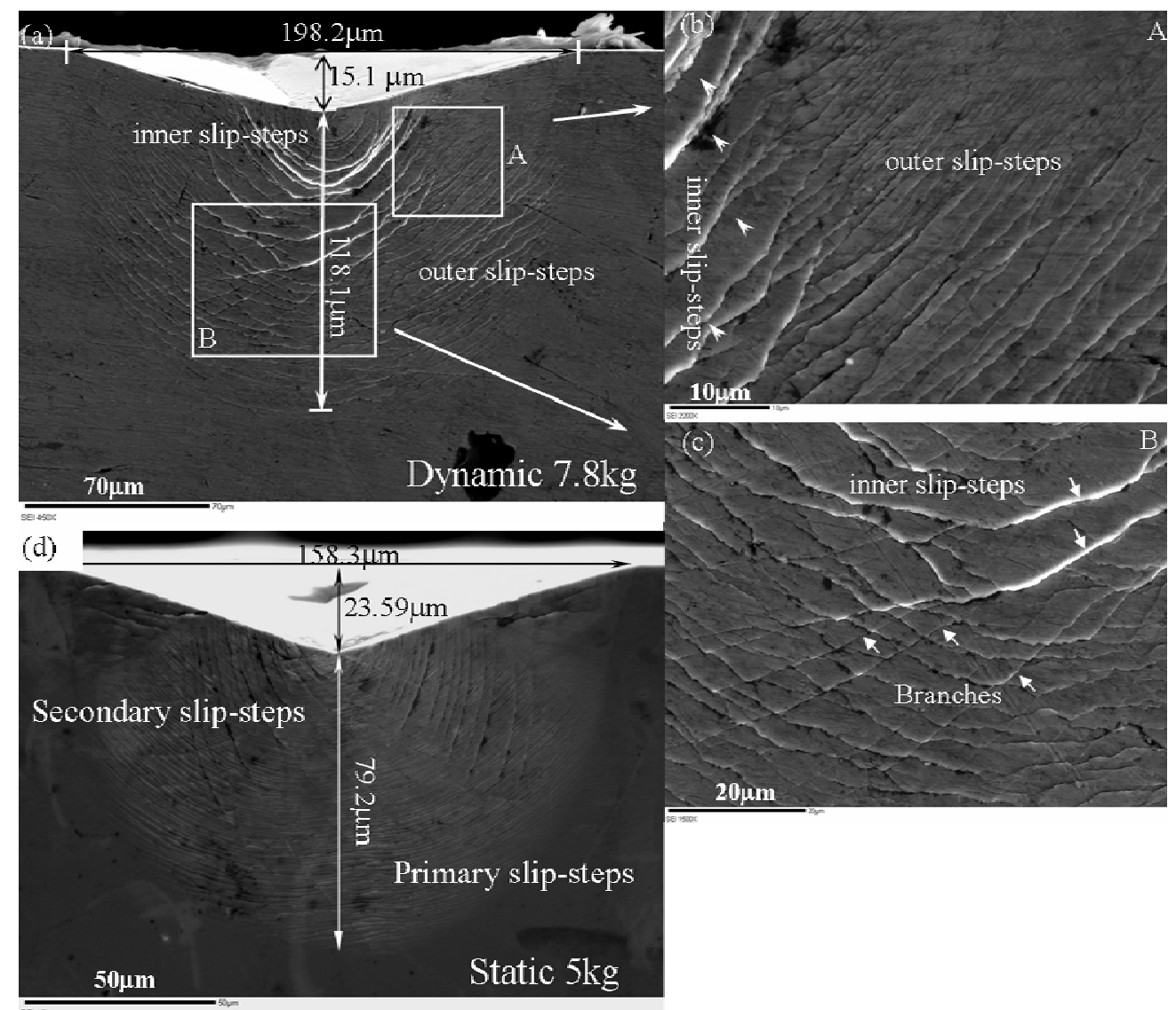

Figure 5.6. Slip step patterns using bonded specimens with the indenter diagonal aligned parallel to bonded interface: (a), (b) and (c) beneath dynamic indentation and (d) beneath static indentation.

Using the bonded split specimen, the shear band patterns beneath the indentation were studied. Two types of semi-circular slip steps of shear bands characterized by two different curvatures were observed beneath the indentation as shown in Figure 5.6. Close to the indentation tip, the slip steps of shear bands exhibited a larger curvature 
while the slip steps surrounding the above set revealed relatively a smaller curvature. The spacing for outer slip steps $d_{o}$ ranges from $\sim 400 \mathrm{~nm}$ to $\sim 3000 \mathrm{~nm}$ and the spacing for inner slip steps $d_{i}$ varies from $\sim 4000 \mathrm{~nm}$ to $\sim 10000 \mathrm{~nm}$. As a comparison, the spacing of primary shear bands, in static indentation ranges only from a few hundred nanometers to a few microns depending on the location with respect to the top surface, see in Figure 5.6(d). To further understand the evolution of these shear band patterns in dynamic indentation, a small load (1.46kg) indentation was performed with it diagonal at a slight angle $\left(\sim 5-10^{\circ}\right)$ to the bonded interface as shown in Figure 5.7. Although the overall shear band patterns are similar, some interesting features have been observed. In the left of the deformation region where the indenter edge aligned almost along the edge of the split sample, slip steps with larger curvature and spacing are seen. On the right side (where the indenter edge is farther away from the specimen edge), the slip steps with smaller curvature and narrower spacing are seen. Also note that on the left side the shear band region is bigger than on the right side. The shear bands on the left side extend almost to the top surface and those on the right do not propagate to same extent. Comparison of these features to those under static indentation reveals that the right side features (denser and smaller curvature) are similar to the primary shear bands under static indentation $[14,15]$. The stress state and the rate of deformation seem to play a significant role in formation and patterning of these shear bands as will be discussed in the next section. Recall the more severe inelastic deformation beneath dynamic indentation. The large spacing of shear bands in dynamic indentation implies that the inelastic deformation accommodated by each 
slip step is higher than in static indentation. More description is provided in the next section.

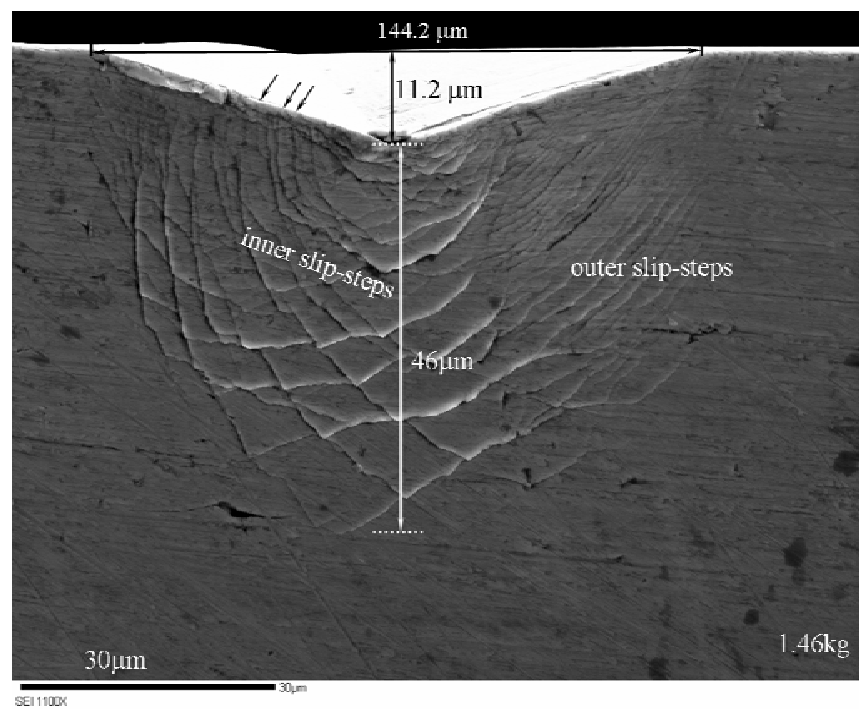

Figure 5.7. slip step patterns beneath a dynamic indentation when the indenter diagonal was aligned at a small angle $\left(5^{\sim 10}\right)$ to the bonding interface.

\subsection{Discussion}

Generally, the negative rate sensitivity of strength (hardness) indicates softening of material during high rate deformation. The observed softening and the differences in patterning of shear bands under dynamic indentations compared to static indentations may imply that (i) the evolution of shear band structure is rate-dependent and (ii) the dynamic indentations cause much more severe local plastic deformation than in static indentation. These arguments are substantiated by the evidence of multiple severe deformation features in dynamic indentations such as coin-like cracks near the apex of the indentation, short parallel set of shear bands near the inner edges of the indentation imprint and finally circular shear bands and cracks (Figure 5.5(c)) on the facets of the indentations. The larger spacing of shear bands at equivalent loads in 
dynamic indentations also implies that greater strain intensity is accommodated in each shear band than in the shear bands formed under static indentations.

The observed softening in hardness under dynamic loads can be rationalized based on the arguments provided by Mukai et al. [8], Li et al [11] and Hufnagel et al [9]. From compression tests on $\mathrm{Pd}_{40} \mathrm{Ni}_{40} \mathrm{P}_{20}$, Mukai et al [8] observed that shear bands initiated in elastic regime even at stress levels $\sim 20 \%$ below the macroscopic yield stress. Li et al [11] had argued that the negative rate sensitivity of the fracture strength for ZrHf-based BMGs in their dynamic compression might be attributed to the nucleation of cracking immediately following the shear band initiation. Hufnagel et al argued that the adiabatic component during dynamic deformation would contribute to the negative strain rate sensitivity. This idea may also be extended to rationalize the negative rate sensitivity of indentation hardness as follows. Unlike conventional uniaxial testing, a major characteristic of indentation is that deformation region is confined beneath a rigid indenter. Lateral confinement in quasi-static compression on Vitreloy-1 has been noted to delay the initiation of cracking and promote plastic deformation in the form of shear band formation [21]. In the present study, multiple shear bands have been observed in both static and dynamic indentations. However, during a static indentation, the slow rise of stress with indentation depth allows sufficient time for shear bands to initiate and grow to mature successively so as to form these shear bands in progression at distances farther away from the tip of indentation. This results in a dense pattern of shear bands with narrow spacing and the applied strain is fully accommodated by this mode of deformation, see Figure 5.6 (d). 
On the other hand, due to short duration of loading during the dynamic indentation, shear bands do not have sufficient time to grow to maturity and cracking could initiate immediately to accommodate the high rate of energy input. The observation that inner slip steps propagate onto the top surface and the significant shear opening of semicircular cracks on the top facets of indentations indicate that higher strain intensity is accommodated by these slip steps (and cracks) than that accommodated in the shear bands formed in static indentations. The rapid evolution of slip steps and cracks relax the local strain intensity in the adjacent region. Consequently, the spacing between the shear bands tends to be larger in dynamic indentations than in static indentation. The cracking also leads to softening of the material and subsequent reduction in hardness under dynamic loading.

Contribution from adiabatic component during high strain rate loading may also play an important role in this softening phenomenon. Local heating and melting of Tin coating on the surface of bent samples of BMGs, reported by Lewandowski and Greer [22], indicate a significant temperature rise during shear bands evolution. Light emission during quasi-static and dynamic compression tests also provides clear evidence for intense local heating or even melting due to shear band propagation and the subsequent catastrophic specimen failure [8, 9, 11]. The concentrated deformation beneath the indentation under a high rate of input energy during dynamic loading can promote softening due to adiabatic heating effects. As is well known, significant localized heating from adiabatic deformation can decrease the viscosity and increase the ability of material to flow. This will soften the material within and adjacent to the 
slip steps and accommodate higher plastic deformation during their evolution. Consequently, a lower density of slip steps (wider spacing) has been observed beneath the dynamic indentations.

Recall that there are two sets of shear bands with different curvatures beneath the dynamic indentations. The inner set of shear bands has larger spacing and larger curvature than outer set of shear bands. The non-uniform spatial distribution and temporal evolution of shear bands is attributed to the spatial and temporal variations in strain rate and stress intensity beneath a Vickers indentation. During the early phase of dynamic indentation, the sharp indenter tip penetrates a flat specimen surface at a high velocity and the indenter velocity decreases with distance as the depth of indentation increases. Consequently, the specimen experiences a higher stress concentration and a higher strain rate deformation locally around the tip region in the beginning. The magnitude of stress diminishes with distance from the tip. Furthermore, the region close to the indentation tip experiences a higher confinement pressure compared to the region farther away because of its contact with the rigid indenter on the top surface. It is now well recognized that the plastic deformation in BMGs (i.e., shear band initiation and growth) is strongly influenced by the confining pressure [21]. The region closer to the tip is surrounded by the rigid indenter on the top and the elastic bulk solid on the other sides. Thus this region experiences higher strain rate, higher stress intensity and higher confinement during the early stages of the indentation process compared to the region farther away from the indenter tip. As the depth of indentation increases, the overall strain rate decreases due to a decrease 
in the indenter velocity as the material volume resisting the indenter increases. At distance farther away from the indentation tip, the confinement pressure also decreases because this far-away region is now confined by the previously dynamically deformed region (which is more compliant than the rigid indenter) and the outer elastically stressed bulk solid. This combined effect of lower confinement stress and lower strain intensity at lower strain rate results in shear band spacing to be reduced compared to the inner region. As the strain rate decreases to zero toward the end of loading phase, the spacing becomes smaller and may even get closer to the spacing observed in the static indentation as reported in [15], which is similar to the outer set of shear bands in dynamic indentation. Thus, the inner set of shear band with larger spacing evolve first during the early phase of indentation and the outer set of shear bands with smaller spacing evolves later at the end of loading phase of indentation.

More in-depth modeling studied on the evolution of shear band spacing and the associated adiabatic heating in a shear band as a function of confinement pressure, shear displacement and strain rate will be presented in Chapter 6 .

\subsection{Conclusions}

A significant softening in indentation hardness is observed under dynamic loads compared to static indentations in three BMGs. At higher strain rates the rapid input of energy leads to more severe local strain intensities leading to nucleation of cracking immediately following the shear band initiation which in turn causes the observed softening of indentation hardness. 
The structural differences in the shear band patterns under static and dynamic indentations are attributed to the differences in the stress state, local strain rate and temperature rise during the deformation. The wider spacing in the inner shear bands (closer to indenter tip) of dynamic indentations are rationalized based on the higher confinement pressure and higher strain intensity in this region compared to those existing in the regions farther away from the indenter tip.

\section{References}

1. Clifton RJ, J Applied Mechanics, 1983;50:941

2. Subhash G., JOM, 1995;47:55-58

3. Lankford J., J. the American Ceramic Society, 1981;64:33

4. Ravichandran G., Subhash G., International J. Solid Structures, 1995;32:2627

5. $\quad$ Bruck H.A., Rosakis A.J., Johnson W.L., J Mater Res, 1996;11:503

6. Subhash G., Dowding R., Kecskes L., Mater Sci Eng, 2002;A334:33

7. Lu J., Ravichandran G., Johnson W.L., Acta Mater, 2003;51:3429

8. Mukai T., Nieh T.G., Kawamura Y., Inoue A., Higashi K., Intermetallics, 2002;10:3429

9. Hufnagel T.C., Jiao T., Li Y., Xing L.Q., Ramesh K.T., J Mater Res, 2002:17:1441

10. Gu X., Jiao T., Kecskes L.J., Woodman R.H., Fan C., Ramesh K.T., Hufnagel T.C., J non-cryst Solids, 2003;317:112

11. Li H., Subhash G., Gao X.L., Kecskes L.J., Dowding R.J., Script mater, 2003;49:1087

12. Jana S., Ramamurty U., Chattopadhyay K., Kawamura Y., Mater Sci. \& Eng. A, 2004;375-377:1191

13. Jana S., Bhowmick R., Kawamura Y., Chattopadhyay K., Ramamurty U., Intermetallics, 2004;12:1097

14. Ramamurty U., Jana S., Kawamura Y., Chattopadhyay K., Acta Mater., 2005:53:705

15. Zhang H.W., Jing X.N., Subhash G., Kecskes L.J., Dowding R.J. , 2005;53:3849

16. Nemat-Nasser S., Isaac J.B., Starrett J.E., Proc. R. Soc. (London), 1991:A435:371 
17. Subhash G., Koeppel B.J., Chandra A., J Eng Mater Technol. (Trans ASME), 1999;121:257

18. Anton R.J., Subhash G., Wear, 2000;239:27

19. Subhash G., ASM Handbook, 1999;8:519

20. Koeppel B.J., Ph.D. dissertation, Michigan Technological University, Houghton, MI, 1997

21. Lu J. PhD Thesis, California Institute of Technology, Pasadena, CA, 2002

22. Lewandowski J.J., Greer A.L., Nature mater., 2006;5:15 


\section{Chapter 6. Theoretical Investigation of Dynamic Response and Shear Bands Evolution in ZrHf-based BMGs}

\subsection{Introduction}

Plastic flow behavior in BMGs is highly inhomogeneous at ambient temperature and such intense localized deformation in the form of shear bands is primarily attributed to a local decrease in viscosity [1]. Free volume model [2-4] and adiabatic heating model [5] are two widely used mechanisms to account for such decrease in viscosity during deformation. Spaepen [2] argued that the formation of free volume is the dominant reason for the decrease in viscosity and the attendant inhomogeneous flow is controlled by the competition between the stress-driven creation and diffusional annihilation of free volume. During the later stage of deformation, significant local adiabatic heating [5] induced by rapid strain localization may cause additional decrease in viscosity. Direct and indirect temperature measurements do verify the temperature rise up to or even above the melting temperatures of BMGs [6-11]. Although numerous efforts have been focused on understanding the underlying deformation mechanisms in BMGs, quantitative depiction of shear band evolution including shear band spacing and shear band patterning under various loading scenarios is yet to be fully analyzed.

Recently, a few computational studies have appeared in the literature on the evolution of shear bands in BMGs [12-14]. A finite deformation numerical model incorporating the influence of viscosity and equilibrium free-volume concentration has been 
reported by Yang et al., [14]. This model suggests that the shear band spacing in plate-bending specimens is controlled by stress relaxation in the vicinity of the shear bands. Experimental observations and modeling efforts described above have motivated to conduct a mechanistic study on the shear band evolution, shear band spacing and attendant thermal effects in BMGs. As discussed in Chapter 5, of special interest are the effects of strain rate, confinement pressure, shear displacement accommodated in shear band and attendant temperature rise on the final spacing of the shear bands. The basis of the current model is a momentum diffusion mechanism in an idealized rigid-plastic body which accommodates shear deformation. This model was originally described by Mott [15] and later extended by Grady and Kipp [16,17] for dynamic fragmentation of brittle solids. In the following, a mechanistic model for shear band formation based on momentum diffusion is provided and the influences of strain rate $\dot{\gamma}$, resolved shear stress and normal stress on the shear band evolution and the resulting temperature rise within the shear bands are analyzed.

\subsection{Analytical model for dynamic shear band evolution}

The shear band evolution in metals under dynamic loading environments is generally modeled using two different approaches: one pioneered by Mott [15] and later modified by Grady and Kipp [16.17], and another by Wright and Ockendon [18] and subsequently used by Molinari [19]. In the first approach, momentum diffusion in the layers adjacent to a shear band is assumed to be the governing mechanism for the shear band evolution and the final shear band spacing is controlled by the stress relaxation in the vicinity of the shear bands. The second approach postulates that 

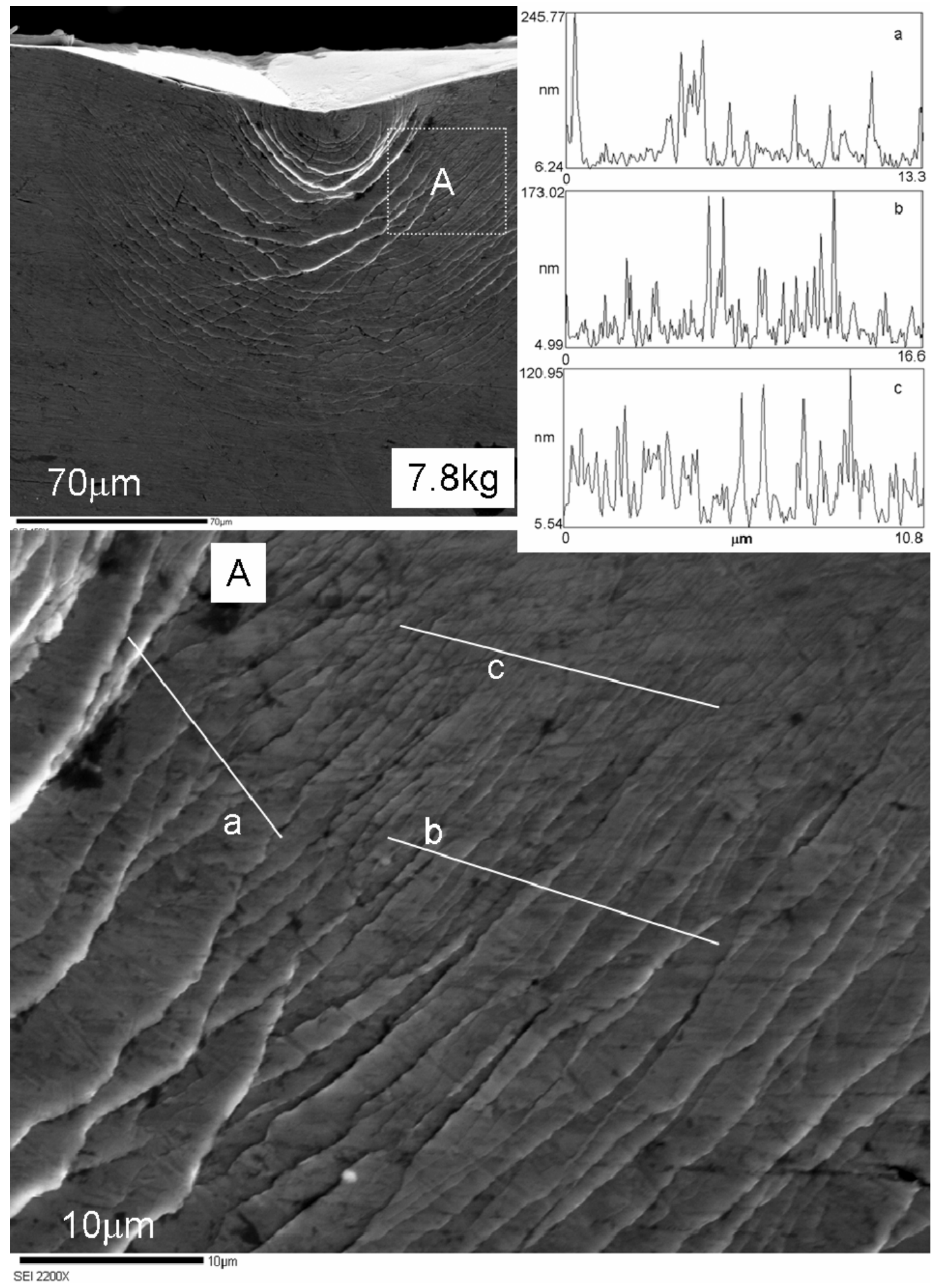

Figure 6.1. Typical shear band pattern beneath a dynamic Vickers indentation and topographic scans along lines 'a', 'b' and ' $c$ '.

dynamic shear band evolution occurs by an unstable growth of perturbations in an otherwise uniform thermal and mechanical stress field; local fluctuations in 
temperature and stress cause the initiation and subsequent growth of shear bands. Meyers et al., [20] remarked that the second approach provides a good description for shear band initiation, while the model by Grady and Kipp [16,17] better describes the shear band evolution at a later stage of growth. In addition, computational analysis by Yang et al., [14] has suggested that shear band spacing in plate-bending specimens is controlled by the stress relaxation in the vicinity of the shear bands, which agrees well with the assumption in the first approach described above [16,17]. Moreover, the current investigation is focused on the final morphology of shear band patterns as shown in Figurer 6.1. Thus, the momentum diffusion approach in terms of momentum and energy balance equations has been utilized to develop a mathematical description of shear band formation. Thermal effects including temperature rise in shear band and thermal softening of flow stress have also been considered in the current model.

On the basis of numerous experimental observations [21-26], it is now well accepted that most of the BMGs are pressure sensitive, which indicates that the deformation behavior of BMGs depends not only on the resolved shear stress acting along the slip plane but also on the normal pressure on the slip plane. As mentioned earlier, in dynamic indentations the deformation is confined in a small region and therefore, higher confinement pressure in the vicinity of the indenter and the non-uniform distribution of the loading pressure beneath the indentation could play important roles in the shear band spacing and the resulting shear band pattern, see Figure 6.1. For simplicity, the confinement in the current model is considered in the form of an applied normal pressure across the shear band as shown Figure 6.2. The normal stress 


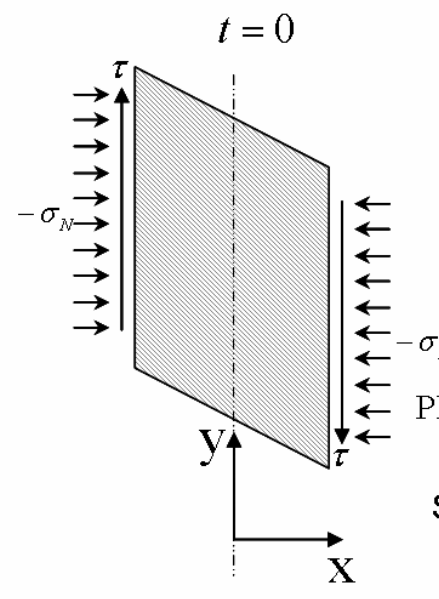

(a)

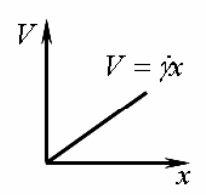

(b)

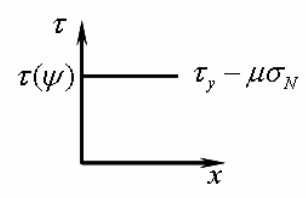

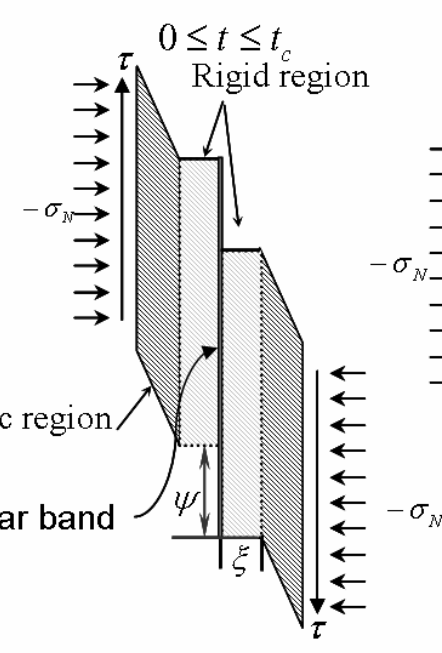
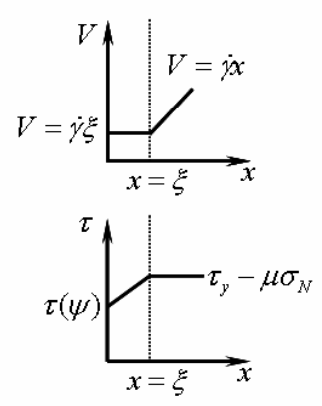

$$
t=t_{c}
$$
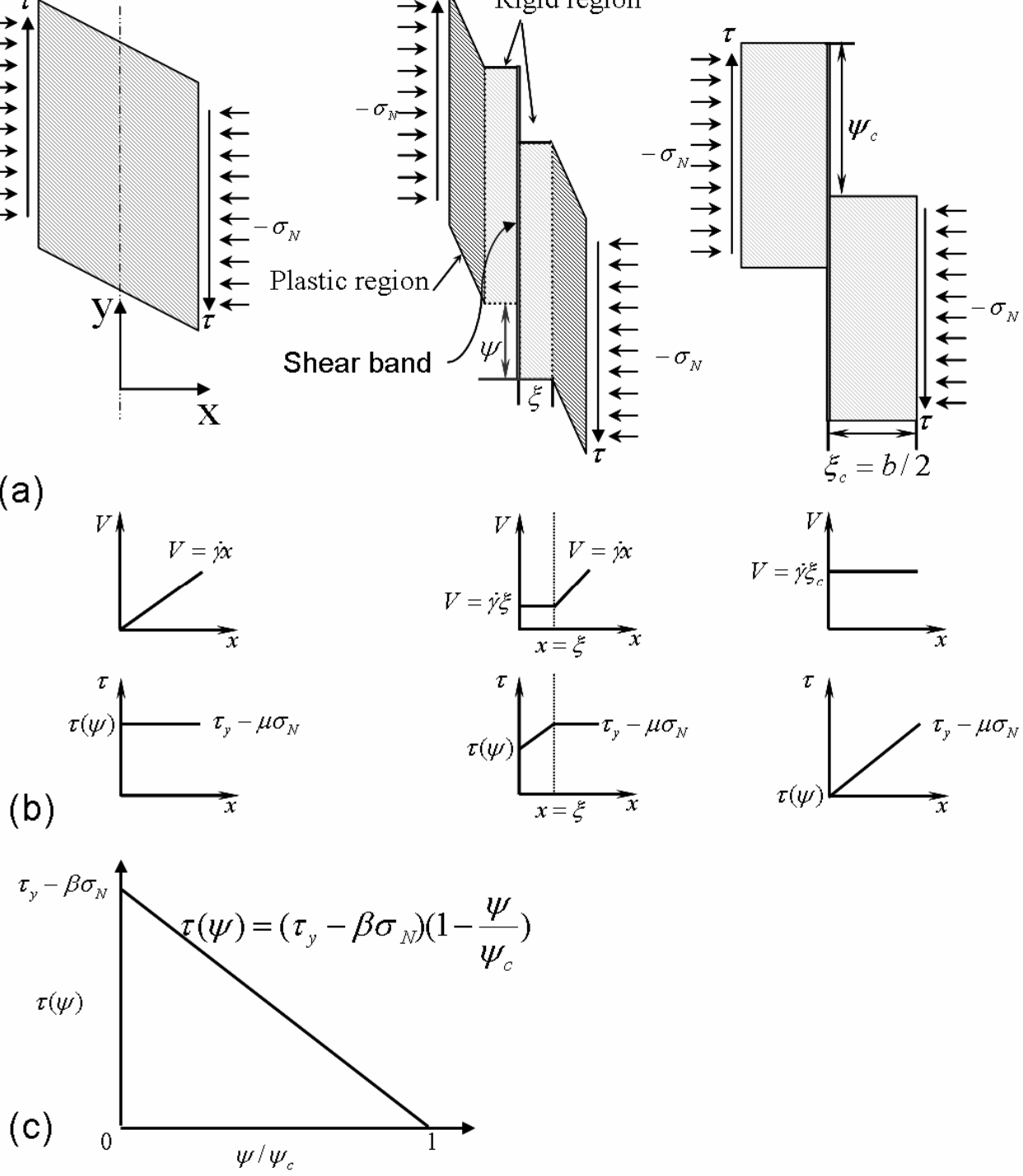

Figure 6.2.(a) Schematic of shear band evolution model, (b) corresponding velocity and stress fields and (c) linear shear stress relaxation model during shear band evolution.

in the direction of the slip plane has been assumed to play no role in the shear band evolution. The non-uniform distribution of stress causes non-uniform local strain beneath an indentation and thus different shear displacements accommodated through shear band evolution in different areas are considered to account for this uneven 
distribution. It is assumed that a critical shear displacement is required to create a shear band, and additional shear displacement may initiate fracture of the material along these planes. In current study, any specific mechanism for shear band nucleation is not considered, rather the process of shear band evolution until it matures, i.e., attains the critical shear displacement, is focused. As a consequence, the attentions are focused only to a small portion of the material beneath the indenter containing only one slip plane. Due to an emphasis on dynamic loading and subsequent shear band formation, shear strain rates in excess of 1000/s are considered in this study.

Figure 6.2 (a) reveals a schematic of the shear band evolution through momentum diffusion mechanism in a rigid ideal-plastic material. High shear deformation is accommodated in the control volume through a localization procedure initiating a shear band along the localization plane (slip plane). The material in the vicinity of the slip plane unloads as momentum diffuses from this plane, and finally the whole domain relaxes and moves as two rigid blocks when the shear band formation is complete (mature). Stress state and velocity profile in the control volume during the evolution of shear bands is presented in Figure 3(b). The shear band initiates along the slip plane $x=0$ at time $t=0$. The material initially undergoes a uniform shear deformation $\psi$ in $y$ direction at a given shear strain rate $\dot{\gamma}$ under the imposed normal pressure of $\sigma_{N}$ and resolved shear stress $\tau$ acting on the shear band. After shear band initiation, shear stress inside the shear band relaxes gradually and the material unloads on both sides to a rigid region of the size of $x= \pm \xi$ at time $t$ while at regions $x>\xi$ and/or $x<-\xi$ it still remains plastic. Note that it is 
disregard that any structural evolution within the shear band which may influence the retardation of shear band evolution. For simplicity, zero thickness of shear band is assumed throughout the analysis and therefore, the shear band always resides at $x=0$. Unlike Grady and Kipp's Model where plastic flow is dependent only on applied shear, in current model a Mohr-Coulomb type relationship is assumed to account for the pressure sensitivity of BMGs. Flow stress $\tau_{y}$ is related to the normal stress $\sigma_{N}$ acting on the shear band through a proportional constant $\beta$, similar to the friction coefficient and varying between zero and one, with a value of zero indicating the absence of pressure sensitivity. Therefore, flow stress is given by

$\tau_{y}=\tau+\beta \sigma_{N}$

In the above relation, positive sign of $\sigma_{N}$ denotes tensile state of stress while negative sign indicates compressive stress. It should be noted here that the second term on the right hand side has an effect of resisting shear deformation along the slip plane, and consequently, increasing the resistance against material flow along these planes. An equation similar in form to Eq (6.1) has been suggested by various authors, where the second term has been identified as viscous stress [14] or a critical stress for the onset of inelasticity $[27,28]$. Different functional relationships can be incorporated in the definition of $\beta$ to examine the effect of various parameters such as temperature, viscosity, and free volume on flow resistance. However, the authors will treat $\beta$ as a constant and use a widely accepted value of $\beta=0.1[25,26]$. Also note that the proposed model does not include the effect of tensile normal stress on a slip plane, and consequently $\beta$ is taken to be zero whenever $\sigma_{N}$ becomes tensile. 
The velocity inside the rigid region (only the right half side $0 \leq x \leq \xi$ is considered because of the symmetry) is assumed to be uniform and can be expressed as $V=\dot{\gamma} \xi$ where $\xi$ is the distance from the shear band center to the boundary of the rigid region as shown in Figure 6.2(b). The rigid region expands to either side of the slip plane. When the shear stress $\tau(\psi)$ at the shear band vanishes (or shear displacement reaches the critical value $\psi_{c}$ ), the shear band is considered to be fully matured.

It is assumed that the relaxation of the resolved shear stress along the slip plane is not instantaneous but takes a finite amount of time. It is further assumed that this stress relaxation is related to the shear displacement $\psi$ with a softening law $[16,17]$ expending a finite amount of energy in the process. For simplicity, a linear relationship for the release of shear stress with increasing shear displacement has been assumed (Figure 6.2(c)), namely

$$
\tau(\psi)=\left(\tau_{y}-\beta \sigma_{N}\right)\left(1-\frac{\psi}{\psi_{c}}\right) \quad 0 \leq \psi \leq \psi_{c}
$$

The momentum of the rigid body per unit area corresponding to the time at which the rigid-plastic interface is at a position $\xi$ is written as

$$
p_{y}=\rho \dot{\gamma} \xi^{2}+\int_{\xi}^{\infty} \rho \dot{\gamma} x d x
$$

where $\rho$ is the density of the material. The equation of motion for the rigid region can be obtained by equating the time rate of momentum in Eq.(6.3) to the misbalance of the shear stress from Eq.(6.1) as

$\rho \dot{\gamma} \xi \dot{\xi}=\tau_{y}-\left(\tau(\psi)+\beta \sigma_{N}\right)$ 
As noted earlier, the velocity is assumed to be uniform and equal to $V=\dot{\gamma} \xi$ in the rigid region $0 \leq x \leq \xi$, and accordingly shear displacement in the shear band at $x=0$ is given by

$\psi=\int_{0}^{t} \dot{\gamma} \xi d t$

Combining Eqs.(6.3), (6.4) and (6.5) results in a system of ordinary differential equations,

$\dot{\xi}=\frac{d \xi}{d t}=\frac{\left(\tau_{y}-\beta \sigma_{N}\right)}{\rho \dot{\gamma} \xi} \frac{\psi}{\psi_{c}}$

and

$\dot{\psi}=\frac{d \psi}{d t}=\dot{\gamma} \xi$

From Eqs.(6.6) and (6.7), $\psi$ and $\xi$ can be related as

$\frac{d \xi}{d \psi}=\frac{\left(\tau_{y}-\beta \sigma_{N}\right)}{\rho \dot{\gamma}^{2} \xi^{2}} \frac{\psi}{\psi_{c}}$

Solving the above first order differential equation with initial conditions $\xi(0)=\psi(0)=0$ provides

$\xi^{3}=\frac{3}{2} \frac{\left(\tau_{y}-\beta \sigma_{N}\right)}{\rho \dot{\gamma}^{2} \psi_{c}} \psi^{2}$

So expressions for $\psi$ and $\xi$ can be obtained from Eq.(6.9) and Eq.(6.7) respectively as

$\psi=\frac{1}{18} \frac{\dot{\gamma}\left(\tau_{y}-\beta \sigma_{N}\right)}{\rho \psi_{c}} t^{3}$ 
$\xi=\frac{1}{6} \frac{\left(\tau_{y}-\beta \sigma_{N}\right)}{\rho \psi_{c}} t^{2}$

When the shear displacement reaches the maximum, i.e. $\psi=\psi_{c}$, the critical time $t_{c}$ can be derived from Eq.(6.10-1) as

$t_{c}=\left(\frac{18 \rho \psi_{c}^{2}}{\left(\tau_{y}-\beta \sigma_{N}\right) \dot{\gamma}}\right)^{1 / 3}$

At the critical time $t_{c}$, shear band is fully formed and the momentum would have diffused to a distance of $\xi_{c}$. Considering symmetry and no interaction between adjacent shear bands, twice this distance $\xi_{c}$ will be the minimum separation (shear band spacing) between adjacent shear bands and can be determined from Eqs. (6.10-2) and (6.11) as

$b=\left[\frac{12 \psi_{c}}{\rho \dot{\gamma}^{2}}\left(\tau_{y}-\beta \sigma_{N}\right)\right]^{1 / 3}$

Examination of Eqs. (6.10-1), (6.11) and (6.12) reveals that the shear band evolution and its final spacing are nonlinearly dependent upon shear strain rate, critical shear displacement, normal confining pressure and flow stress of the material. However, heat generation due to energy dissipation in the shear band, attendant temperature field in the surrounding medium and its effect on the shear band evolution have not been considered yet. Considering that a portion of the plastic work done inside the shear band is converted to heat, time rate of heat generation $\dot{q}$ can be related to the rate of plastic work as

$\dot{q}=\lambda \cdot \tau(\psi) \cdot \dot{\psi}$ 
with $\lambda$ as the fraction of plastic work converted into heat (typically it is assumed to be $0.9 \sim 1$ and a value of unity is used in the following analysis). The generated heat can be diffused to the surrounding material by the process of conduction giving rise to a temperature rise in the vicinity of the shear band. As is well known, yield strength of the BMGs depend strongly on the ambient temperature: when ambient temperature approaches the glass transition temperature $T_{g}$, yield strength of BMGs decreases sharply due to a dramatic decrease in the viscosity. So the authors are left with a fully coupled thermo-mechanical problem to study the effect of thermal transients on the shear band evolution. Towards this end, the temperature and strain rate dependence of the shear strength of the material have to be considered. Employing the conventional definition of viscosity under shear deformation, the shear strength (flow stress) can be written as (Steif et al., 1982)

$\tau_{y}=\eta \cdot \dot{\gamma}^{p}$

where $\eta$ is the viscosity and $\dot{\gamma}^{p}$ the effective plastic shear strain rate (nominal strain rate of macroscopic deformation). Based on experimental data for a Zr-based BMG at various temperatures and strain rates [29], a phenomenological viscosity law, which fits well the transition from steady state Newtonian flow to non-Newtonian flow, has been proposed by Johnson et al., [30] in the form of

$$
\eta=\frac{\eta_{o}}{D(\dot{\gamma}, T)} \exp \left(\frac{\vartheta}{\varsigma_{T}}\right)
$$

with $\eta_{o}$ as the viscosity of the liquid in the high temperature 'gas' limit while $\vartheta$ is a geometrical factor of the order of unity. The Cohen-Grest (CG) temperature-dependent free volume concentration $\varsigma_{T}[14,31,32]$ can be determined 
by

$\varsigma_{T}=\frac{1}{2 d_{1}}\left[T-T_{\text {ref }}+\sqrt{\left(T-T_{\text {ref }}\right)^{2}+d_{2} T}\right]$

where $d_{1}, d_{2}$ and $T_{\text {ref }}$ are material parameters. In the current analysis, the reference temperature $T_{\text {ref }}$ is set as the glass transition temperature. A dramatic decrease in viscosity can be observed when approaching the glass transition temperature as will be discussed in Section 6.3. In addition, $D(\dot{\gamma}, T)=1+\exp \left(\frac{\vartheta}{\varsigma_{T}}\right)\left(\frac{\eta_{0} \dot{\gamma}^{p}}{\tau_{y 0}}\right)^{b(T)}$ in which $\tau_{y 0}$ is the shear yield stress at room temperature and $b(T)=1.0-\vartheta_{\eta}\left(T-T_{0}\right)^{3}$ with $\vartheta_{\eta}=4.325 \cdot 10^{-10} \mathrm{~K}^{-3}$ and $T_{0}=298 \mathrm{~K}$.

Finally, the evolution of temperature in the core as well as in the vicinity of the shear band is governed by the heat transfer equation:

$$
\frac{\partial T}{\partial t}=\alpha \frac{\partial^{2} T}{\partial x^{2}}+\frac{\dot{q}}{\rho \cdot c}
$$

Where $\alpha, c$ and $\dot{q}$ are the thermal conductivity, the heat capacity and the rate of heat generation, respectively. A semi-analytical solution strategy has been devised for Eq (6.13-6.17) and the results are discussed in the next section.

\subsection{Results and discussion}

Utilizing the above theoretical framework, a parametric study of the relevant variables in shear band evolution is presented with and without consideration of the thermal effects. The final shear band spacing and its dependence on various material parameters and loading environments are discussed first. Time evolution of the shear 
band is considered next, followed by a discussion on the thermal transient problem involving heat generation and temperature rise. Material properties of Zr-based BMG and parameters used in the current investigation have been adopted from elsewhere $[10,14,30,32-26]$ and are listed in Table 6.1. Critical shear displacement $\psi_{c}$ accommodated in a shear band is difficult to determine precisely as it varies with the loading conditions during tests. Tensile tests by Yang et al., [37] revealed a shear displacement up to 500nm, while the authors observed a shear displacement beyond $10 \mu \mathrm{m}$ in quasi-static compressive tests [38]. In nano-indentation tests, Kim et al., [39] suggested a shear displacement of $2 \mathrm{~nm}$. As a parametric investigation, the authors vary this parameter between $100 \mathrm{~nm}$ to $5 \mu \mathrm{m}$ which is expected to encompass various scenarios from nano-indentation to high strain rate indentation tests.

Table 6.1. Properties and parameters employed in numerical analysis

\begin{tabular}{ll}
\hline Thermal conductivity $\alpha$ & $3 \times 10^{-6} \mathrm{~m}^{2} \cdot \mathrm{s}^{-1}$ \\
Heat capacity $c$ & $400 \mathrm{~J} \cdot \mathrm{kg} \cdot \mathrm{K}^{-1}$ \\
Viscosity of liquid $\eta_{\mathrm{o}}$ & $4 \times 10^{-5} \mathrm{~Pa} \cdot \mathrm{s}$ \\
Geometrical parameters $\vartheta$ & 0.105 \\
Materials parameters $d_{1}$ & $46981 \mathrm{~K}$ \\
Materials parameters $d_{2}$ & $162 \mathrm{~K}$ \\
Materials parameters $T_{r e f}$ & $673 \mathrm{~K}$ \\
Converting fraction $\lambda$ & 1 \\
Density $\rho$ & $6640 \mathrm{~kg} / \mathrm{m}^{3}$ \\
Shear strength & $1.0 \mathrm{GPa}$ \\
proportionality coefficient $\beta$ & 0.1 \\
\hline
\end{tabular}

The macroscopic strain rate $\dot{\gamma}^{p}$ above $1000 / \mathrm{s}$ is common in dynamic indentations [40]. However, the local strain rate within shear band is not easy to determine precisely although it has been recognized to be much higher than the macroscopic value. Wright et al., [11] observed the displacement velocity of $9.5 \times 10^{-5} \mathrm{~m} / \mathrm{s}$ in a single serration during a quasi-static compression (macroscopic strain rate of $\dot{\varepsilon}=10^{-4} / \mathrm{s}$ ). Assuming 
the typical thickness of shear band to be around 20nm [41], the local shear strain rate $\dot{\gamma}$ could be as high as 5000/s even for a quasi-static test. Supposing the strain accommodated by a shear band is $100 \mathrm{~m} / \mathrm{m}$ and the total loading duration is $100 \mu$ s in a typical dynamic indentation [42], the strain rate can be as high as $10^{6} / \mathrm{s}$. This is still underestimated because the actual duration for a shear band evolution in dynamic tests would be much shorter than the total loading duration. Thus, local shear strain rate varying from $10^{3} / \mathrm{s}$ to $10^{9} / \mathrm{s}$ have been used in the current study which is expected to encompass the macroscopic loading rates ranging from quasi-static to dynamic cases.

It is also noted that the normal pressure (confining stress component) on the shear bands play a pronounced role on shear band spacing as shown in Eq (6.12). Considering the self confinement from surrounding material and the rigid Vickers diamond indenter on the top, the normal pressure acting on the region containing the shear bands beneath the indenter can be very high. Consequently, a parametric study with normal pressure values of 0,5 and 10GPa corresponding to deformation under pure shear to the highly confined deformation right beneath the indenter has been undertaken.

\subsubsection{Shear band spacing}

To facilitate the comparison between the modeling results and the observations, a brief description emphasized on the morphology of shear band spacing shown in Figure 6.1 is presented first. Semi-circular slip steps of shear bands characterized by different curvatures and spacing were observed beneath the indentation. Close to the 
indenter tip, the slip steps exhibit a larger curvature and wider spacing while the outer slip steps surrounding the inner ones revealed a relatively smaller curvature and finer spacing. It is noted that the spacing between neighboring slip steps is not uniform for either the inner slip steps or for the outer slip steps. The spacing is smaller in the region close to the top surface (away from the indenter tip) and is larger right below the indentation tip. The spacing of outer slip steps $d_{\text {os }}$ ranges from $\sim 0.4 \mu \mathrm{m}$ to $\sim 3 \mu \mathrm{m}$ while the spacing for inner slip steps $d_{\text {is }}$ varies from $\sim 3 \mu \mathrm{m}$ to $\sim 10 \mu \mathrm{m}$. Topological scans along three lines shown in Figure 6.1 clearly capture not only the out-of-plane shear displacement in each shear band, but also the shear band spacing between the neighboring shear bands. Both the vertical shear displacement and the spacing gradually decrease from region 'a' to 'b' and then to 'c'.

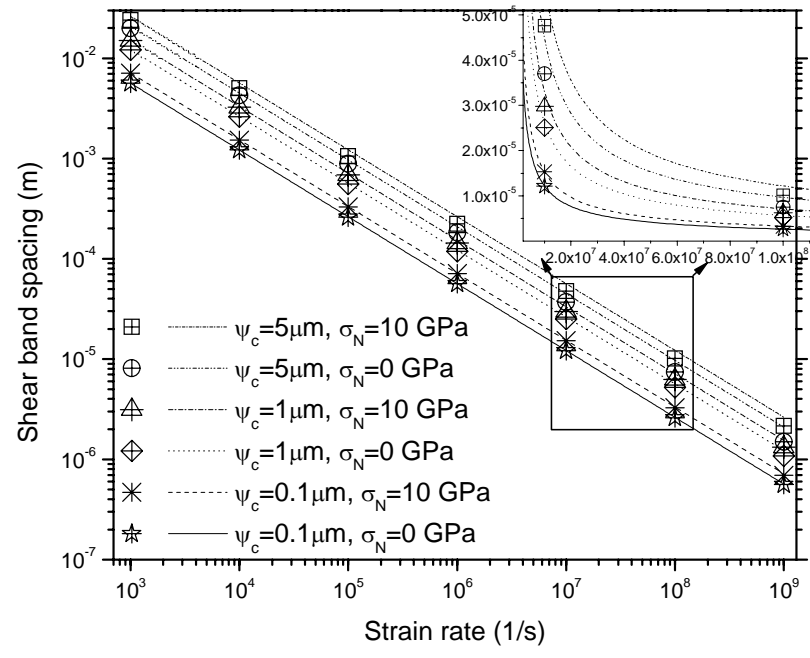

Figure 6.3. Dependence of shear band spacing on strain rate, critical shear displacement and normal stress. An expanded view of portion of the curve is provided on a linear scale in the inset.

Figure 6.3 reveals a log-log plot of variation of the minimum shear band spacing with 
strain rate, normal stress and critical shear displacement. In this figure, the results considering the thermal effects are shown as separated symbols (obtained from Eq.(6.12)-(6.17)) while the continuous lines denote the results without consideration of thermal effects (from Eq.(6.12)). Although both results appear to be the same on this log-log plot, the difference is indeed significant especially for high confinement and/or large critical shear displacement as shown in the expanded inset. It is observed that the minimum shear band spacing decreases with (i) increasing strain rate in this strain rate regime, (ii) decreasing shear displacement and (iii) decreasing normal pressure. Increasing local shear strain rate from $10^{3} / \mathrm{s}$ to $10^{9} / \mathrm{s}$ leads to a significant decrease in the shear band spacing by an order of $\sim 10^{4} \mathrm{~m}$. It is noted that under high strain rate $\left(\dot{\gamma} \geq 10^{8} / \mathrm{s}\right.$ ), the shear band spacing is in the range of around $0.5 \mu \mathrm{m}$ to $10 \mu \mathrm{m}$ depending on the magnitude of normal pressure and critical shear displacement. Recall the experimental observations in Figure 6.1 of wider shear band spacing $(3 \sim 10 \mu \mathrm{m})$ right beneath the indentation and a decreasing spacing $(0.4 \sim 3 \mu \mathrm{m})$ approaching the top surface and far away from the indenter tip. This variation can now be explained by noting that the confinement pressure and vertical shear displacement (see inset in Figure 1) are much higher just beneath the indenter tip as compared to the regions away from it, especially near the top surface (scan along line 'c'). This increased confinement along with higher critical shear displacement is responsible for the observed wider spacing of shear bands closer to the indenter tip. With a high magnitude of normal pressure $\left(\sigma_{N}=10 \mathrm{GPa}\right)$ and high critical shear displacement ( $\psi_{c}=5 \mu \mathrm{m}$ ), the shear band spacing is simulated to be between $2.2 \mu \mathrm{m}$ 
for $\dot{\gamma}=10^{9} / \mathrm{s}$ and $10 \mu \mathrm{m}$ for $\dot{\gamma}=10^{8} / \mathrm{s}$. In the absence of the normal pressure $\left(\sigma_{N}=0 G P a\right)$ and a low value of critical shear displacement $\left(\psi_{c}=0.1 \mu m\right)$ (similar to the stress conditions far away from the indenter tip), shear band spacing varies from $0.5 \mu \mathrm{m}$ at $\dot{\gamma}=10^{9} / \mathrm{s}$ to $2.6 \mu \mathrm{m}$ at $\dot{\gamma}=10^{8} / \mathrm{s}$. Thus, a good correlation between the simulation results and experimental observations has been reached through our analytical model. Also note that, the difference with and without consideration of the thermal effect is not significant for low confinement pressure and small shear displacement. This observation is reasonable because under these circumstances, the temperature rise is small as will be seen later, and the model without considering thermal effects captures the phenomenon of shear band evolution reasonably well.

Also, it should be noted that at higher critical shear displacement (e.g. $\psi_{c}=5 \mu m$ ) and high normal pressure (e.g. $\sigma_{N}=10 G P a$ ), a significant deviation between the results considering thermal effects (separate symbols) and without thermal effects (continuous lines) has been identified as shown in the inset of Figure 6.3. This observation will be discussed in more detail in Section 6.3.3 where we will present the thermal transient phenomenon associated with shear band evolution.

During the indentation process when the tip of the indenter comes in contact with the specimen, the rate of deformation can be significantly higher compared to the time when the indenter has progressed deeply into the specimen and a large volume of material is subjected to loading effects. Thus, the strain rate is higher in the region closer to the indenter tip and decreases gradually in the regions farther away from the tip. In addition, the region closer to the tip is subjected to higher confinement pressure 
as it is in contact with the rigid indenter compared to the region farther away. In the current model the larger spacing closer to the tip is rationalized based on the higher confinement pressure and the finer spacing at regions farther away is attributed to lower confinement stress. Thus, the confinement pressure $\sigma_{N}$ seems to have more significant effect on the shear band springs rather than strain rate $\dot{\gamma}$ in the current model.

\subsubsection{Time for shear band evolution}

Figure 6.4 reveals that the duration for shear bands evolution depends not only on the strain rate, but also on the critical shear displacement $\psi_{c}$ and the normal pressure $\sigma_{N}$. Similar to Figure 6.3, the separate symbols in Figure 6.4 correspond to the results with thermal effects, while the lines correspond to the results without thermal effects based on Eq. (6.11). It can be observed that the evolution time for the shear bands decreases with (i) increasing shear strain rate, (ii) decreasing $\psi_{c}$ and (iii) increasing $\sigma_{N}$. The shear band evolution time is predicted to range from a few nanoseconds to a couple of microseconds depending on the varied parameters. This observation indicates that shear bands propagate quite rapidly to maturity, i.e. to reach critical shear displacement. This may also explain why even with high speed cameras and thermal imaging systems it is still quite difficult to capture the in-depth details of shear band evolution even under a quasi-static loading regime [7, 9, 37].

The effect of normal stress is well captured in Figure 6.4. The compressive normal stress can promote the shear band formation by decreasing the time to reach critical shear displacement because of the pressure sensitivity of BMGs. On the other hand, 
thermal effects seem to extend the duration of shear band evolution to reach the critical shear displacement especially under high strain rate and high compressive normal pressure (observe the significant deviation between the separate symbols and lines in Figure 6.4). This behavior results from the temperature dependence of flow stress in BMGs and can be attributed to a significant decrease in the flow stress at elevated temperatures induced by the higher normal pressure and the high strain rate loading conditions. This reduction in flow stress delays the propagation of shear bands thus extending the time duration for maturity (refer to Eq. 6.11). The temperature effect on the flow stress of BMGs will be further discussed in Section 6.3.4.

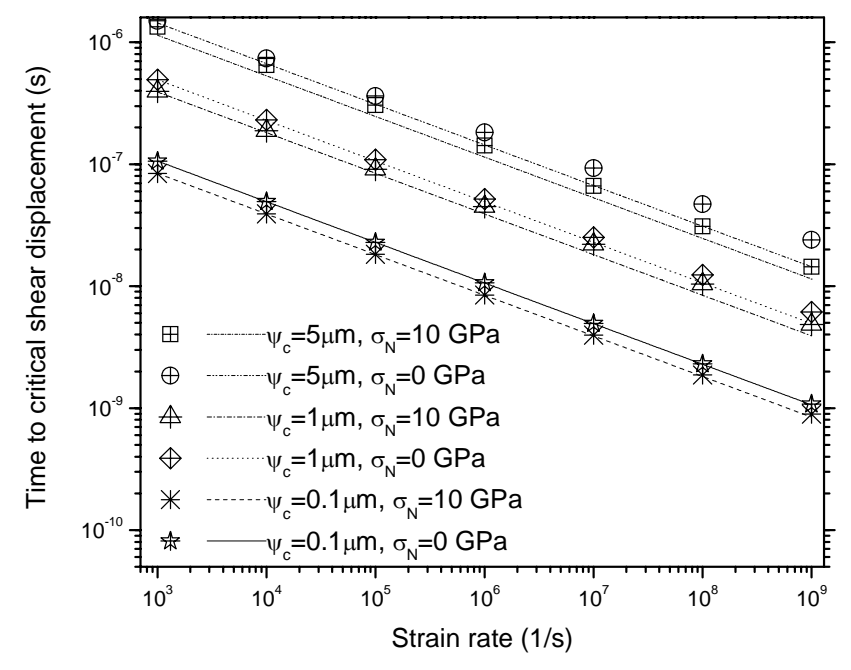

Figure 6.4. Time to critical shear displacement as a function of normal stress and strain rate.

\subsubsection{Temperature rise inside shear bands}

Figure 6.5 presents the maximum temperature inside a shear band during its evolution at various strain rates, confining stresses and critical shear displacements. It is noted 
that the temperature increases with increasing strain rate, normal pressure and critical shear displacement. Considering the high rate of heat generation at higher strain rates, introduction of more plastic work (which is subsequently converted to heat) at higher applied normal pressure, and larger shear displacement accommodated along the slip planes (Eq. (6.2), (6.10-1) and (6.13)), it is easy to rationalize the trends in the temperature rise in Figure 6.5. It is also interesting to note that at strain rates beyond $\dot{\gamma}>10^{5} / \mathrm{s}$, a higher compressive normal pressure $\left(\sigma_{N}=10 G P a\right)$ leads to a higher local temperature rise even at a critical shear displacement of $1 \mu \mathrm{m}$ than that at a critical shear displacement of $5 \mu \mathrm{m}$ under pure shear deformation mode ( $\sigma_{N}=0 G P a$ ).

This result clearly indicates the dominant effect of compressive normal stress on the consequent temperature rise in the core of a shear band.

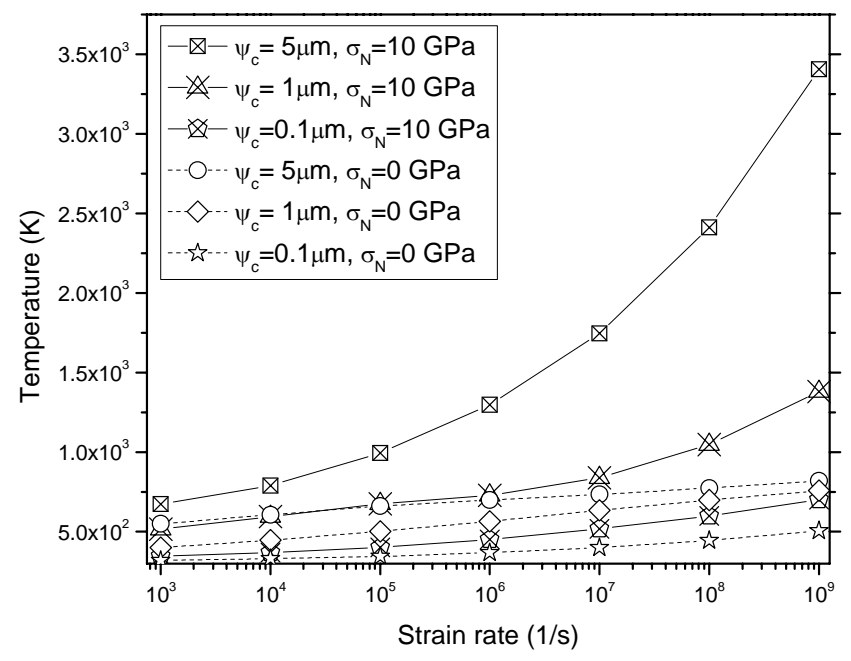

Figure 6.5. Temperature rise in shear band core as a function of strain rate, critical shear displacement and normal stress. Note that normal stress has a higher influence on the temperature rise than strain rate.

Figure 6.6 displays the temperature rise inside a shear band as a function of the shear 
displacement accumulated along a slip plane. A similarity in the profiles of temperature rise with shear displacement is observed in Figure 6.6(a) although the critical shear displacement is quite different. Once again, a significant temperature rise in excess of $2000 \mathrm{~K}$ at higher shear displacements is observed.
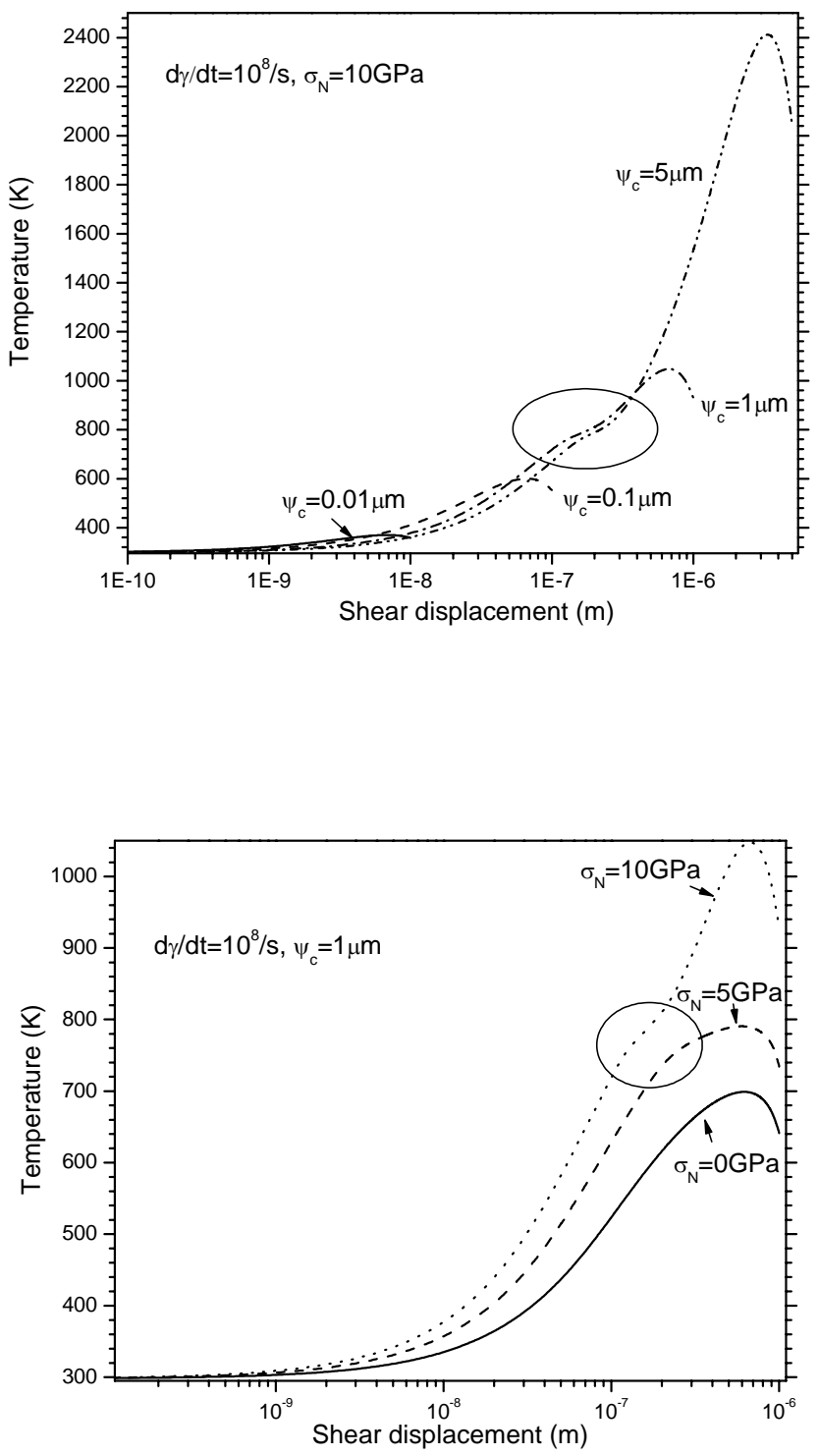

Figure 6.6. Dependence of temperature rise in a shear band core during shear band evolution on shear displacement as a function of (a) critical shear displacement and (b) normal stress. 
Another interesting feature to note is that a decrease in temperature occurs when the accumulated shear displacement approaches the critical shear displacement. This phenomenon results from the significant relaxation of shear stress on the shear band at the final stages of the shear band evolution (as observed from Eq. (6.2) when $\psi \rightarrow \psi_{c}$ ), i.e., the relaxation of shear stress generates less work at the final stage of shear band evolution and also, the continued heat diffusion from shear band into adjacent material causes the decrease in temperature within the shear band.

The influence of normal pressure on temperature rise during shear band evolution is shown separately in Figure 6.6 (b). During the early stages of shear band evolution when the shear displacement accumulated inside a shear band is less than a nanometer, the dependence of temperature rise on compressive normal pressure is negligible. However, when the shear displacement accumulated in a shear band reaches $10 \mathrm{~nm}$ and above, the influence of compressive normal pressure becomes more pronounced and increase with normal pressure. Moreover, it can be seen that even for a small value of the critical shear displacement of $1 \mu \mathrm{m}$, the influence of compressive normal stress on maximum temperature rise can vary by around $300 \mathrm{~K}$ when $\sigma_{N}$ varies from 0GPa to 10GPa. This result can also be observed from Figure 6 where the maximum temperatures generated with $\psi_{c}=0.1,1$ and $5 \mu \mathrm{m}$ under varying normal pressures are presented.

\subsubsection{Flow stress variation associated with temperature rise}

Recall from Section 6.2 and Eq. (6.14-6.17) that flow stress is also dependent on temperature. However, at temperature close to the glass transition, a dramatic 
decrease in viscosity is expected. Figure 6.7 reveals the influence of strain rate on temperature rise and subsequent drop in shear strength (flow stress) of the material. The influence of strain rate has been noted even at very early stage of shear band evolution where the accumulated shear displacement inside a shear band is only in nanometers. The differences in temperature rise profiles become even more significant with higher shear displacement and at higher strain rates.

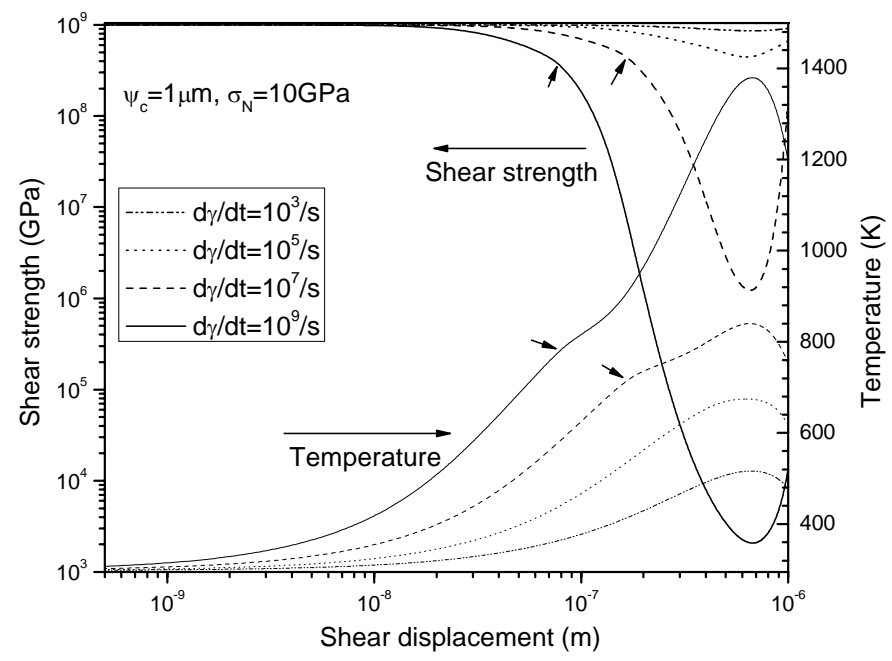

Figure 6.7. Temperature rise and associated flow stress softening during shear band evolution as a function of strain rate.

Under low loading rate at $\dot{\gamma}=10^{3} / \mathrm{s}$, flow stress softening is negligible and correspondingly local temperature rise inside the shear band is low (far below the glass transition temperature). At strain rates beyond $10^{7} / \mathrm{s}$, a rapid decrease in flow stress is noted with increasing shear displacement. This significant drop in flow stress seems to correspond to a slight deviation in the temperature profile as marked by the arrows. Finally, the flow stress reaches a minimum value and reverts its trend towards 
the latter stage of shear band evolution. Simultaneously, the temperature reaches a maximum value and then decreases. The decrease in temperature and the associated increase in flow stress at this latter stage of shear band evolution have been attributed to the relaxation of resolved shear stress acting on the shear band as discussed earlier in Section 6.2 (Figure 6.2(c)). As is well known, flow stress varies with both temperature and strain rate. At a certain strain rate, flow stress depends strongly on local temperature rise. At the beginning of shear band evolution, temperature rise is slow and thus flow stress decreases slightly. However, when temperature reaches a critical value such as the glass transition temperature, flow stress decreases rapidly due to a dramatic decrease in viscosity associated with temperature rise. This reduction in flow stress results in a decrease in the rate of temperature rise because of the simultaneous decrease in rate of plastic work. Thus, an inflection point in the temperature profile is observed as indicated in Figure 6.6 (marked by circles) and Figure 6.7 (marked by arrows). However, the decrease in viscosity will lead to an increase in accumulation rate of shear displacement, which in turn increases the generation rate of plastic work and the rate of temperature rise. So there is a competition between these two opposing phenomenon during the evolution of the shear bands which give rise to the characteristic temperature profiles as observed in these figures.

Thus, the hardness softening with strain rate reported in Figure 5.3 and 5.4, as well as the negative rate sensitivity of fracture strength reported by Hufnagel et al., [9] and Li et al., [43] can now be explained based on the results shown in Figure 6.7. In the 
figure, the temperature rise is significant with higher local strain rate. The associated decrease in flow stress is also significant giving rise to the observed trend in hardness in Figure 5.4 and fracture strength reported above. Finally, the limitation of the current model will be briefly discussed. A linear relationship between $\tau(\psi)$ and $\psi$ is assumed as in Eq. (6.2), which may not be realistic. This particular form for stress relaxation with shear band growth is used because it leads to explicit analytical solution. Also, it has been shown in crack propagation context that the exact relationship between them may not have a profound effect in understanding the underlying physics. Due to a lack of proper description of shear stress relaxation within a shear band, the linear model is a reasonable first approximation. However, during the final stage of shear band formation, it is not expected to provide a good representation of the shear band evolution behavior, because of its decay to zero stress. This is not true even for a thermally softening material when the stress would decay to some low, but non-zero value. A zero stress may mean the onset of cracking at the shear band which is not included in the analysis. Thus, the decrease in temperature rise after the maximum peak may not actually appear during shear band evolution. However, it is believed that the assumed behavior in Eq.(6.2) will lead to correct dimensional and functional trends and to approximately correct quantitative results, which is reasonably verified by the agreement between the experimental observations and the modeling results.

The current momentum diffusion model is applicable only for dynamic loading and the resulting shear band formation but not for quasi-static loading. The shear band 
spacing in quasi-static indentation has been observed to be very small, namely, around 100 to 200nm, as reported by Zhang et al., [35], which is not in line with the prediction of the current model at low strain rate scenarios. This obvious deviation may indicate that some other mechanisms are operative at this time scale in addition to or instead of the momentum diffusion mechanism assumed in the analysis.

Mohr-Coulomb type failure law in Eq. (6.1) is used by the authors taking into account only the effective normal pressure on the slip plane. Other failure models including intermediate principal stress have been suggested in the literature [44] and can be included in the current model.

Finally, it should be noted that the shear band is assumed to be devoid of any structure in a region of zero thickness residing at $x=0$. A finite thickness of the shear band, has always been observed, but has not been considered in the current analysis. However, owing to very small width of the shear band compared to neighboring features, the above assumption is reasonable and the model predictions of main features of dynamic shear band evolution appear to be valid.

\subsection{Conclusions}

A mechanistic description of shear band evolution in BMGs under dynamic loads is presented. A coupled thermo-mechanical model is proposed that utilizes momentum diffusion mechanism for the growth and the evolution of final spacing of shear bands. The influence of strain rate, confinement pressure and critical shear displacement on the shear band spacing, temperature rise within the shear band, and the associated 
variation in flow stress have been analyzed. Consistent with the known pressure sensitive behavior of BMGs, the current model clearly captures the influence of the normal stress in the formation of shear bands. The normal stress not only reduces the time to reach critical shear displacement but also causes significant temperature rise during the shear band formation. Based on this observation, the variation of shear band spacing in a typical dynamic indentation test has been rationalized. The temperature rise within a shear band can be in excess of $2000 \mathrm{~K}$ at high strain rate and high confinement pressure conditions. The associated drop in viscosity and flow stress may explain the observed softening in fracture strength and indentation hardness.

\section{References}

1. Chen M.H., Goldstein M., Journal of Applied Physics, 1972;43:1642

2. Spaepen F., Acta Metallurgica et Materialia, 1977;25:407

3. Argon, A.S., Acta Metallurgica et Materialia, 1979;27:45

4. Steif, P.S., Spaepen, F., Hutchinson, J.W., Acta Metallurgica et Materialia, 1982;30:447

5. Leamy, H.J., Chen, H.S., Wang, T.T., Metallurgical and Materials Transition, 1972;3:699

6. Bruck, H.A., Rosakis, A.J., Johnson, W.L., Journal of Materials Research,1996;11 (2), 503

7. Flores, K.M., Dauskardt, R.H., Journal of Materials Research,1999;14(3):638.

8. Gilbert, C.J., Ager III, J.W., Schroeder, V., Ritchie, R.O., Lloyd, J.P., Graham, J.R., Applied Physics Letters, 1999;74(25):3809

9. Hufnagel, T.C., Jiao, T., Li, Y., Xing, L-Q., Ramesh, K.T., Journal of Materials Research, 2002;17 (6):1441

10. Lewandowski, J. J., Greer, A.L., Nature Materials, 2006;5:15

11. Wright W.J., Schwarz R.B., Nix, W.D., Materials Science \& Engineering, 2001;A319-321:229

12. Conner, R.D., Johnson, W.L., Paton, N.E., Nix, W.D., Journal of Applied Physics, 2003;94 (2):904 
13. Conner, R.D., Li, Y., Nix, W.D., Johnson, W.L., Acta Meterialia, 2004;52:2429

14. Yang, Q., Mota, A., Oritz, M., Computational Mechanics, 2006;37:194.

15. Mott, N.F., Proceedings of the Royal Society of London, 1947; A189:300

16. Grady, D.E., Kipp, M.E., Journal of the Mechanics and Physics of Solids, 1987;35:(1):95

17. Kipp, M.E., Grady, D.E., Journal of the Mechanics and Physics of Solids, 1985;33 (4):399

18. Wright, T.W., Ockendon, H., International Journal of Plasticity, 1996;12 (7):927

19. Molinari, A., Journal of the Mechanics and Physics of Solids, 1997;45(9):1551

20. Meyers, M.A., Nesterenko, V.F., LaSalvia, J.C., Xue. Q., Materials Science \& Engineering, 2001;A317:204

21. Donovan, P.E., Acta Metallurgica, 1989;37(2):445

22. Liu, C.T., Heatherly, L., Easton, D. S., Carmichael, C. A., Schneibel, J. H., Chen, C. H., Wright, J. L., Yoo, M. H., Horton, J. A., Inoue, A., Metallurgical and Materials Transactions, 1999;A29:1811

23. Lowhaphandu, P., Montgomery, S.L., Lewandowski, J.J., Scripta Materialia, 1999; 41(1):19

24. Vaidyanathan, R., Dao, M., Ravichandran, G., Suresh, S., Acta Materialia, 2001;49:3781

25. Wright, W.J., Saha, R., NIX, W.D., Materials Transaction JIM, 2001;42(4):642

26. Zhang, Z.F., Eckert, J., Schultz, L., Acta Materialia,2003;51:1167

27. Taub, A.I., Acta Metallurgica et Materialia, 1982;30(12):2117

28. Taub, A.I., Acta Metallurgica et Materialia, 1982;30(12):2129

29. Lu, J., Mechanical behavior of a bulk metallic glass and its composites over a wide range of strain rate and temperatures, PhD. Thesis, California Institute of Technology, 2002;14-92.

30. Johnson, W.L., Lu, J., Demetriou M.D., Intermetallics,2002;10:1039

31. Grest, G.S., Cohen, M.H., Advanced Chemical Physics, 1981;48:455

32. Masuhr, A., Waniuk, T.A., Busch, R., Johnson, W.L., Physical Review Letters, 1999;82 (11):2290

33. Busch, R., Masuhr, A., Johnson W.L., Materials Science \& Engineering, 2001;A304-306:97

34. Glade, S.C., Busch, B., Lee, D.S., Johnson, W.L., Wunderich, R.K., Fecht, H.J., Journal of Applied Physics, 2000;87(10):7242

35. Zhang H.W., Jing X.N., Subhash, G., Kecskes, L.J., Dowding, R.J., Acta 
Materialia, 2005;53:3849

36. Zhang, H.W., Subhash, G., Jing, X.N., Kecskes, L.J., Dowding, R.J., Philosophical Magazine Letters, 2006;86(5):333

37. Yang, B., Morrison, M.L., Liaw, P.K., Buchanan R.A., Wang, G., Liu, C.T., Denda, M., Applied Physics Letters, 2005;86(14):141904.

38. Zhang, H.W., Subhash, G., Maiti, S., 2006, unpublished results.

39. Kim, J.-J., Choi, Y., Suresh, S., Argon, A.S., Science, 2002;295:654

40. Subhash, G., In ASM Handbook, Mechanical Testing and Evaluation, ASM International, 2000;V8:519

41. Zhang, Y., Greer, A.L., Applied Physics Letters, 2006;89:071907

42. Subhash, G., Zhang, H.W., Journal of Materials Research, 2006; in print.

43. Li, H., Subhash, G., Gao, X,-L., Kecskes, L.J., Dowding, R.J., Scripta Materialia, 2003;49:1087

44. Lu, J., Ravichandran, G., Journal of Materials Research, 2003;18 (9):2039 


\section{Chapter 7. Conclusions and Future Work}

The crystallization behavior and mechanical properties of $\mathrm{Zr}$ /Hf-based BMGs were studied by thermodynamic analysis and nano-indentation tests. Thermal analysis showed that glass transition temperature $T_{g}$, onset temperature of first crystallization $\mathrm{T}_{\mathrm{x} 1}$, and supercooling region $\Delta \mathrm{T}_{\mathrm{x}}$ increase with increasing $\mathrm{Hf}$ content while the reduced glass transition temperature $T_{\text {rg }}$ decreases. Hardness and modulus were found to increase with Hf substitution for Zr. The increasing mechanical strength with Hf content was attributed to a local change of the amorphous structure with a change in the composition.

A bonded interface technique was successfully used to investigate the formation of various sets of shear bands beneath a Vickers indentation in BMGs. At small indentation load, only semi-circular primary shear bands surrounding the indent were observed. With increasing load secondary and tertiary shear bands were developed inside this plastic region. A modified ECM was used to predict the size of the plastic zone as a function of load. This model provides a good estimate of the plastic zone size compared to other models available in the literature. Based on the stress distribution inside the hemispherical plastic zone, the radial stress component had been rationalized to be responsible for primary semi-circular shear bands formation, and shear stress components for secondary and tertiary shear band formation.

Comparison of various hardness-yield-strength relationships currently available in the literature for BMGs has been presented. It was shown that the Tabor's relationship and the ECM by Johnson do not provide good agreement with results for Zr-Hf 
BMGs. A theoretical analysis of the relationships between the hardness and the yield strength for ZrHf-based BMGs within the framework of the expanding-cavity model was provided. The relationship not only considers the material properties $\left(\frac{E}{\sigma_{y}}\right.$ and $v$ ) and the indenter geometry $\theta$, but also the pressure sensitivity index $\alpha$. The current model predictions along with those of Dao (Eq.(4.3)) and Marsh (Eq.(4.4)) had been shown to provide good agreement with the experimental data for a wide range of BMG compositions.

Dynamic Vickers indentations were also performed on ZrHf-based BMGs. A decrease in indentation hardness at elevated strain rate has been observed. For equivalent loads, dynamic indentations produced more severe deformation pattern on the loading surface than static indentations. Using bonded interface technique, the induced shear band patterns beneath the indentations were studied. Different from static indentations where majority of the deformation was primarily accommodated by closely spaced semi-circular shear bands surrounding the indentation, two sets of widely spaced semi-circular shear bands with two different curvatures were observed beneath dynamic indentations. The observed shear band patterns were rationalized based on the variations in the confinement pressure and strain rate with in the indentation region during dynamic indentations. The strain softening of indentation hardness is attributed to nucleation of cracking immediately following the shear band initiation due to the rapid loading rate.

A mechanistic description of shear band evolution in BMGs under dynamic loads was also presented. The coupled thermo-mechanical model proposed had revealed the 
normal stress not only reduces the time to reach critical shear displacement but also causes significant temperature rise during the shear band formation. Based on this observation, the variation of shear band spacing in a typical dynamic indentation test has been rationalized. The temperature rise within a shear band can be in excess of 2000K at high strain rate and high confinement pressure conditions. The associated drop in viscosity and flow stress may explain the observed softening in fracture strength and indentation hardness.

Finally, a brief description for the future work will be presented. Although the coupled thermo-mechanical model provided a good explanation for the experimental observations under dynamic loading conditions, extension of this model to account for the deformation behavior of BMGs under quasi-static condition is yet to be done. Static indentations revealed finer spaced shear bands than those in dynamic indentations (see Figure 3.5, 5.6 and 7.1 for comparison) and this phenomenon is not in line with the current model predictions. Perturbation analysis (another available model for space band spacing analysis) reveals a smaller shear band spacing around millimeters but it is still much larger than experimental observations. Thus, modification of the existed model or even establishment of a new model might be necessary. Moreover, although deformation behavior such as shear band patterns and flow stress softening associated with the shear band evolution have been observed and well modeled in current work, the microstructral variation inside shear bands and in vicinity of shear bands such as crystallization and free volume migration during plastic deformation are still not well understood. In the coupled thermo-mechanical model, variation of free volume concentration can be captured during the deformation as shown in Eq.6.16 and Chapter 6.2. The variation of free volume concentration also influences the viscosity, which otherwise dominates the effective diffusivity 
( $D_{\text {eff }} \sim \eta^{-1}$ ) in the materials. Coupled with localized temperature rise, crystallization behavior during deformation might be qualitatively and even quantitatively predicted. (nucleation rate: $I_{n} \sim D_{\text {eff }} \exp \left(-\Delta G^{*} / k T\right)$ ). Thus a possible relationship between crystallization and shear band evolution in BMGs may be able to be established and account for observations by other researchers. 


\section{PUBLICATION LISTS}

1. Shear band patterns in metallic glasses under static indentation, dynamic indentation and scratch processes, Ghatu Subhash, Hongwen Zhang, in progress, 2007

2. Local heating associated with shear band evolution under quasi-static compression in a Zr-based BMG, Hongwen Zhang, Ghatu Subhash, Spandan Maiti, in progress, 2007

3. Shear band evolution in a Zr-based BMGs under dynamic indentation, Hongwen Zhang, Spandan Maiti, Ghatu Subhash, Submitted to Acta Materialia, 2006

4. Dynamic indentation response and negative strain rate sensitivity of hardness in ZrHf-based bulk metallic glasses, Ghatu Subhash, Hongwen Zhang, $\underline{J}$ Materials Research, Vol.22, Feb, 2007

5. Evaluation of Hardness-Yield Strength Relationships in Bulk Metallic Glasses ,

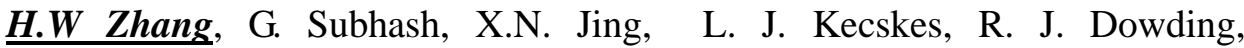
Philosophical Magazine Letter, Vol 86, May, 2006)

6. Investigation of shear band evolution in amorphous alloys beneath a Vickers indenter, Hongwen Zhang, Xiaoning Jing, Ghatu Subhash, Laszlo J Kecskes, Robert J. Dowding, Acta Materialia, Vol 53, Aug, 2005.

7. Kinetics of primary nanocrystallization in Al-rich metallic glass with

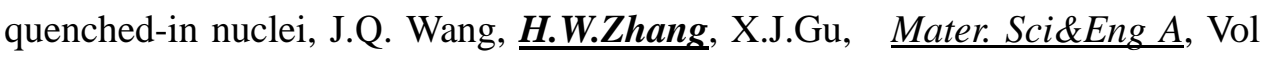
375-377, 2004

8. Mechanical behavior of bulk (ZrHf)TiCuNiAl amorphous alloys, $\underline{\text { Hongwen }}$ Zhang, Ghatu Subhash, Lazlo J Kecskes, Robert J Dowding, Scripta Materialia, Vol 49, 2003

9. Mechanical behavior of Hf/Zr bulk metallic glasses using Nano Indentation, G. Subhash, Hongwen_Zhang and $\mathrm{Hao} \mathrm{Li}$, International Conference on Mecchanical Behavior of Materials (ICM-9), Geneva, Switzerland, May 25-29, 2003.

10. Identification of nanocrystal nucleation and growth in $\mathrm{Al}_{85} \mathrm{Ni}_{5} \mathrm{Y}_{8} \mathrm{Co}_{2}$ metallic glass with quenched-in nuclei, J.Q.Wang, H.W.Zhang, X.J.Gu, K.Lu, F.Sommer, E.J.Mittemeijer, Applied Physics Letters, Vol 80, No18, 2002

11. Kinetics of crystallization nucleation and growth in Al-rich metallic glass, ZHANG Hongwen, Wang Jiangqiang, Lu ke, ACTA METALLURGICAL SINICA, Vol 38, No6, 2002 (in Chinese)

12. Pressure-enhanced Thermal Stability against Eutectic Crystallization in

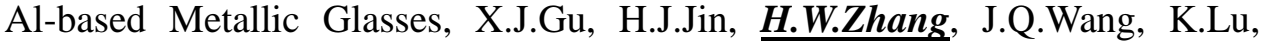
Scripta Materialia, Vol 45, Oct,2001 
13. Progress in Amorphous Al-based Metallic Glasses, ZHANG Honqwen, Wang Jiangqiang, Hu Zhuangqi, Review of Material Science, Vol 26, No12, 2001

14. Effect of The Third Element on The Structure of Casting Al-Bi Immiscible Alloys, ZHANG Honqwen, XIAN Aiping, ACTA METALLURGICAL SINICA, vol.36, No.4,2000

15. Study of Al-Bi Immiscible Alloy prepared by Control-Casting Technique, ZHANG Hongwen, XIAN Aiping, ACTA METALLURGICAL SINICA, vol.35, No.11,1999 